\title{
ENHANCEMENT OF CONCRETE COMPOSITE DECKS
}

\author{
by \\ Christopher Carson McComb
}

advised by

Prof. Fariborz Tehrani

\author{
A final paper \\ submitted in partial \\ fulfillment of the requirements for the degree of \\ Bachelor of Science in Civil Engineering \\ in the Lyles College of Engineering \\ California State University, Fresno
}

May 2012 


\begin{abstract}
Reinforced concrete construction and steel construction are two of the most common contemporary construction methods. Both methods make use of composite decks as floor systems and diaphragms. During the design of composite decks, the steel deck is typically disregarded when calculating the strength of the slab since shear transfer can't be ensured. This essentially results in efficient use of material. This report presents a method for ensuring shear transfer through the use of typical sheet metal screws, driven through the corrugated steel deck and embedded in the concrete. Both experimental and analytical work support an increase in strength with the addition of embedded fasteners, and an increase in strength with the addition of synthetic reinforcing fibers.
\end{abstract}




\section{Table of Contents}

List of Figures

List of Tables . viii

Acknowledgements ix

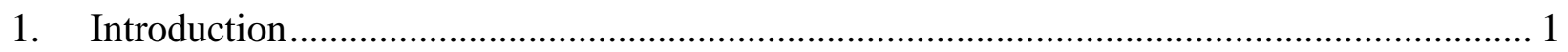

2. Literature Review................................................................................................... 2

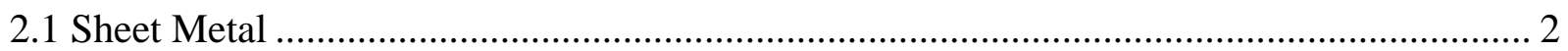

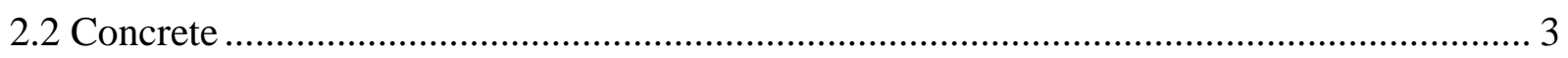

2.2.1 Fiber Reinforcement of Concrete...................................................................... 4

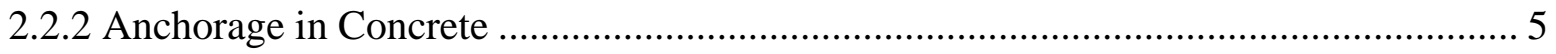

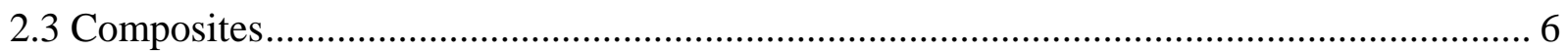

2.3.1 Shear Transfer in Composites ....................................................................... 8

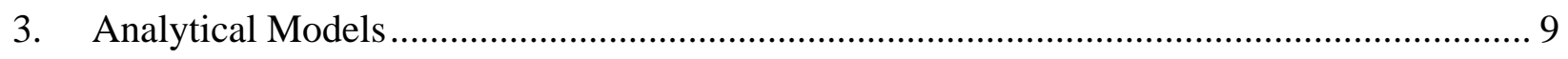

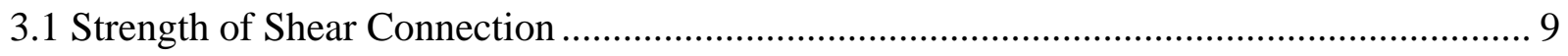

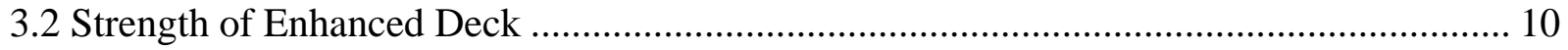

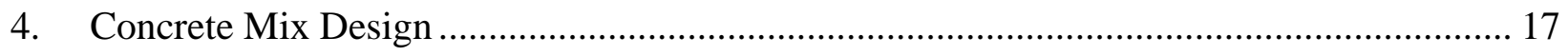

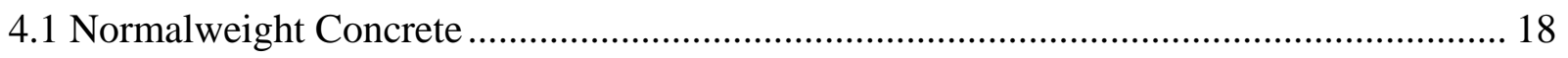

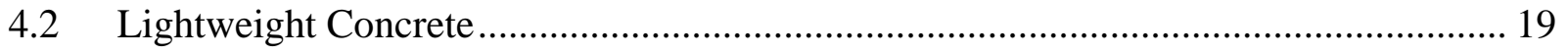

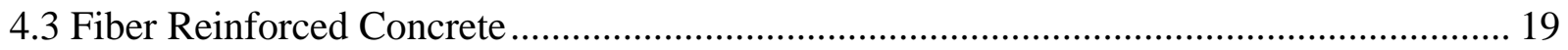

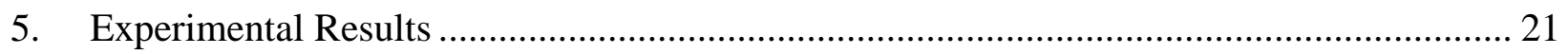




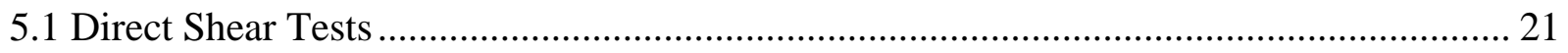

5.1.1 Apparatus and Specimen Construction.................................................................. 21

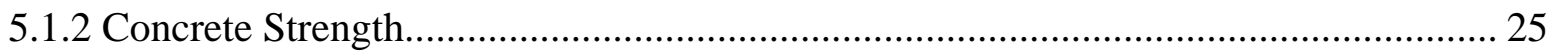

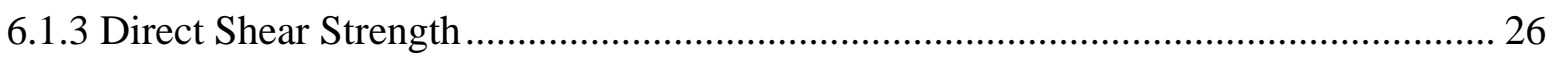

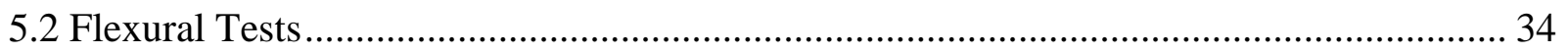

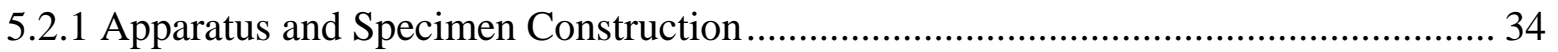

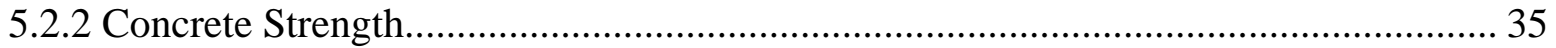

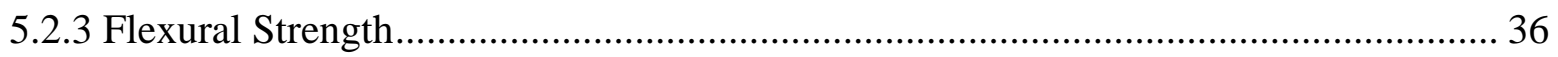

5.2.5 Discretization Resolution Analysis ........................................................................... 46

6. Revised Numerical Model .................................................................................... 48

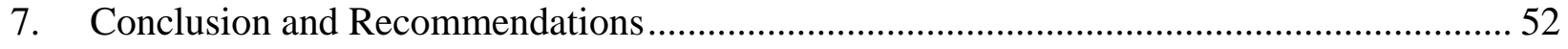

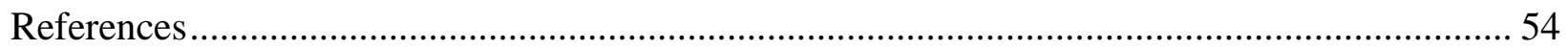

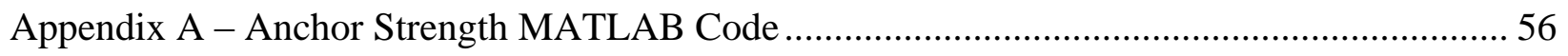

Appendix B - Concrete Stress MATLAB Code ………………............................................. 58

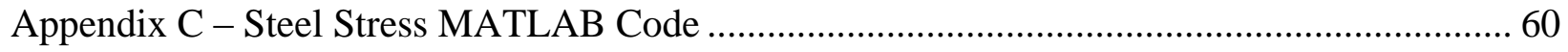

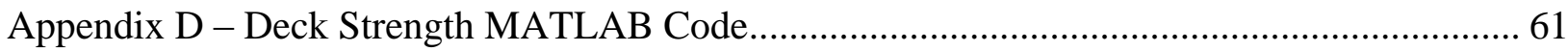

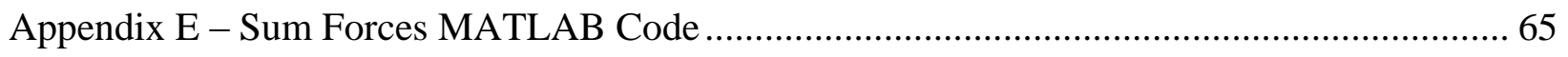

Appendix F - Section Performance MATLAB Code ................................................................... 67

Appendix G - Gradation of Lightweight Aggregate ……......................................................... 78

Appendix H - Manufacturer Documentation for Forta Ferro Fibers............................................ 79 
Appendix I - Manufacturer Documentation for Propex Fibermesh 650 Fibers ........................ 85 


\section{List of Figures}

Figure 1 - Cross section of CFDST tested by Zao et al. [12] .................................................... 7

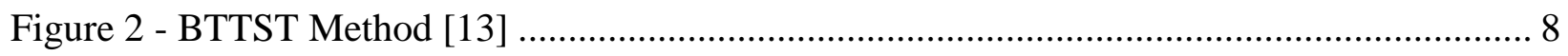

Figure 3 - Theoretical stress strain curve for concrete with $\mathrm{f}_{\mathrm{c}}{ }_{\mathrm{c}}=3500 \mathrm{psi}$ and $\mathrm{w}_{\mathrm{c}}=150 \mathrm{pcf} \ldots \ldots . .13$

Figure 4 - Theoretical stress strain curve for ASTM A653 steel ........................................... 14

Figure 5 - Discretization and Force-Summing Scheme .................................................. 15

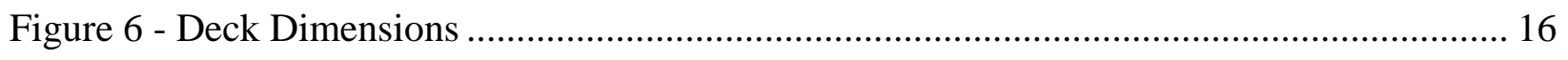

Figure 7 - Moment curvature relationship ..................................................................... 17

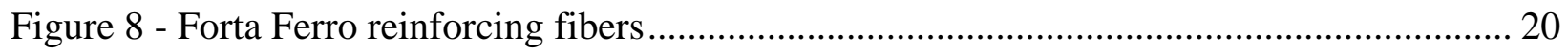

Figure 9 - Propex Fibermesh 650 reinforcing fibers....................................................... 20

Figure 10 - Dimensions of direct shear block .................................................................. 22

Figure 11 - Top fixture of direct shear test assembly ................................................... 23

Figure 12 - Bottom fixture of direct shear assembly ..................................................... 24

Figure 13 - Direct shear block and test fixture assembly.............................................. 24

Figure 14 - Load-deflection curve for lightweight concrete with no fibers............................. 26

Figure 15 - Load-deflection curve for lightweight concrete with Propex fibers....................... 27

Figure 16 - Load-deflection curve for lightweight concrete with Forta fibers......................... 27

Figure 17 - Load-deflection curve for normal-weight concrete with no fibers ........................ 28

Figure 18 - Load-deflection curve for normal-weight concrete with Propex fibers ................... 28

Figure 19 - Load-deflection curve for normal-weight concrete with Forta fibers ..................... 29

Figure 20 - Types of failure exhibited by direct shear specimens ....................................... 30

Figure 21 - General idealization of load-deflection curve ............................................. 31

Figure 22 - Idealized load-deflection curves for lightweight concrete mixes ........................... 32 
Figure 23 - Idealized load-deflection curves for normal-weight concrete mixes

Figure 24 - Surface of lightweight Propex specimen, displaying poor consolidation 33

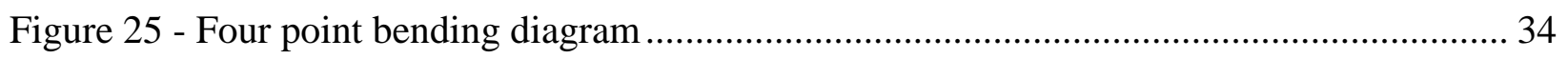

Figure 26 - Non-enhanced lightweight concrete beam, no fibers ...................................... 36

Figure 27 - Enhanced lightweight concrete beam, no fibers ............................................. 37

Figure 28 - Enhanced lightweight concrete beam, Propex fibers ....................................... 37

Figure 29 - Enhanced lightweight concrete beam, Forta fibers .......................................... 38

Figure 30 - Enhanced normal-weight concrete beam, no fibers ........................................ 38

Figure 31 - Enhanced normal-weight concrete beam, Propex fibers ....................................... 39

Figure 32 - Enhanced normal-weight concrete beam, Forta fibers ........................................ 39

Figure 33 - Typical failure in beams with (left) and without (right) embedded fasteners ........... 40

Figure 34 - Typical failure surface with screw at base ............................................... 41

Figure 35 - Head of embedded fastener, post-failure .................................................... 44

Figure 36 - Change of deck cross-section during loading ............................................... 44

Figure 37 - Enhanced normal-weight concrete beam, Propex fibers (small deflection) ............. 45

Figure 38 - Sensitivity of solution to number of discretized strips .................................... 47

Figure 39 - Revised model, lightweight beam with no fibers ........................................... 49

Figure 40 - Revised model, lighweight beam with Forta fibers ......................................... 49

Figure 41 - Revised model, normal-weight beam with no fibers ...................................... 50

Figure 42 - Revised model, normal-weight beam with Propex fibers ................................... 50

Figure 43 - Revised model, normal-weight beam with Forta fibers ..................................... 51 


\section{List of Tables}

Table 1 - Ultimate Strengths from Concrete Cylinder Compressive Tests ............................... 25

Table 2 - Ultimate Stress from Concrete Cylinder Compressive Tests .................................. 25

Table 3 - Comparison of predicted and measured strengths .............................................. 30

Table 4 - Ultimate Strengths from Concrete Cylinder Compressive Tests .............................. 35

Table 5 - Ultimate Stress from Concrete Cylinder Compressive Tests ..................................... 35

Table 6 - Comparison of measured and predicted strengths of beams .................................. 42 


\section{Acknowledgements}

The author is grateful for the lightweight aggregate donated by the Utelite Corporation, the synthetic fibers donated by the Forta Corporation, the fibers donated by the Propex Operating Company, the corrugated steel deck donated by Verco Decking, Inc., cutting services provided by Strategic Mechanical, Inc., concrete sand provided by Lehigh Hanson, and miscellaneous materials provided by the Lyles College of Engineering. Partial funding was also graciously provided by Associated Students, Inc. Also, the author would like to thank Mr. Steve Scherer and Mr. Derick Gangbin for their amazing support and helpfulness. Finally, Prof. Fariborz Tehrani cannot be thanked enough for his advice, guidance and patience. 


\section{Introduction}

Concrete is one of the most ubiquitous building materials, and has been widely used for millennia [1]. Ancient Egyptians were known to use calcined impure gypsum, and the Greeks improved upon previous methods by adding crushed stone [1]. More recent developments resulted in the reinforcement of concrete with other materials that exhibits high tensile strength. This often takes the form of Grade 60 steel reinforcing bars, and the resulting composite is referred to as reinforced concrete. Reinforced concrete is a very versatile building material, composing structural elements from slab-on-grade foundations to diaphragms and columns for multi-story buildings. However, substantial time and money is spent constructing forms in which to pour the concrete, as well as in setting the reinforcing bars [2]. Detailing of a reinforced concrete structure is also a time intensive process, because of the distributed nature of the reinforcement [2]. This can result in cluttered rebar, resulting ultimately in a structure that is time- and labor-intensive, considering the limitations that the American Concrete Institute places on the size, spacing, and number of bars [2]. The finite nature of steel bars can also introduce stress concentrations in the concrete section.

Composite concrete deck is another composite of steel and concrete. This method of construction typically uses both sheet steel (at the bottom surface of the deck) and reinforcing steel bars (in the interior of the deck) to achieve sufficient strength and constructability. The steel deck is primarily used to support the concrete while it cures. The steel deck is not included in design calculations, because it is generally assumed that the concrete doesn't act as a composite with the deck. Ensuring that the steel deck acts as a composite with the concrete would save on material costs by improving its overall strength. 
This works seeks to demonstrate a method for the improvement of shear transfer between steel deck and concrete, thereby improving the flexural strength of the deck. It is expected that this improved shear transfer can be improved with the use of standard fasteners. The work is presented in two sections. First, the model used to predict the shear strength of the fasteners were experimentally validated. Second, the flexural performance of sections of deck in flexural were experimentally determined, and checked against analytical predictions.

\section{Literature Review}

\subsection{Sheet Metal}

Cold-formed steel sheet (colloquially known as sheet metal) is formed using a cold roll forming process. This process begins with piece of stock metal plate or bar and plate is made incrementally thinner as it passes through sets of rollers [3]. This process can accommodate carbon steel plates as thick as 0.75 in [3]. Once a sheet of the correct thickness has been produced, the final shape can be produced through the use of several more rollers, a stamping process, or some combination of the two. Any embossments or corrugations on the deck must be produced through a stamping process.

Following the forming process, the steel has been work-hardened, meaning that it has been stressed past the yield point of the base material. This decreases the size of individual grains, and increases the number of grain boundaries. The increased number of grain boundaries inhibits the further growth of any slip plains (the primary mechanism of plastic deformation) [4]. This results in increased ultimate strength and decreased ductility [4]. 
While high strength and low ductility might be desirable for some applications, it is often desirable to return some of the ductility to the material. This can be accomplished through tempering the steel. A tempering process involves holding the steel at an elevated temperature for a specified length of time [5]. This relaxes the crystal structure of the steel, allowing diffusion to occur across grain boundaries and allowing grains to grow in size [5]. This effectively reverses the effects of plastic deformation while maintaining the material's geometry. The temperature is then dropped to "freeze" the grains, locking the material in at a specific ductility and strength [5]. In addition to increasing the ductility of the material, a tempering process decreases the ultimate tensile strength [5]. However, it also improves the toughness, which is desirable for many structural applications [5].

\subsection{Concrete}

Even without reinforcing steel, concrete is still considered a composite. Typical, nonfiber-reinforced concrete is classified as a large-particle, particle-reinforced composite [4]. The matrix is composed of hydrated cementitious material, while the particulates are the fine and coarse aggregate. Portland cement is the most commonly used cementitious material, and is composed primarily of calcium oxide and silicon dioxide [1]. When in the presence of water, these oxides hydrate and harden, a process called "curing".

The cement paste is generally the weakest material in the concrete, and primarily serves to bond the aggregate together. Natural aggregate varies in composition depending on region, and can be produced from a variety of different rocks such as granite, trap, schist, quartzite, and sandstone [1]. Despite the variability, most natural aggregates are stronger than cured cement. Therefore, concrete fractures around aggregate during failure, providing minor mechanical interlock. This maintains some of the integrity of the concrete after failure, especially when 
loaded in shear. This is not the case, however, if the aggregate is classified as lightweight. Most lightweight aggregates are weaker than cement paste, so fracture continues through individual pieces of aggregate [1]. Since the failure surface is planar, very little mechanical interlock occurs.

The properties of a given concrete mixture often display large standard deviations. This inconsistency is caused by the non-homogeneity of the concrete. One sample can be seen with the naked eye to vary from another, so it follows that the properties should vary as well. In addition, curing conditions play a large part on the properties of the cured concrete. Therefore, concrete from the same batch can display different properties based on where it is placed at a jobsite [1]. Lower deviation can be obtained by using small, well-graded aggregate and by ensuring consistency in curing conditions.

\subsubsection{Fiber Reinforcement of Concrete}

One of the major shortcomings of concrete is its low tensile strength. This shortcoming is so great that the tensile strength of concrete is largely disregarded in design [2]. However, the tensile strength of concrete can be improved through the addition of reinforcing fibers. In addition to increasing the tensile strength of the concrete, the addition of fibers can increase the toughness, impact resistance, fatigue strength and resistance to crack growth [6]. These improved properties are accomplished through the inhibition of crack growth by the reinforcing fibers [7]. Once a crack forms, fibers that span the crack are engaged. As the crack width increases, the stress in the fiber-matrix interface also increases, until the point at which they rupture or begin to pull out of the matrix [7].

Reinforcing fibers are typically broken into three categories: steel, glass, synthetic and natural [8]. Steel reinforcing fibers are produced with a variety of diameters, lengths, end shapes 
and cross-sections. They are generally small enough to become distributed randomly throughout the matrix, and have the high strength and stiffness characteristic of steel [8]. This makes steelreinforcing fibers an excellent choice for distributed reinforcement in structural applications. AR (alkali resistant) glass fiber is the most widely used glass reinforcing fiber [8]. Because of the manufacturing process used to produce the AR glass fibers, geometry is not as varied or as accurate as that of steel fibers. Because of problems with volumetric stability over time, AR glass fiber-reinforced concrete has been primarily used to produce exterior building façade panels [8]. Synthetic reinforcing fibers vary widely with respect to their properties, structure and material composition. Common synthetic reinforcing fiber materials include aramid, carbon, nylon, and polyester, with the most common being polypropylene [7,8]. In low dosages, synthetic reinforcing fibers can improve the early performance of the concrete and reduced the likelihood of plastic shrinkage cracking. However, improvement of fully cured concrete is only noted for large volume percentages of reinforcing fibers (between $0.4 \%$ and $0.8 \%$ ) [8]. Synthetic fibers find their largest use in cast-in-place concrete [8]. Natural fibers are widely used throughout the world, and were the first reinforcing fibers. Their use in recommended when low cost and the use of local materials are important design considerations [8]. It is interesting to note that the strength of concrete with natural reinforcing fibers actually appears to increase while experiencing weathering [8]. Despite the promising characteristics and wide use of natural reinforcing fibers, very little research has been conducted with them [8].

\subsubsection{Anchorage in Concrete}

The design of anchors embedded in concrete is outlined in ACI 318, Appendix D. The strength of a cast in place anchor loaded in shear is evaluated based on the shear strength of the anchor itself, and the breakout and pryout strengths of the anchor [9]. The breakout strength of 
the anchor is dependent on the strength of the concrete, the geometry of the anchor, and the placement of the anchor relative to the edges of the concrete [9]. The pryout strength is generally dependent on the same value, but is also related to the tensile breakout strength.

The calculations presented by the American Concrete Institute usually begin by defining surfaces along with fracture will occur. These surfaces generally begin at the point where the anchor is embedded, and extend away from the anchor at an angle of $55^{\circ}$ from the direction of loading [9]. The area of this failure surface, when multiplied by the shear strength of the concrete, gives the basic strength needed to induce that failure. A series of correction factors are then applied to determine the design strength.

\subsection{Composites}

Composites make use of two or more materials in order to produce a final section that will perform better under given conditions than either of the two base materials [4]. Typically, the base materials are arranged so that a very specific type of loading can be resisted effectively. Transverse shear must be given special attention when designing composites, because the boundary between materials can present a weakened plane [4]. If friction at the boundary doesn't provide sufficient strength, a chemical or mechanical fastener must be considered to maintain the integrity of the section [4].

The composite structures to be studied are classified as sandwich composites [10]. Sandwich composites are subject to failure if any of the constituent materials fail, or if the section fails due to transverse shear. Transverse shear failure can occur within the body of the materials, but is most likely to occur at interface between them, because of the weakened shear plane. If we consider local buckling, sandwich composites are also subject to two more limit states: crushing and delamination [10]. Crushing occurs if the outer material buckles inward, 
crushing the interior material and delamination occurs if the outer material buckles outward, disassociating itself from the interior material [10].

Hancock's review of the development of CFS construction briefly discusses CFS/concrete composites [11]. The review recognizes that the main difficulty in the design of CFS/concrete composites is the development of shear transfer between the two materials. This transfer can be accomplished using principles well-developed in connection design for CFS [11].

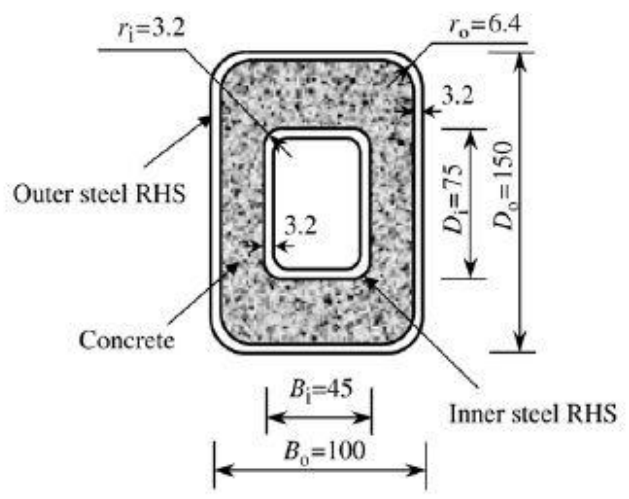

Figure 1 - Cross section of CFDST tested by Zao et al. [12]

Figure 1 depicts a tubular composite called a concrete-filled double-skinned steel tube (CFDST). A total of 30 of these CFDST were tested under combinations of flexural and axial loading [12]. In every test, buckling or folding of the exterior CFS jacket was observed as a failure mode. Another study was conducted to examine the slip and strength of the bent-up triangular shear tab transfer (BTTST) method [13] (see Figure 2). This experiment concluded that bent-up shear tabs were an effective means of shear transfer. However, the cutting and bending of these tabs is a time-intensive process.

Based on the previous work with BTTST, a method was presented for creating a composite floor system that involved casting the upper flange of back-to-back CFS channels 
directly into a deck with typical reinforcement [14]. Composite action between the CFS and the concrete deck was enhanced with the use of BTTST. In addition, more than half of the large scale specimens failed due to rupture of the CFS channels, resulting in sudden failure. Sudden failure is generally to be avoided in structural design, so this cannot be considered a viable construction practice..
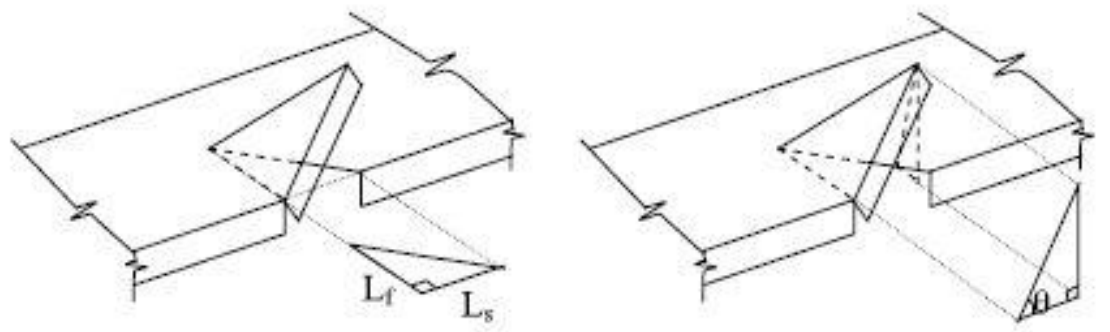

Figure 2 - BTTST Method [13]

\subsubsection{Shear Transfer in Composites}

Shear transfer in timber/concrete composite floors has been explored using such fasteners [15]. Deam et al explored the viability of cladding screws, framing brackets, coach screws and cut-outs in the timber beam for shear transfer. The cut-outs in the beam provided the best shear transfer, especially when reinforced with a cladding or coach screw [15].

Screws have also been used for shear transfer in CFS/Calcium Silicate framed wall panel systems. Nithyadharan et al (2011) experimentally measured the resistance of a screw loaded monotonically and dynamically in single shear between a CaSi wall panel and a CFS stud. All but one failure mode noted during the testing was due to failure of the CaSi wall panel. These failure modes included bearing failure of the CaSi wall panel, pull-through of the screws, and delamination of the CaSi wall panel [16]. The authors concluded that a large amount of energy was dissipated through the screwed connection in all cases. 
The design of screws as part of a sheet metal connection involves a number of limit states. In typical sheet metal design for shear resistance, the principal limit states that are taken into consideration are bearing failure of the sheet metal, rupture/tearing of the sheet metal, and tilting of the screw [17]. The values for each of these limit states varies depending on the edge distance, screw diameter, and strength and thickness of the sheet metal [17]. The values obtained from these limit states must then be compared to the strength of the screw in question. This value must either be obtained experimentally of provided by the manufacturer, and can range from tens to hundreds of pounds for standard sheet metal screws $[17,18]$.

Several studies have recognized the need for effective shear transfer in composites [13, 14], as well as a review paper [11]. In addition, shear transfer has been effectively accomplished in concrete/timber composites using mechanical fasteners [15]. Therefore, the enhancement of shear transfer in steel/sheet metal composites appears both possible and feasible. This is born out by preliminary results.

\section{Analytical Models}

\subsection{Strength of Shear Connection}

The model used to calculate the strength of the shear connection draws from the design codes for concrete anchorage and light gage steel $[9,17,18]$. When calculating the strength of the shear connection, four limit states were considered:

1. Rupture of the steel deck

2. Shear failure of the connector

3. Breakout failure in the concrete 


\section{Pryout failure in the concrete}

The strength required to rupture the steel deck was calculated with the following equation:

$$
V=2.7(t \cdot D) F_{u}
$$

Where $t$ is the thickness of the deck, $D$ is the diameter of the connector, and $F_{u}$ is the ultimate strength of the steel used for the deck.

The strength of the connector was derived from a list of allowable strengths for screws of several diameters [18]. A curve-fit was applied to this information using excel, assuming that the data was of the form $V=A D^{2}$. The value of A was determined to be 33764.27. All subsequent connector strengths were calculated as:

$$
V=33764.27 D^{2}
$$

The third and fourth limit states were calculated in accordance with ACI 318. It was assumed that the anchors would be cast in place, cracking would occur at the service load, and no eccentric loads would be applied. This resulted in the following simplified equations for concrete breakout and pryout, respectively:

$$
\begin{aligned}
& V_{b o}=\left(\frac{A_{v c}}{A_{v c o}}\right) \Psi_{e d} \Psi_{h} V_{b} \\
& V_{p o}=k_{c p}\left(\frac{A_{n c}}{A_{n c o}}\right) \Psi_{e d} N_{b}
\end{aligned}
$$

All of the values in the above equations were determined per ACI 318. The code developed to simplify these calculations is provided in Appendix A.

\subsection{Strength of Enhanced Deck}

Many models describing the performance of concrete have been proposed and validated. These range from models for simplistic uniaxial stress, to models based on theories of continuum 
damage mechanics. A uniaxial stress state can easily be approximately by applying an appropriate curve-fit to the compressive stress-strain curve of a concrete specimen. A model has also been developed to describe the performance of concrete under triaxial stress [19]. However, these models are still primarily curve-fits to available data. More recently, theoretical models based on continuum damage mechanics have been proposed [20]. After review, a model of this type was determined to be too computationally intensive for this stage in the model development, but will be considered for future iterations. In addition, discrete models have been developed to describe concrete. However, a discrete model would be unnecessarily high-fidelity and too computationally intensive for this model.

For reasons of numerical expedience, the concrete will be idealized as being in a state of uniaxial stress. This then allows the compressive stress-strain behavior of concrete to be numerically described by the Hognestad curve [22]. This piecewise-defined function is defined as follows:

$$
\begin{array}{ll}
f_{c}=f_{c}^{\prime}\left[2\left(\frac{\varepsilon_{c}}{\varepsilon_{0}}\right)-\left(\frac{\varepsilon_{c}}{\varepsilon_{0}}\right)^{2}\right] & \text { for } 0<\varepsilon_{c}<\varepsilon_{0} \\
f_{c}=f_{c}^{\prime}\left[1-Z\left(\varepsilon-\varepsilon_{0}\right)\right] & \text { for } \varepsilon_{0}<\varepsilon_{c}<0.003
\end{array}
$$

Where $f_{c}^{\prime}$ is the compressive strength of the concrete, the value of $\mathrm{Z}$ can be calculated as:

$$
Z=\frac{0.5\left(f_{c}^{\prime}-1000\right)}{3+\varepsilon_{0} f_{c}^{\prime}}
$$

One should note that equation $5 \mathrm{~b}$ has been modified from the original formulation [27]. The value of $\varepsilon_{0}$ is approximately 0.002 .

The stress strain curve of concrete can be extended for tensile stress if we consider concrete loaded in tension to remain elastic up to the point that it fractures (which is typical of most ceramic materials) [4]. After initial fracture the material has a consider amount of strength which consists of mechanical interlock between particles, and can be modeled as another 
decreasing linear segment [21]. We can describe the tensile stress as a function of strain with the equation:

$$
\begin{aligned}
& f_{c, t}=\varepsilon_{c} E_{c} \quad \text { for } \varepsilon_{t}<\varepsilon_{c}<0 \\
& f_{c, t}=-\frac{f_{r}}{4 \varepsilon_{t}} \varepsilon_{c}+1.25 f_{r} \quad \text { for } \varepsilon_{t}<\varepsilon_{c}<5 \varepsilon_{t}
\end{aligned}
$$

where $\varepsilon_{t}$ can be calculated as follows:

$$
\varepsilon_{t}=\frac{f_{r}}{E_{c}}
$$

and where $E_{c}$ is the elastic modulus of concrete. This value is most accurately found with the ACI recommended equation [9]:

$$
E_{c}=33 w_{c}^{1.5} f_{c}^{\prime 0.5}
$$

where $w_{c}$ is the unit weight of concrete in $\mathrm{lbs} / \mathrm{ft}^{3}$ and $f_{c}^{\prime}$ is the compressive strength in psi. The variable $f_{r}$ stands for the modulus of rupture. The value of $7.5 \sqrt{f_{c}^{\prime}}$ is recommended by ACI, but the value is more accurately calculated as [23]:

$$
f_{r}=2.627\left(f_{c}^{\prime}\right)^{\frac{2}{3}}
$$

where $f_{c}^{\prime}$ is given in psi. (Note, this equation was modified to accept values of $f_{c}^{\prime}$ in psi instead of MPa as originally published.) Thus, for a concrete mix with $f_{c}^{\prime}=3500 p s i$ and $w_{c}=$ $150 p c f$ we can derive the following stress strain curve shown in Figure 3. The code used to create this graph is provided in Appendix B. 


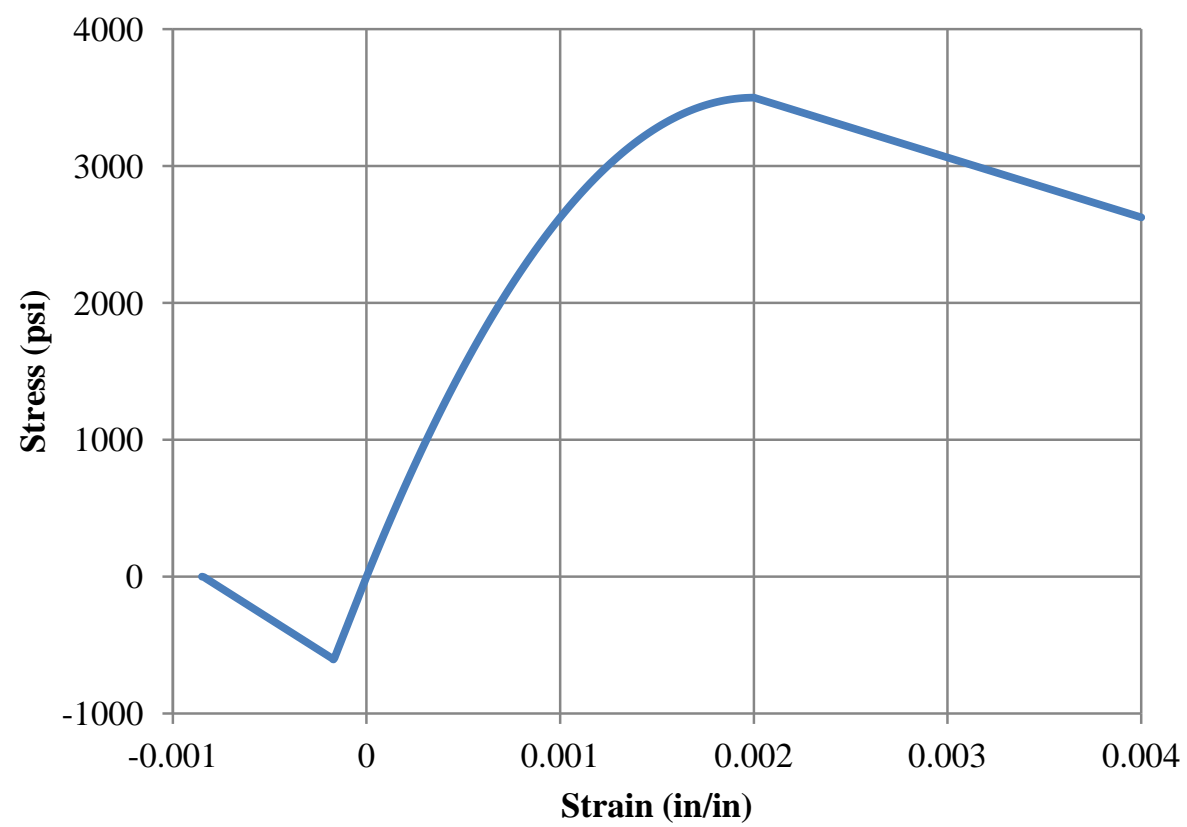

Figure 3 - Theoretical stress strain curve for concrete with $\mathrm{f}^{\prime}{ }_{\mathrm{c}}=\mathbf{3 5 0 0} \mathrm{psi}$ and $\mathrm{w}_{\mathrm{c}}=\mathbf{1 5 0} \mathrm{pcf}$

There are three common idealizations for steel stress-strain curves [24]. The first type considers steel to be a linear elastic, perfectly plastic material. This idealization considers the post-yield stress-strain curve to be entirely horizontal, and is employed by the design guidelines of the ACI [24]. The second idealization considers the stress-strain curve to be two continuous linear segments. The first follows the true linear elastic curve, and the slope of the second line is determined so that the strain-energy of the both the model and the true stress-strain curve are equal $[23,24]$. The third idealization type takes into account the elastic region of the stress-strain curve, a horizontal post-yield plateau, and a strain-hardening region (either linear or a quadratic curve-fit) [26].

The model used for the stress-strain behavior of steel shall be of the third type:

$$
\begin{array}{ll}
f_{s}=E \varepsilon_{s} & \text { for } 0<\varepsilon_{s}<\varepsilon_{y} \\
f_{s}=F_{y} & \text { for } \varepsilon_{y}<\varepsilon_{s}<15 \varepsilon_{y}
\end{array}
$$




$$
\begin{array}{ll}
f_{s}=(700 \mathrm{ksi})\left(\varepsilon_{s}-15 \varepsilon_{y}\right)+F_{y} & \text { for } 15 \varepsilon_{y}<\varepsilon_{s}<\varepsilon_{u} \\
f_{s}=\frac{0.1 F_{u}}{\varepsilon_{u}-\varepsilon_{f}} \varepsilon_{s}+F_{u}\left(1-\frac{0.1 \varepsilon_{u}}{\varepsilon_{u}-\varepsilon_{f}}\right) & \text { for } \varepsilon_{u}<\varepsilon_{s}<\varepsilon_{f}
\end{array}
$$

where $E$ is the elastic modulus of steel $(29000 \mathrm{ksi}), F_{y}$ is the yield strength, $F_{u}$ is the ultimate strength, $\varepsilon_{f}$ is the elongation at failure, and $\varepsilon_{u}$ and $\varepsilon_{y}$ can be solved for as follows:

$$
\begin{gathered}
\varepsilon_{y}=\frac{F_{y}}{E} \\
\varepsilon_{u}=\frac{F_{u}-F_{y}}{(700 \mathrm{ksi})}+15 \varepsilon_{y}
\end{gathered}
$$

where $F_{u}$ is the ultimate tensile strength of the steel being considered. The stress-strain curve for steel is mostly the same in tension and compression, so the same set of equations will be used for both. Using this model, we can produce a stress-strain curve for steel conforming to ASTM A653 with $F_{y}=36.3 \mathrm{ksi}$ and $F_{u}=68.9 \mathrm{ksi}$ (see Figure 4). This is the same steel used for many steel deck products. This code used to develop this figure is provided in Appendix C.

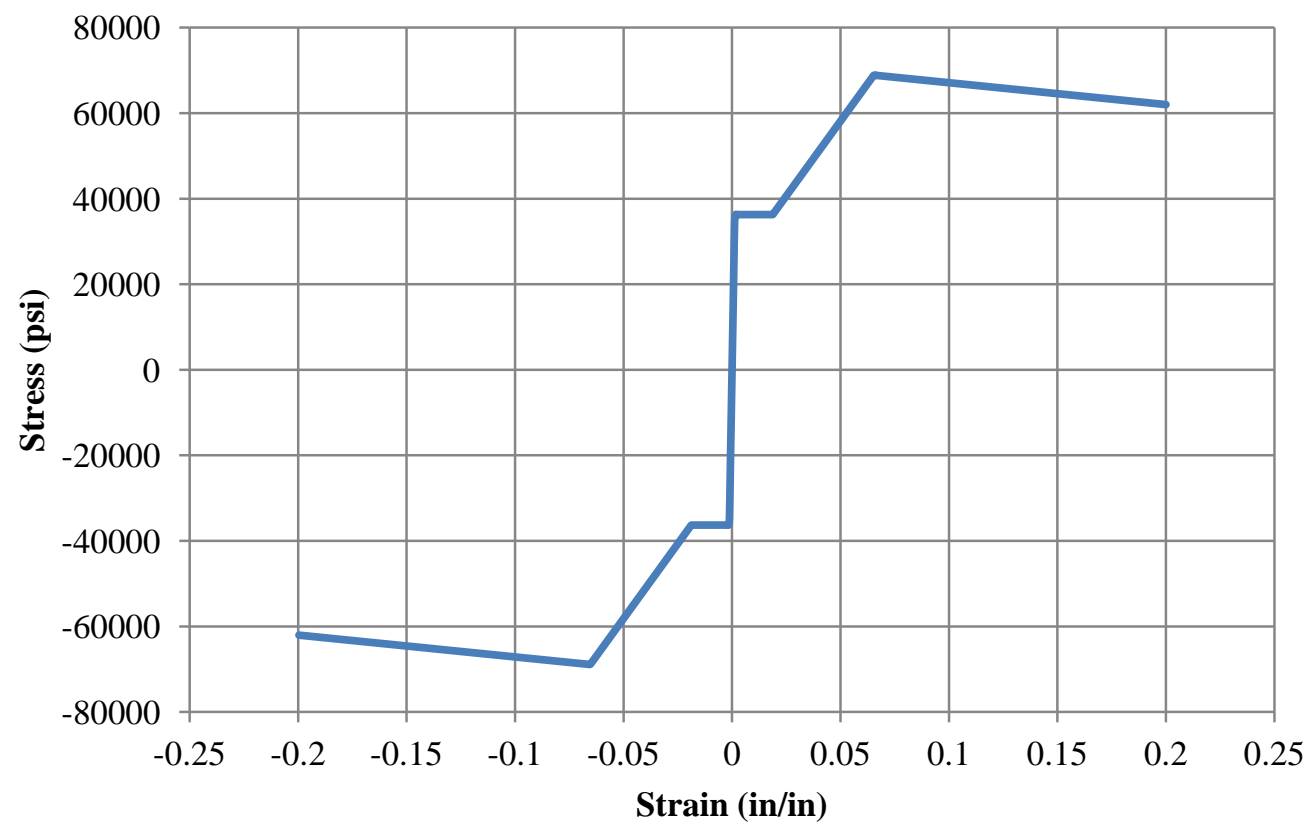

Figure 4 - Theoretical stress strain curve for ASTM A653 steel 
The steel model is not entirely accurate because it does not fully account for decrease in strength immediately prior to failure. In addition, it has been shown that the stress-strain behavior of steel can be better approximated by using a quadratic curve-fit for the strainhardening region [27]. However, the computational efficiency of a model employing only straight lines justifies the use of this model.

These material models can now be combined with the shear connection strength model to calculate the strength of a given deck cross-section. In order to allow the allowable moment of a deck section to be calculated numerically, the depth of the section was discretized into several horizontal slices (see Figure 5). A value for the strain at the top of the deck is then defined, and an iterative procedure is used to vary the depth of the neutral axis until the cross-section is in static equilibrium. The moment contributed from each strip is then summed to determine the moment strength for the chosen strain, and the curvature is calculated.
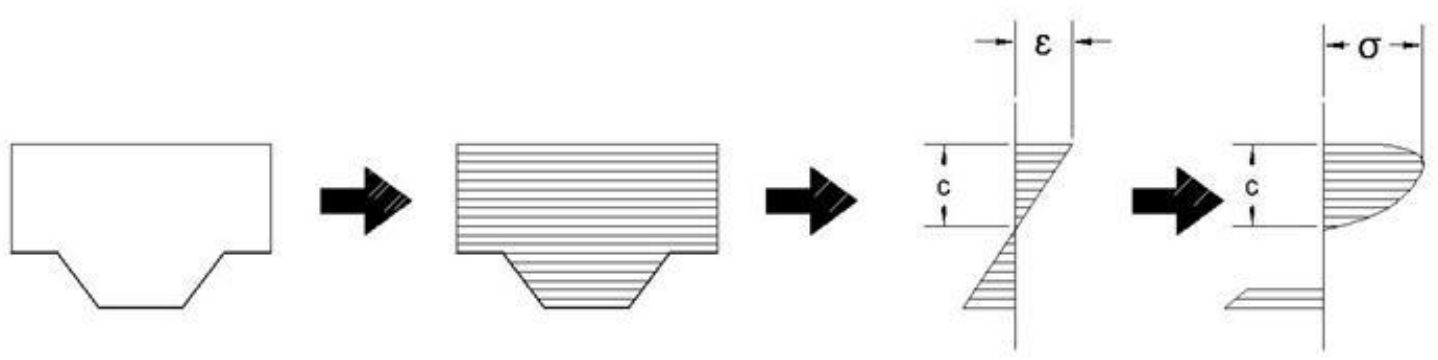

Figure 5 - Discretization and Force-Summing Scheme

The shear at the interface between the two materials was also considered. This was calculated in accordance with standard principals of mechanics of materials. When calculating the moment of inertia a transformed section was utilized, disregarding all material that had failed. The shear per connector was then calculated based on the distance between connectors. Based on this load, the deflection at the connection was calculated based on an empirical 
relationship (the development is discussed further in later sections). This deflection was then incorporated into the curvature of the deck between fasteners. Integrating this curvature function appropriately allowed the overall deflection of the deck to be calculated.

This procedure allowed the moment curvature relationship to be calculated for a given section of deck. For a deck with the cross-section shown in Figure 6, steel deck stress-strain relationship as shown in Figure 4 and normalweight concrete with compressive strength 3000 psi the moment-curvature relationship is shown in Figure 7.

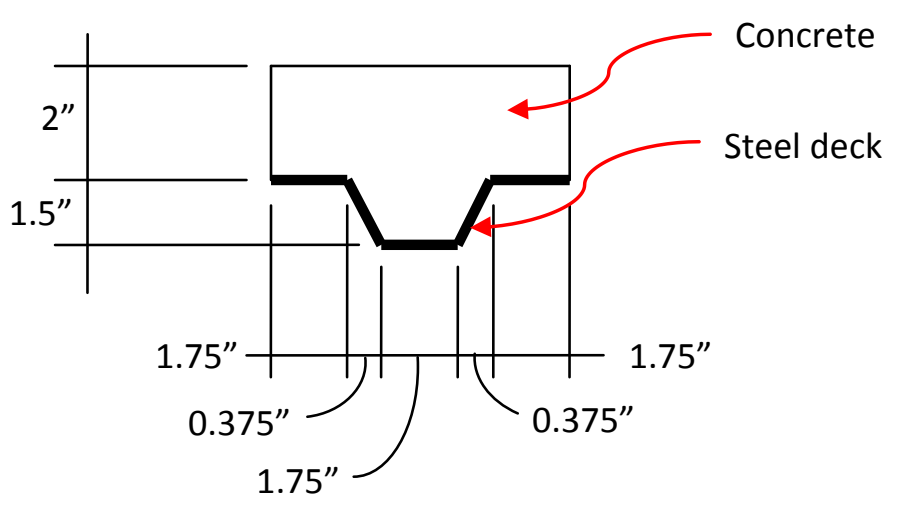

Figure 6 - Deck Dimensions 


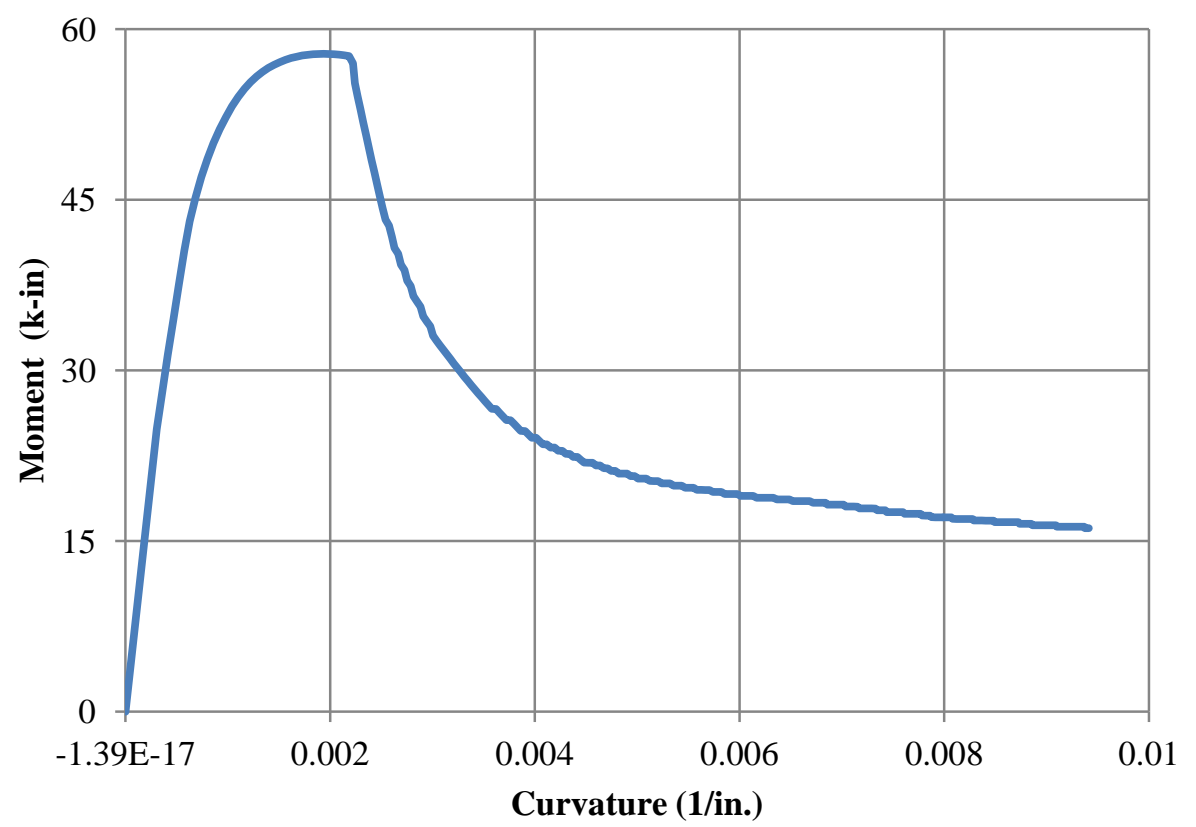

Figure 7 - Moment curvature relationship

The moment curvature relationship displays a peak at about 57.83 kip-in at a curvature of about $0.0019 \mathrm{in.}^{-1}$, and a strength at failure of about $16.13 \mathrm{k}$-in, at a curvature of about $0.0094 \mathrm{in} .^{-}$ 1. If the deck acted as a fully composite, then this curve could be applied directly to the loading conditions to predict the deflection. However, since the composite deck does not act as a full composite it is necessary to take into account the slip that occurs between the two materials, resisted by the embedded fasteners. This slip was characterized experimentally as several loaddeflection relationships for embedded fasteners of this nature, and incorporated into the flexural model. These relationships will be discussed in subsequent sections.

\section{Concrete Mix Design}

Initially, a series of challenges were experienced when attempting to achieve the requisite design strength. The 28-day strength was at least 1000 psi below the design strength for every 
mix and were observed to be extremely dry and to consolidate badly. After consulting Doug Taylor (a lecturer at CSU Fresno who specializes in concrete mix design) it was recognized that the low 28-day strengths were caused by 2 factors. First, it was recognized that the sand initially procured for the project was ungraded and rough, unlike typical concrete sand. The angular, ungraded nature of the sand particles would have required a much higher amount of cement paste, which is why the previous mixes were observed to be dry and consolidate badly. Second, it was recognized that the mix proportions determined for the lightweight concrete mixes were flawed. Taylor provided a mix design which was used for this project and performed admirably.

\subsection{Normalweight Concrete}

As with the lightweight aggregate mixes, a 28-day compressive strength of 3500 psi was desired. Therefore, the target 28-day compressive strength is set to 4700 psi [28]. A target slump of 3 in was chosen. For this strength and slump, the recommended water-to-cementitious materials ratio is 0.5 [28]. Based on a nominal maximum aggregate size of 1.0 in. and a target slump of 3 inches, $325 \mathrm{lbs} / \mathrm{cy}$ of water is recommended [28]. In turn, this set the necessary cement weight at $650 \mathrm{lbs} / \mathrm{cy}$.

A fineness modulus of 2.6 was assumed. Based on this assumed fineness modulus, the recommended bulk volume fraction of coarse aggregate is 0.68. It was assumed that the dryrodded unit weight of the coarse aggregate is $100 \mathrm{pcf}$. This allows the required weight of coarse aggregate to be calculated as $1836 \mathrm{lbs} / \mathrm{cy}$. Using specific gravity values of 3.15 and 2.64 for cement and fine aggregate, respectively, the required weight of fine aggregate is calculated as 1236.51 lbs using the absolute volume method [28].

Moisture contributed by the coarse aggregate is approximately $1.5 \%$ and moisture contributed by fine aggregate is approximately 5.3\% [28]. The estimated requirement for added 
water becomes $231.95 \mathrm{lbs}$ when moisture in aggregate is accounted for. Accounting for moisture in fine and coarse aggregates also changes the masses associated with these materials. Revised mix proportions are $231.95 \mathrm{lbs} / \mathrm{cy}$ water, $620 \mathrm{lb} / \mathrm{cy}$ cement, $1872.72 \mathrm{lbs} / \mathrm{cy}$ normal-weight coarse aggregate and $1310.7 \mathrm{lbs} / \mathrm{cy}$ concrete sand.

\subsection{Lightweight Concrete}

Although early attempts were made to design lightweight concrete using the Absolute Volume Method, it was determined that a great deal of time could be saved by employing a mix design recommended by Doug Taylor. This mix design called for $367 \mathrm{lbs} / \mathrm{cy}$ water, $690 \mathrm{lb} / \mathrm{cy}$ cement, $883 \mathrm{lbs} / \mathrm{cy}$ coarse lightweight aggregate and $1410 \mathrm{lbs} / \mathrm{cy}$ concrete sand.

\subsection{Fiber Reinforced Concrete}

Two types of fibers were used in this project: Propex Fibermesh 650 fibers and Forta Ferro fibers. They were both polypropylene macro reinforcing fibers, but were processed in very different ways, resulting in slightly different properties. Since the two fiber types are made up of the same material, the most meaningful way to compare them is using geometry. A sample of the Forta Ferro fibers (to be abbreviated 'Forta' for the remainder of this report) are shown in Figure 8 . These fibers are 2.25 " in length, round in cross-section, and approximately $1 / 32$ " in diameter. The fibers are typically bunched in groups of 10 to 20 fibers, and are typically wavy. 


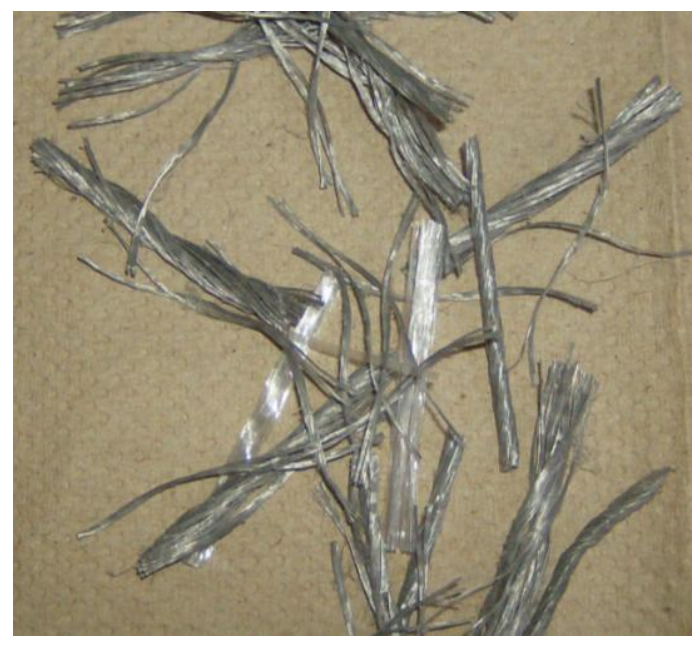

Figure 8 - Forta Ferro reinforcing fibers

A sample of the Propex Fibermesh 650 fibers (to be abbreviated 'Propex' for the remainder of the report) are shown in Figure 9. These fibers are 1.5" in length, flat in crosssection, and are about $1 / 16$ " on their widest face. These fibers do not bunch up, and are display only a bend.

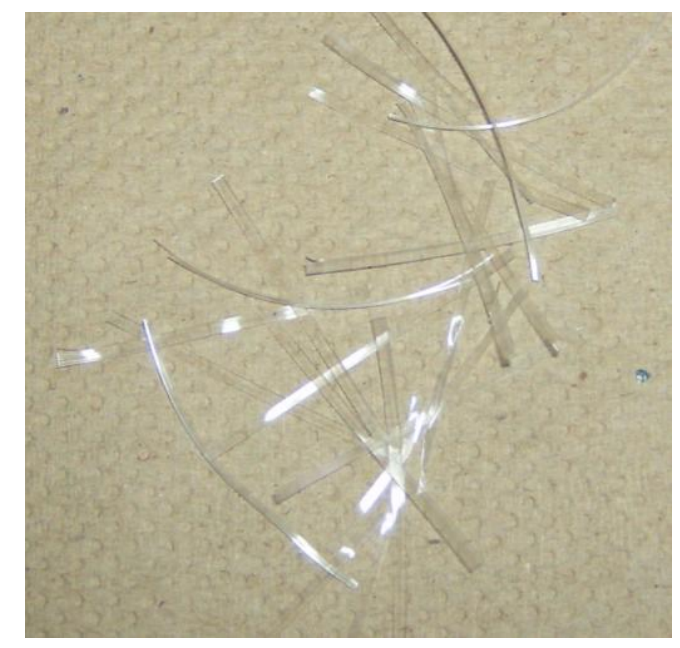

Figure 9 - Propex Fibermesh 650 reinforcing fibers

Both manufacturers recommended a dosage rate of $5 \mathrm{lbs} / \mathrm{cy}$ for slab over metal deck construction. In order to make the results of this project more applicable to the current state of 
the construction industry, the recommended dosage rate was used for all mixes that used fibers. Data sheets for both fiber types are included in the Appendices.

\section{Experimental Results}

Both of the analytical models developed above (the first for the shear connections, and the second for the flexural capacity of the section) were experimentally validated using a variety of mix designs.

\subsection{Direct Shear Tests}

\subsubsection{Apparatus and Specimen Construction}

In order to adequately test the connection of the screw to the concrete and the sheet metal, it was necessary to load that connection in direct shear. This was accomplished by preparing specimens as follows. First, one screw $(1 / 4$ ” x 1 1/4" stainless steel) was driven through a strip of sheet metal (2"x10"x16 gauge, low-carbon steel). Then two of these assemblies were cast in place on opposite sides of a 4 " $\mathrm{x} 4$ " $\mathrm{x} 6$ " block of concrete. In order to facilitate attachment for loading, (2) $9 / 16 " \varnothing$ holes were drilled into each sheet metal strip. Dimensions of the specimens are as shown in Figure 10. A total of five direct shear blocks were constructed for each of six different mix designs (plain normalweight concrete, normalweight concrete with Forta fibers, normalweight concrete with Propex fibers, plain lightweight concrete, lightweight concrete with Forta fibers, and lightweight concrete with Propex fibers). 


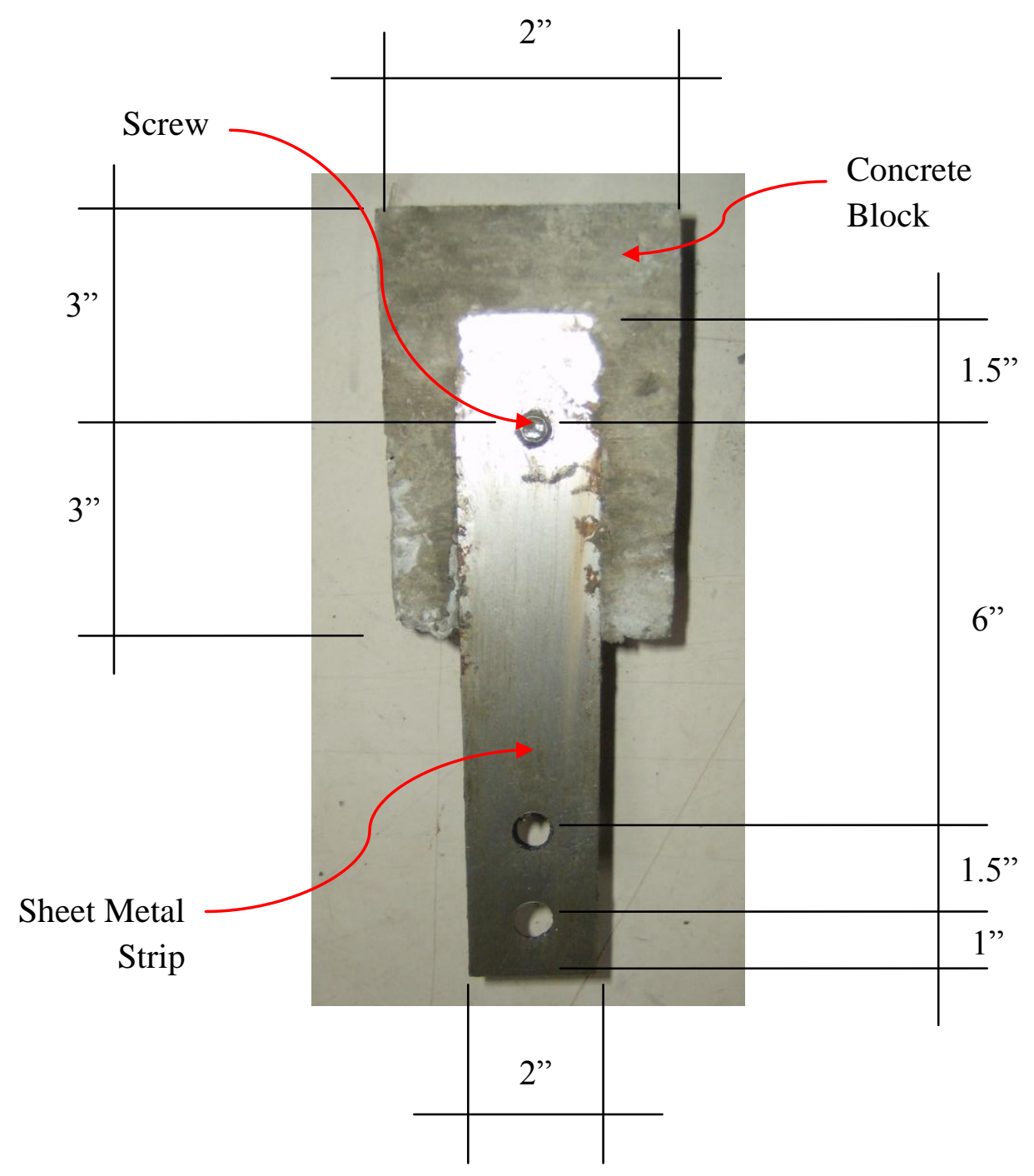

Figure 10 - Dimensions of direct shear block

Test fixtures were then created to allow the connections of the specimen to be loaded appropriately. The top fixture consisted of a "saddle" in which the concrete block was allowed to sit (see Figure 11). This fixture was composed of a bolt (intended to screw into the hydraulic actuator) and a 4" long piece of HSS6x8x3/8. 


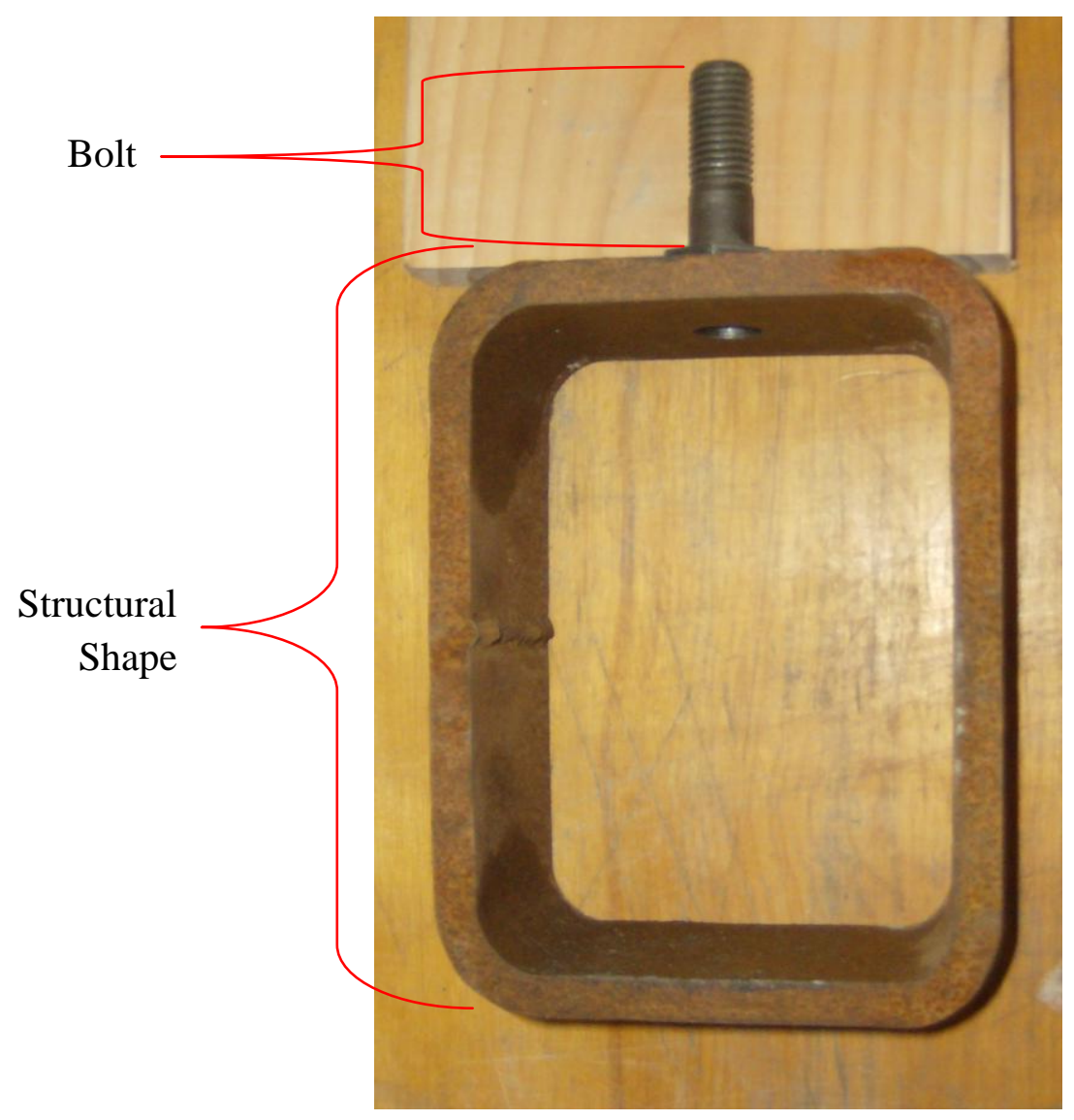

Figure 11 - Top fixture of direct shear test assembly

The bottom fixture allowed the sheet metal strips to be attached using a pair of through bolts. This fixture consisted of a pair of $1 / 8$ " steel plates (cut to fit and used as washers), a 4 " long portion of HSS4x4x1/4, and a bolt (intended to screw into the hydraulic actuator). All holes drilled were $5 / 8$ " $\varnothing$. The through bolts used to attach the sheet metal tabs to the lower fixture were made with $1 / 2$ " threaded rod with matching nuts. The assembly, with direct shear block inserted and ready for loading, is shown in Figure 13. 


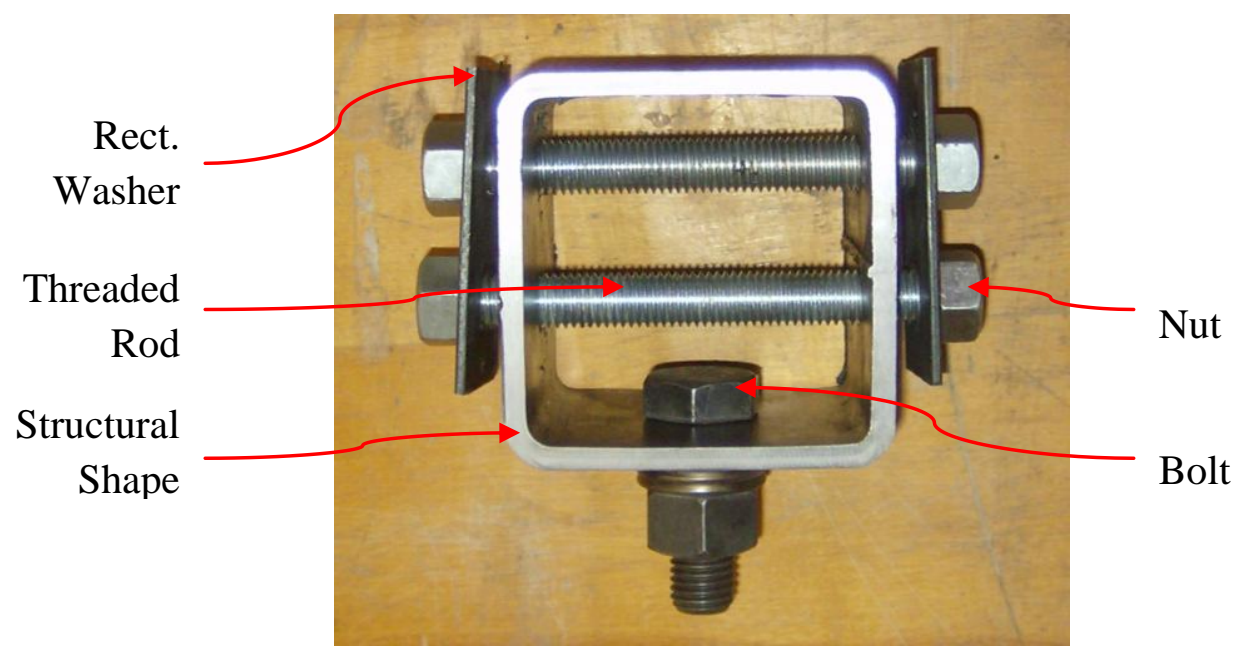

Figure 12 - Bottom fixture of direct shear assembly

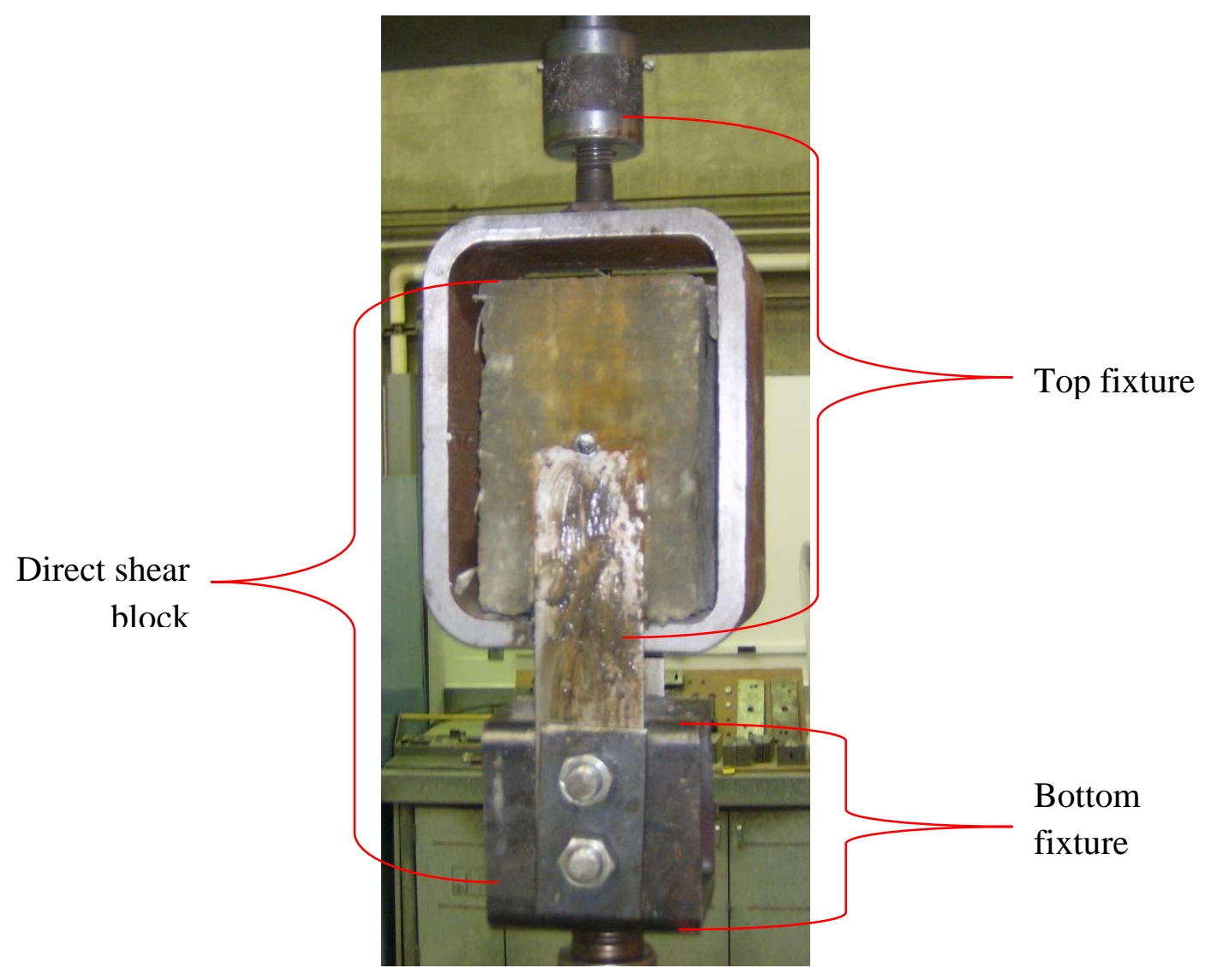

Figure 13 - Direct shear block and test fixture assembly 


\subsubsection{Concrete Strength}

In addition to the direct shear specimens, a set of 3 compression cylinders was created for each mix design. These cylinders were broken at the same time as the direct shear blocks using a compressive test. The compressive test results are shown in Table 1.

Table 1 - Ultimate Strengths from Concrete Cylinder Compressive Tests

\begin{tabular}{|l|l|l|l|l|}
\hline \multirow{2}{*}{$\begin{array}{c}\text { Aggregate } \\
\text { Type }\end{array}$} & \multirow{2}{*}{$\begin{array}{c}\text { Fiber } \\
\text { Type }\end{array}$} & \multicolumn{3}{|c|}{ Ultimate Load (lbs) } \\
\cline { 3 - 5 } & Cyl. 1 & Cyl. 2 & Cyl. 3 \\
\hline Lighweight & None & 21650 & 19360 & 27783 \\
\hline Lighweight & Forta & 36013 & 29559 & 33931 \\
\hline Lighweight & Propex & 14596 & 18391 & 18183 \\
\hline Normal-weight & None & 28798 & 41218 & 27513 \\
\hline Normal-weight & Forta & 24944 & 36315 & 24094 \\
\hline Normal-weight & Propex & 37974 & 19792 & 28685 \\
\hline
\end{tabular}

Ultimate compressive strengths were then computed from this data. The ultimate compressive stresses are shown in Table 2, along with basic statistical data. These stresses were used below to predict the strength of the direct shear blocks using the ACI procedure outlined previously.

Table 2 - Ultimate Stress from Concrete Cylinder Compressive Tests

\begin{tabular}{|l|l|c|c|c|c|c|}
\hline \multirow{2}{*}{ Aggregate Type } & \multirow{2}{*}{$\begin{array}{l}\text { Fiber } \\
\text { Type }\end{array}$} & \multicolumn{3}{|c|}{ Ultimate Stress (psi) } & Average & Standard \\
\cline { 3 - 5 } & & Cyl. 1 & Cyl. 2 & Cyl. 3 & Stress & $\begin{array}{c}\text { Ssi) } \\
\text { Deviation }\end{array}$ \\
\hline Lighweight & None & 1722.9 & 1540.6 & 2210.9 & 1825 & 347 \\
\hline Lighweight & Forta & 2865.8 & 2352.2 & 2700.1 & 2639 & 262 \\
\hline Lighweight & Propex & 1161.5 & 1463.5 & 1447.0 & 1357 & 170 \\
\hline Normal-weight & None & 2291.7 & 3280.0 & 2189.4 & 2587 & 602 \\
\hline Normal-weight & Forta & 1985.0 & 2889.9 & 1917.3 & 2264 & 543 \\
\hline Normal-weight & Propex & 3021.9 & 1575.0 & 2282.7 & 2293 & 723 \\
\hline
\end{tabular}




\subsubsection{Direct Shear Strength}

When the direct shear blocks were loaded, all ultimate strengths were around $4000 \mathrm{lbs}$, with the ultimate deflections being between 0.4 " and 0.7 ". The predominant failure type was pullout in the concrete. This was correctly predicted by the procedure discussed previously.

The full results (with the exception of those specimens that were obviously flawed) are shown below in . At least three specimens were broken for each mix type. It is important to note that the specimens were constructed so that two connections were loaded in parallel simultaneously. The curves shown below are the raw experimental data from the tests, meaning that the data shown must be halved in order to correlate to the behavior of a single embedded screw. This is done later when the curves are idealized.

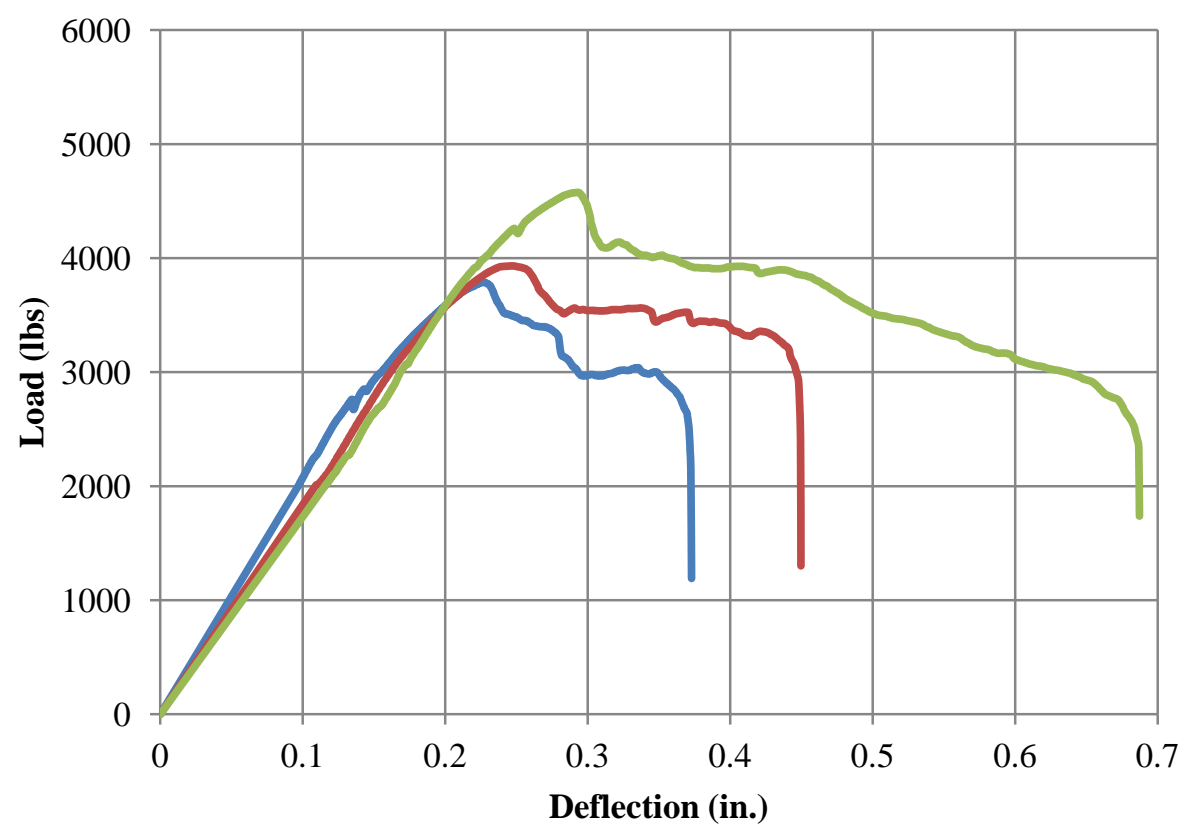

Figure 14 - Load-deflection curve for lightweight concrete with no fibers 


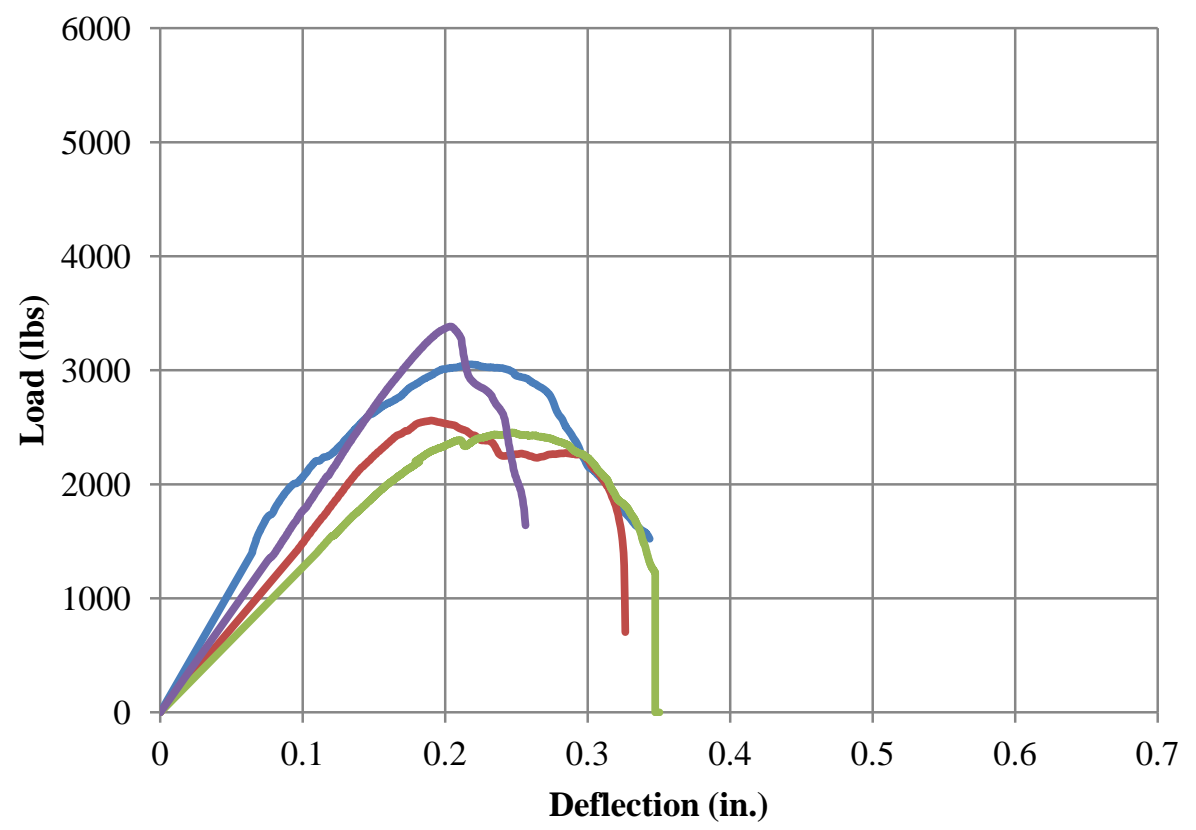

Figure 15 - Load-deflection curve for lightweight concrete with Propex fibers

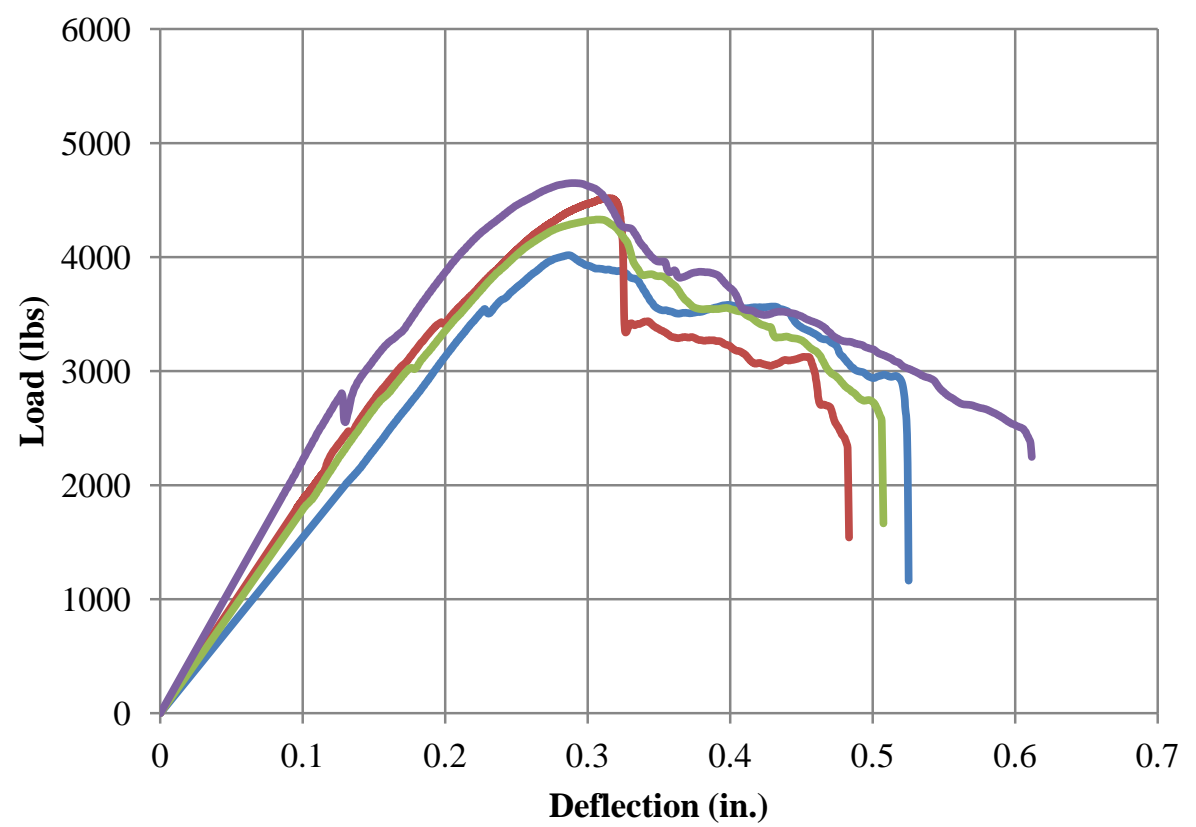

Figure 16 - Load-deflection curve for lightweight concrete with Forta fibers 


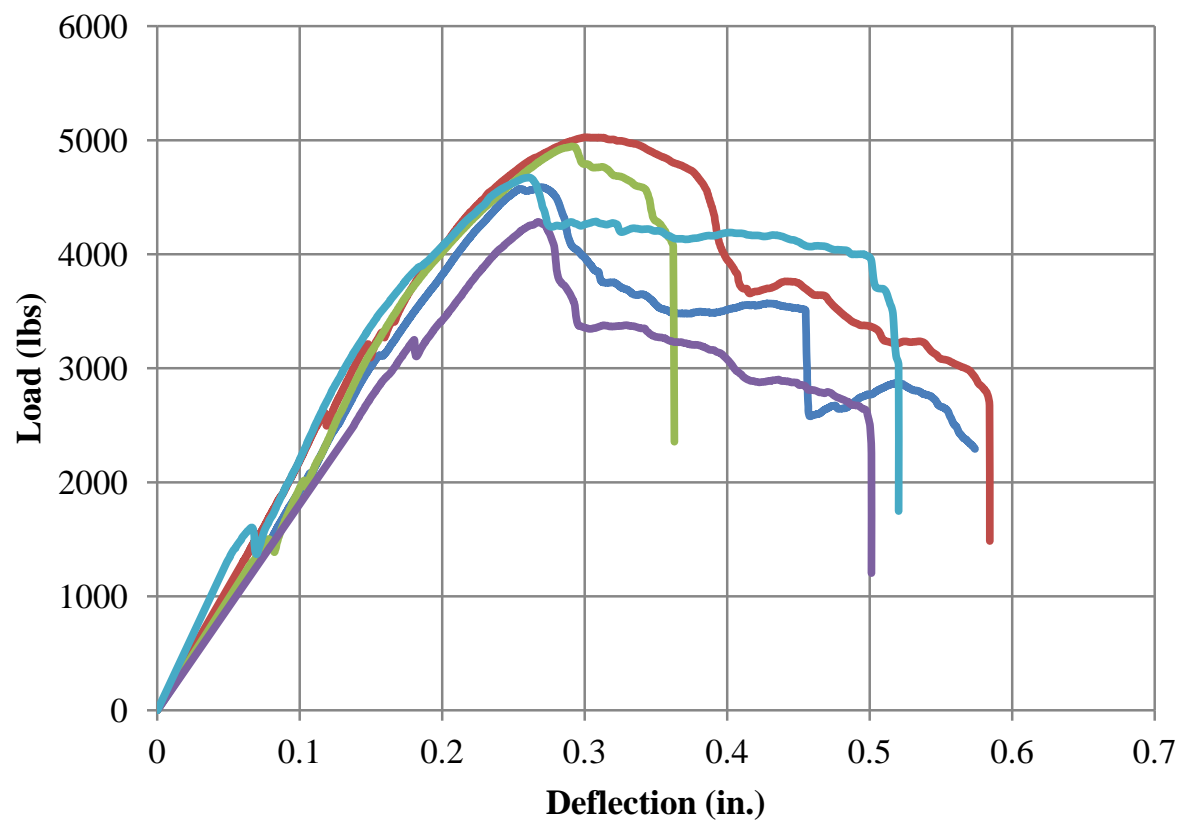

Figure 17 - Load-deflection curve for normal-weight concrete with no fibers

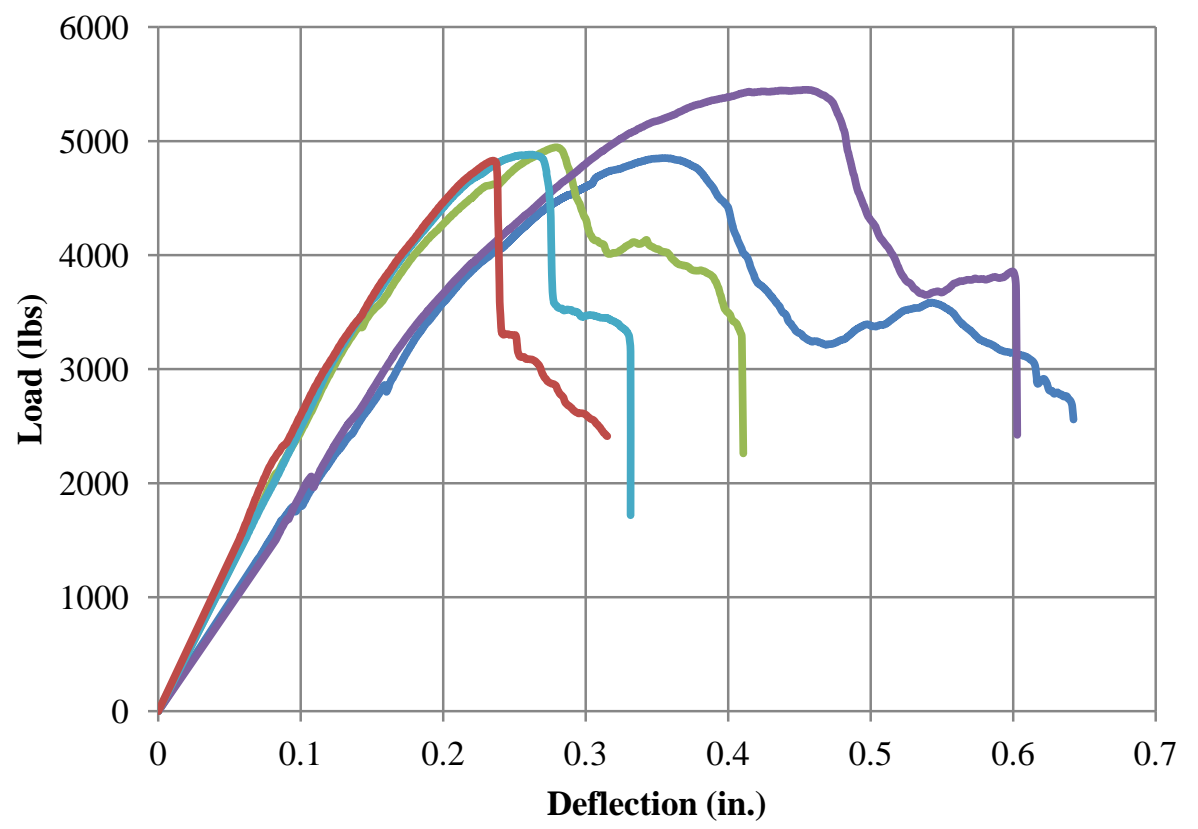

Figure 18 - Load-deflection curve for normal-weight concrete with Propex fibers 


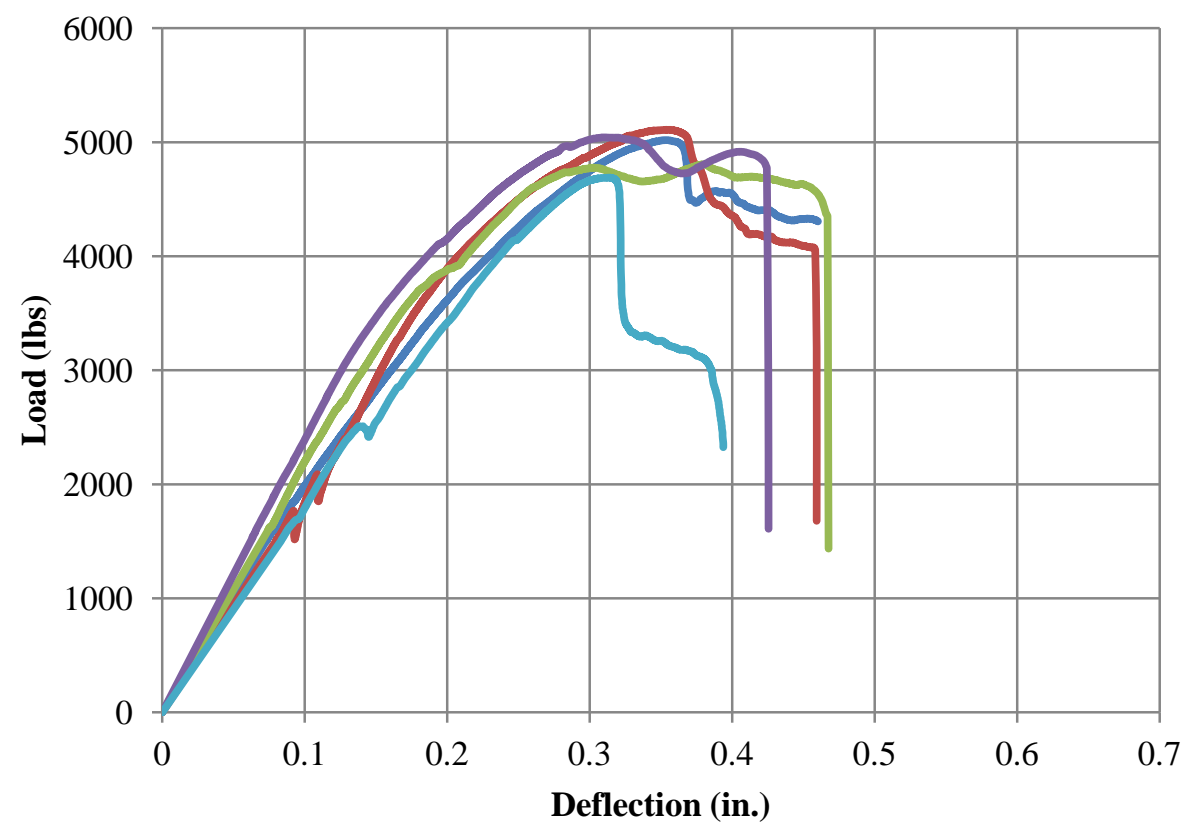

Figure 19 - Load-deflection curve for normal-weight concrete with Forta fibers

Some of the above figures do not have 5 curves on them. This is because several specimens were removed due to obvious imperfections (such as large voids due to incorrect consolidation). In nearly all cases, pullout failure was experienced by the specimens (see Figure 20, left). However, in 2 cases the failure was due to rupture of the screw (Figure 20, center), and in 1 case was due to the formation of a large crack emanating from the screw (Figure 20, right). However, the formation of the large crack as assisted by poor compaction in that specimen, which can be plainly seen in the figure. 

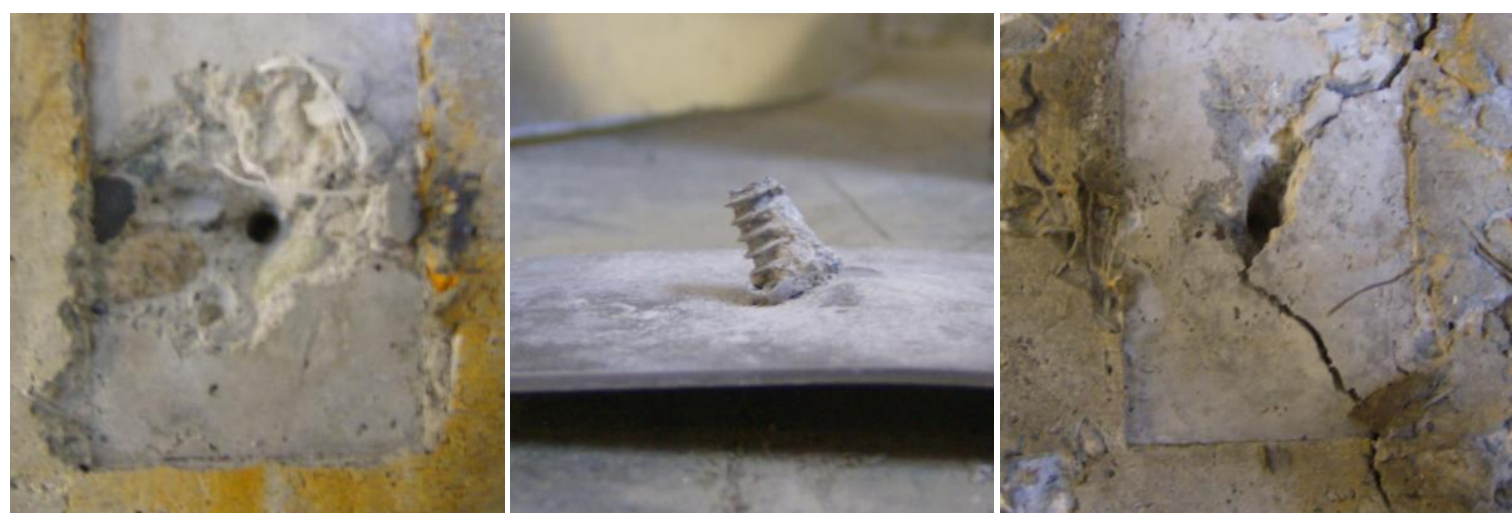

Figure 20 - Types of failure exhibited by direct shear specimens

One data point that we can pull from the above tests is the average maximum for each mix type. This maximum can then be compared to the maximum predicted by the model which was presented previously. This comparison is shown in the table below.

Table 3 - Comparison of predicted and measured strengths

\begin{tabular}{|l|l|c|c|c|}
\hline \multirow{2}{*}{$\begin{array}{c}\text { Aggregate } \\
\text { Type }\end{array}$} & \multirow{2}{*}{$\begin{array}{c}\text { Fiber } \\
\text { Type }\end{array}$} & \multicolumn{2}{|c|}{ Measured Strength (lbs) } & Predicted \\
\cline { 3 - 4 } & & Average & St. Dev. & $\begin{array}{c}\text { Strength } \\
\text { (lbs) }\end{array}$ \\
\hline Lighweight & None & 2049 & 210 & 310 \\
\hline Lighweight & Propex & 1431 & 217 & 268 \\
\hline Lighweight & Forta & 2189 & 137 & 373 \\
\hline Normal-weight & None & 2352 & 148 & 370 \\
\hline Normal-weight & Propex & 2496 & 130 & 348 \\
\hline Normal-weight & Forta & 2467 & 89 & 346 \\
\hline
\end{tabular}

A cursory look at this table indicates that the measured strength far exceeds the predicted strength. It is anticipated that this happened because the design code used to predict the failure is both very conservative, and typically not used for small embedded anchorage. The predominant failure (both that which was predicted, and that which was observed) occurred when the screw was pulled out of the concrete. The strength of this type of failure was predicted using ACI 
equations. Since ACI equations have historically been used for larger structural anchorage, little attention has been paid to the accuracy of ACI equations for anchorage of this size.

A closer look at the above figures above indicates that there are four distinct zones during the loading of the specimen. The first zone is a linear elastic region. The second zone is a plastic region, at the end of which the specimen reaches its ultimate strength. The third zone is a sudden drop, as pieces of the concrete in between the threads of the screw are sheared off. The fourth zone indicates that the screw is being pulled out of the concrete. The first, third and fourth zones will be modeled as being linear, and the second zone will be idealized as being parabolic. In order to fully define all of these zones, at least 6 distinct points are needed from each curve. The zones (numbered) and the points needed to define them (denoted by the lettered black circles) are shown in Figure 21.

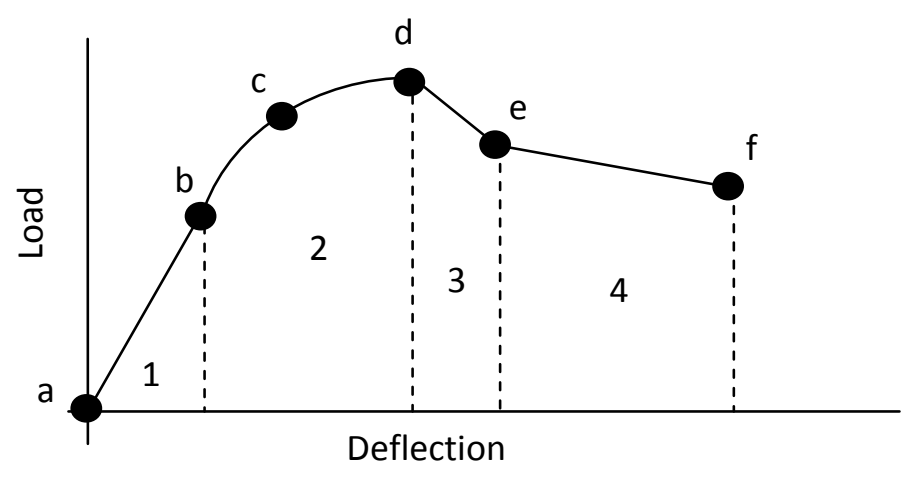

Figure 21 - General idealization of load-deflection curve

Point $\mathrm{a}$ is located at the origin. Point $\mathrm{b}$ is located at $1 / 2$ of the deflection of point $\mathrm{d}$, and point $\mathrm{c}$ is located at $3 / 4$ of the deflection of point $d$. Point $d$ is at the maximum load value of the curve. Point e occurs at the end of the drop that comes after the peak load is reached, and point $\mathrm{f}$ occurs at the maximum deflection of the test. These points were determined for every test, and values with the same mix design were averaged in order to yield a single curve for that mix. 
Tests that displayed anomalies in their load-deflection curves were omitted. The average values were then used to produce the curves generated from them are shown in Figure 22 and Figure 23. A parabolic curve fit was applied to points $b, c$ and $d$ in order to smooth that region. These curves will be used to predict strength and deflection of composite deck that uses these embedded fasteners.

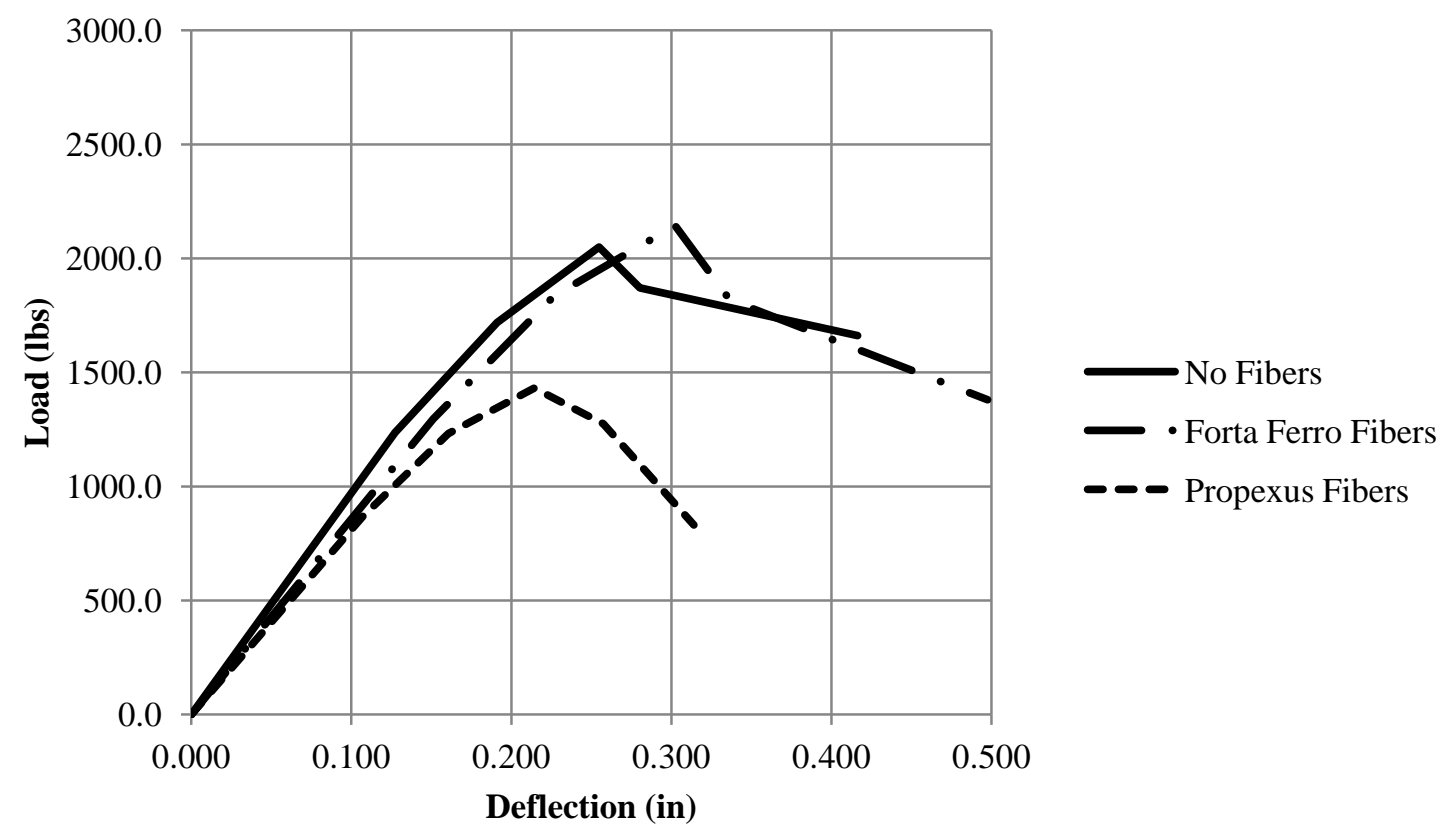

Figure 22 - Idealized load-deflection curves for lightweight concrete mixes 


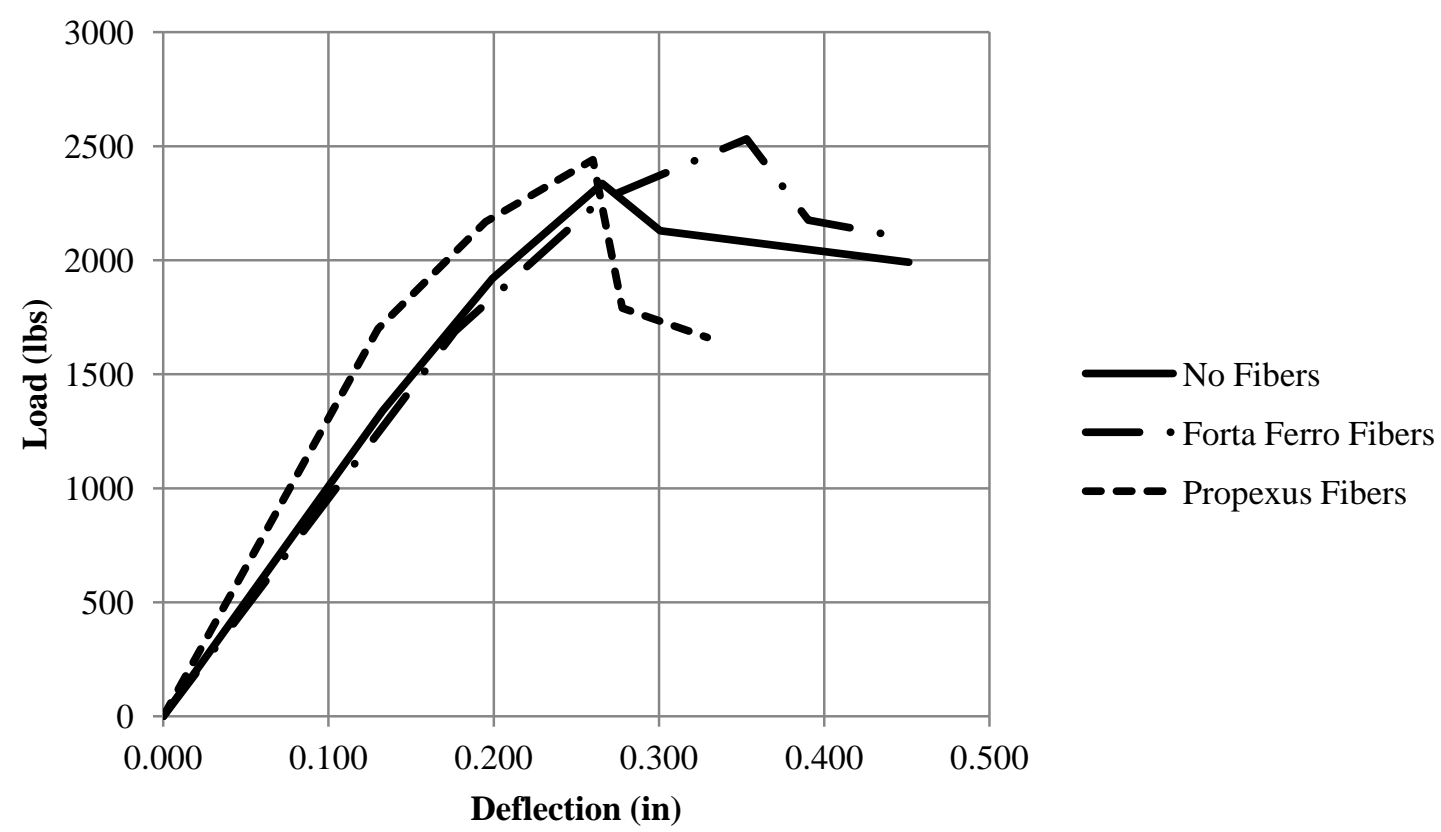

Figure 23 - Idealized load-deflection curves for normal-weight concrete mixes

It is interesting to note that mixes with Propex fibers displayed decreased ductility at the connection, and decreased strength when lightweight aggregate was used. The reduced strength can most easily be attributed to lack of sufficient consolidation near the screw. A visual inspection of the specimens that used lightweight aggregate with Propex fibers indicated this (see Figure 24). However, lack of consolidation was not noted in normal-weight specimens.

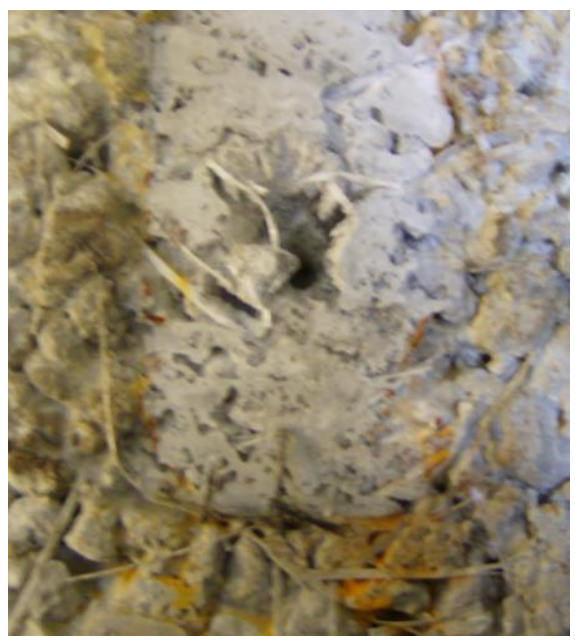

Figure 24 - Surface of lightweight Propex specimen, displaying poor consolidation 


\subsection{Flexural Tests}

\subsubsection{Apparatus and Specimen Construction}

Rather than test full sheets of corrugated steel deck, it was determined that satisfactory results could be obtained by testing single ribs of the composite deck. For this purpose, 21 single ribs of 16 gauge deck were cut, each 36" long. Each piece of deck had cross-sectional dimensions as shown in Figure 6. These pieces then had 1/4"Ø x 1 1/4" stainless steel sheet metal screws driven through them. The screws were located in the center of the 1.75 " bottom web of the deck, and placed every 2". The first screw was placed 1" from the end of each piece of deck. Each piece of deck then had approximately 2" of concrete poured on top of it. A total of 3 deck beams were prepared for each of the six mix types, and 3 deck beams were also prepared with no sheet metal screws. These were prepared using plain lightweight concrete.

In order to distinguish shear failure from flexural failure, it was necessary to test the deck beams in four-point bending. The locations of the contact points were as shown in Figure 25. This type of loading scheme resulted in maximum moment (but very little shear) being applied in the middle 10 " span.

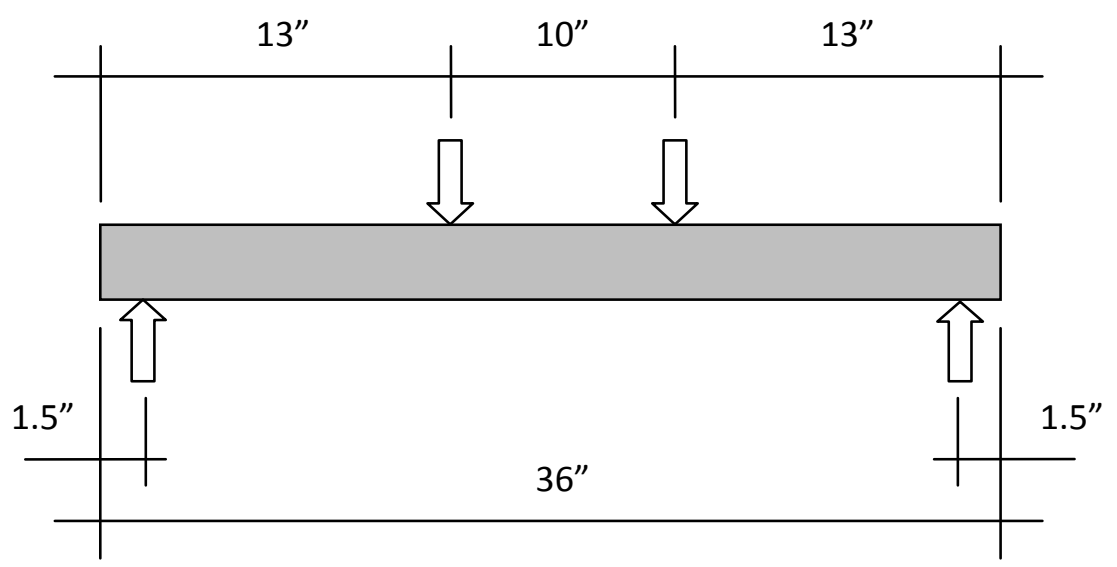

Figure 25 - Four point bending diagram 


\subsubsection{Concrete Strength}

In addition to the direct shear specimens, a set of 3 compression cylinders was created for each mix design. These cylinders were broken at the same time as the direct shear blocks using a compressive test. The compressive test results are shown in Table 4.

Table 4 - Ultimate Strengths from Concrete Cylinder Compressive Tests

\begin{tabular}{|l|l|l|l|l|}
\hline \multirow{2}{*}{ Aggregate Type } & \multirow{2}{*}{ Fiber } & \multicolumn{3}{|c|}{ Ultimate Load (lbs) } \\
\cline { 3 - 5 } & Type & Cyl. 1 & Cyl. 2 & Cyl. 3 \\
\hline Lighweight & None & 25272 & 24992 & 18797 \\
\hline Lighweight & Forta & 26295 & 25834 & 26655 \\
\hline Lighweight & Propex & 28721 & 28682 & 25026 \\
\hline Normal-weight & None & 31064 & 26881 & 26105 \\
\hline Normal-weight & Forta & 20504 & 20298 & 25537 \\
\hline Normal-weight & Propex & 31849 & 29014 & 27585 \\
\hline
\end{tabular}

Ultimate compressive strengths were then computed from this data. The ultimate compressive stresses are shown in Table 5, along with basic statistical data. These stresses were used below to predict the flexural strength of the enhanced composite beams.

Table 5 - Ultimate Stress from Concrete Cylinder Compressive Tests

\begin{tabular}{|l|l|l|c|c|c|c|}
\hline \multirow{2}{*}{ Aggregate Type } & \multirow{2}{*}{$\begin{array}{c}\text { Fiber } \\
\text { Type }\end{array}$} & \multicolumn{2}{|c|}{ Ultimate Stress (psi) } & \multirow{2}{*}{$\begin{array}{c}\text { Average } \\
\text { Stress (psi) }\end{array}$} & $\begin{array}{c}\text { Standard } \\
\text { Deviation }\end{array}$ \\
\hline Lighweight & None & 2011.1 & 1988.8 & - & 2000 & 16 \\
\hline Lighweight & Forta & 2092.5 & 2055.8 & 2121.1 & 2090 & 33 \\
\hline Lighweight & Propex & 2285.5 & 1991.5 & 1991.5 & 2090 & 170 \\
\hline Normal-weight & None & 2472.0 & 2139.1 & 2077.4 & 2229 & 212 \\
\hline Normal-weight & Forta & 1631.7 & 1615.3 & 2032.2 & 1760 & 236 \\
\hline Normal-weight & Propex & 2534.5 & 2308.9 & 2195.1 & 2346 & 173 \\
\hline
\end{tabular}

It should be noted that when the lightweight concrete cylinders (both fiber reinforced and plain) were tested, many displayed a lengthwise shear failure rather than any sort of compressive 
failure. It is expected that this sort of failure was due to uneven loading of the cylinders. This could be corrected in the future by using sulfur endcaps (only neoprene caps were used here).

\subsubsection{Flexural Strength}

When the enhanced beams were broken, the ultimate strengths were between 3000 and $5000 \mathrm{lbs}$, and the final deflections were between 2" and 3". This can be compared to approximate values for non-enhanced beams of about $2000 \mathrm{lbs}$ and 3", respectively. The full results are shown below. The dashed lines indicate the predicted load-deflection behavior. The predictions were developed using stress-strain relationships for plain concrete (even if fibers were present). Preliminary plans called for the development of experimental stress-strain curves for each mix, but it became apparent that the equipment available was no sufficient for this task. However, the load deflection curves for the embedded fasteners do account for the presence of fibers.

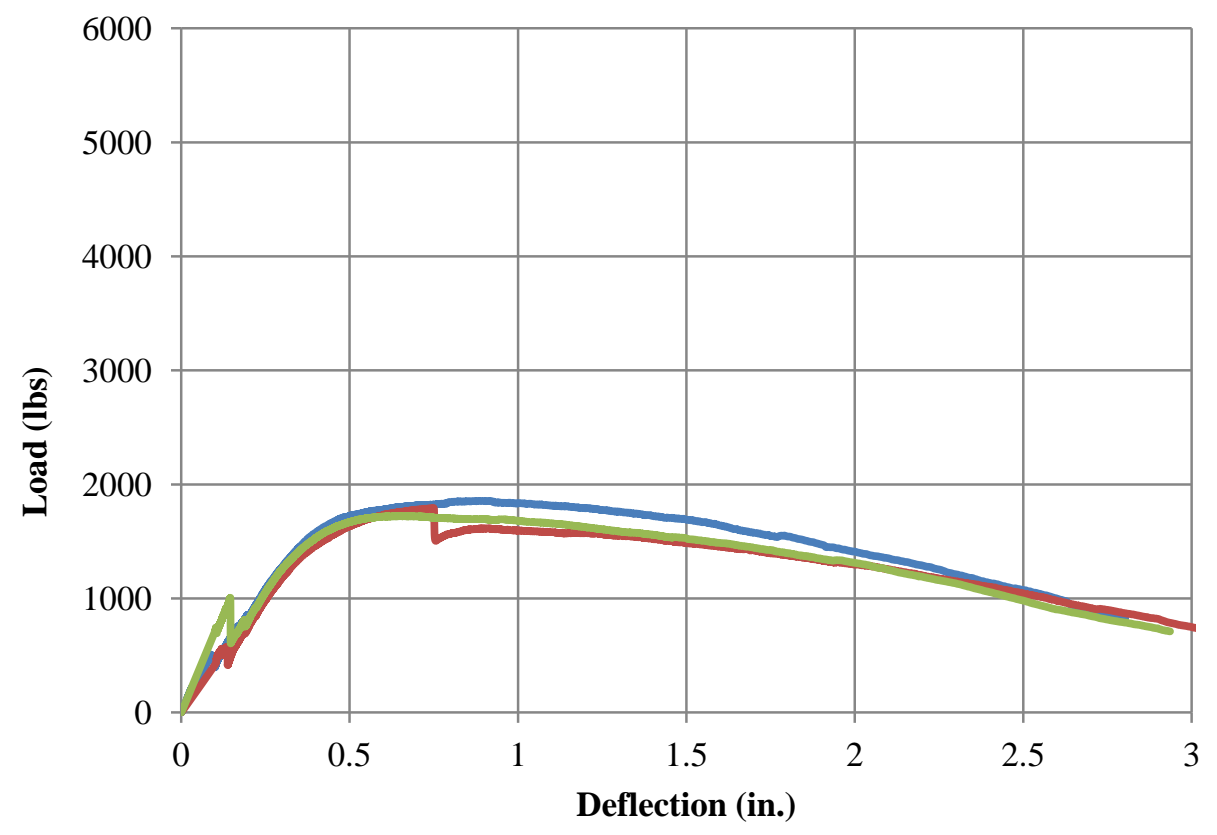

Figure 26 - Non-enhanced lightweight concrete beam, no fibers 


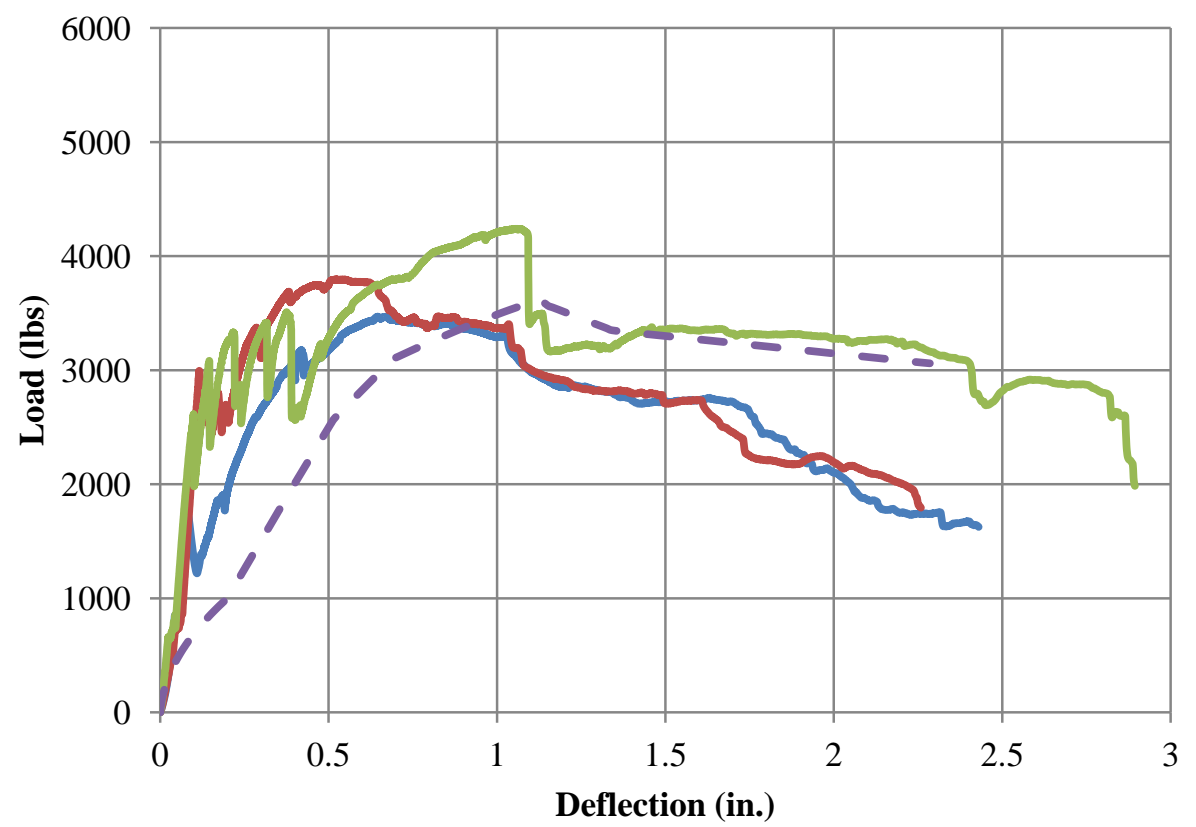

Figure 27 - Enhanced lightweight concrete beam, no fibers

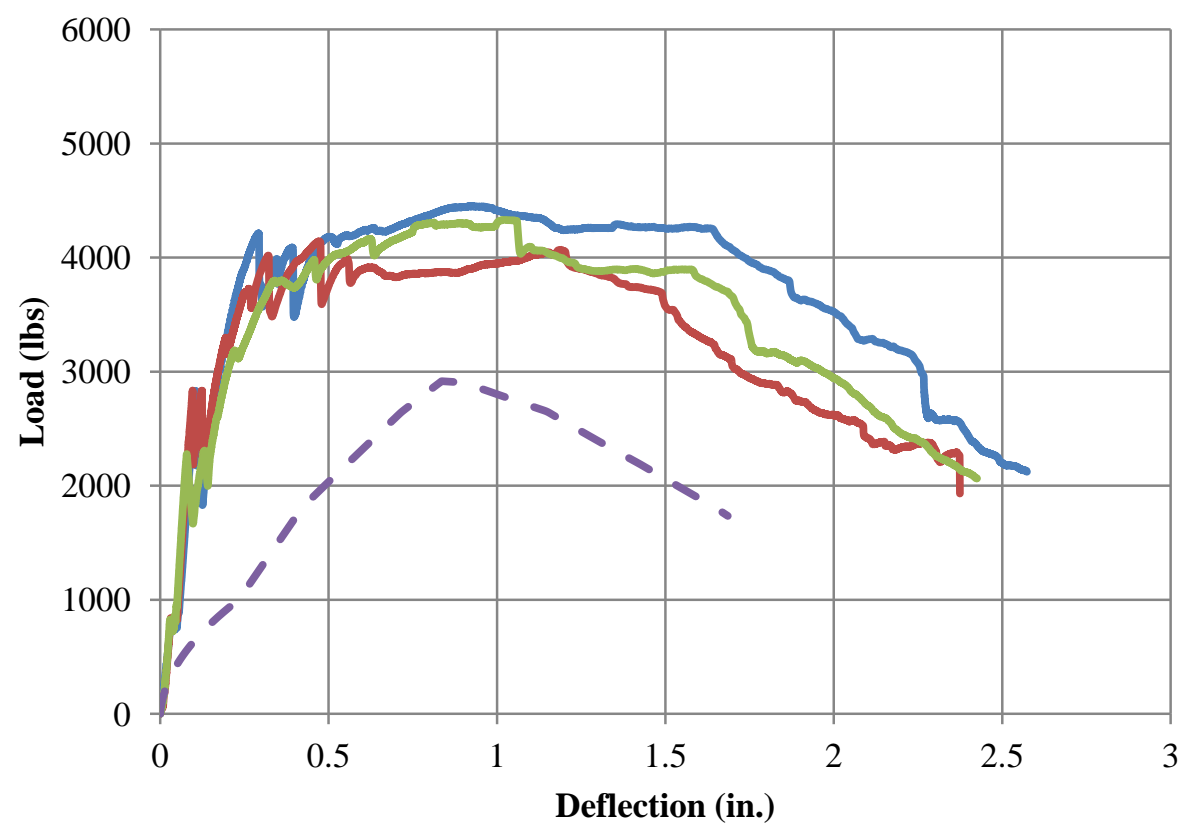

Figure 28 - Enhanced lightweight concrete beam, Propex fibers 


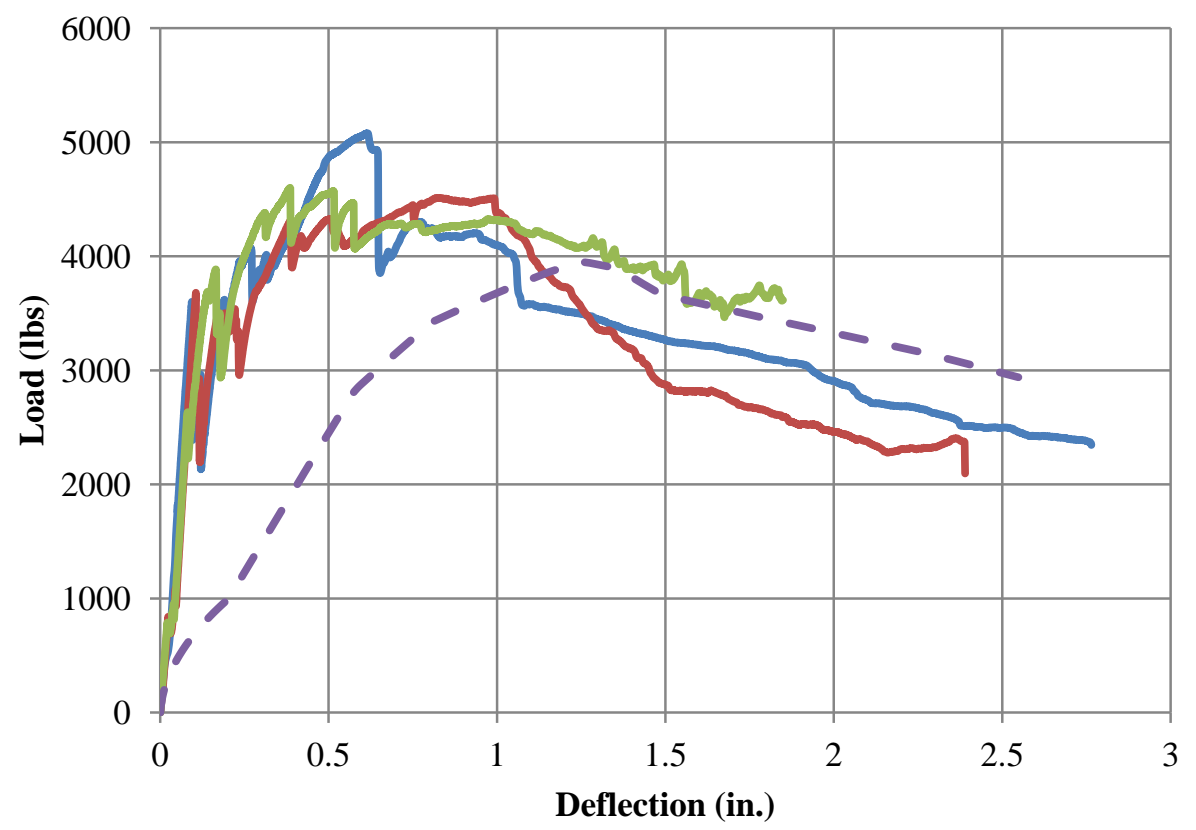

Figure 29 - Enhanced lightweight concrete beam, Forta fibers

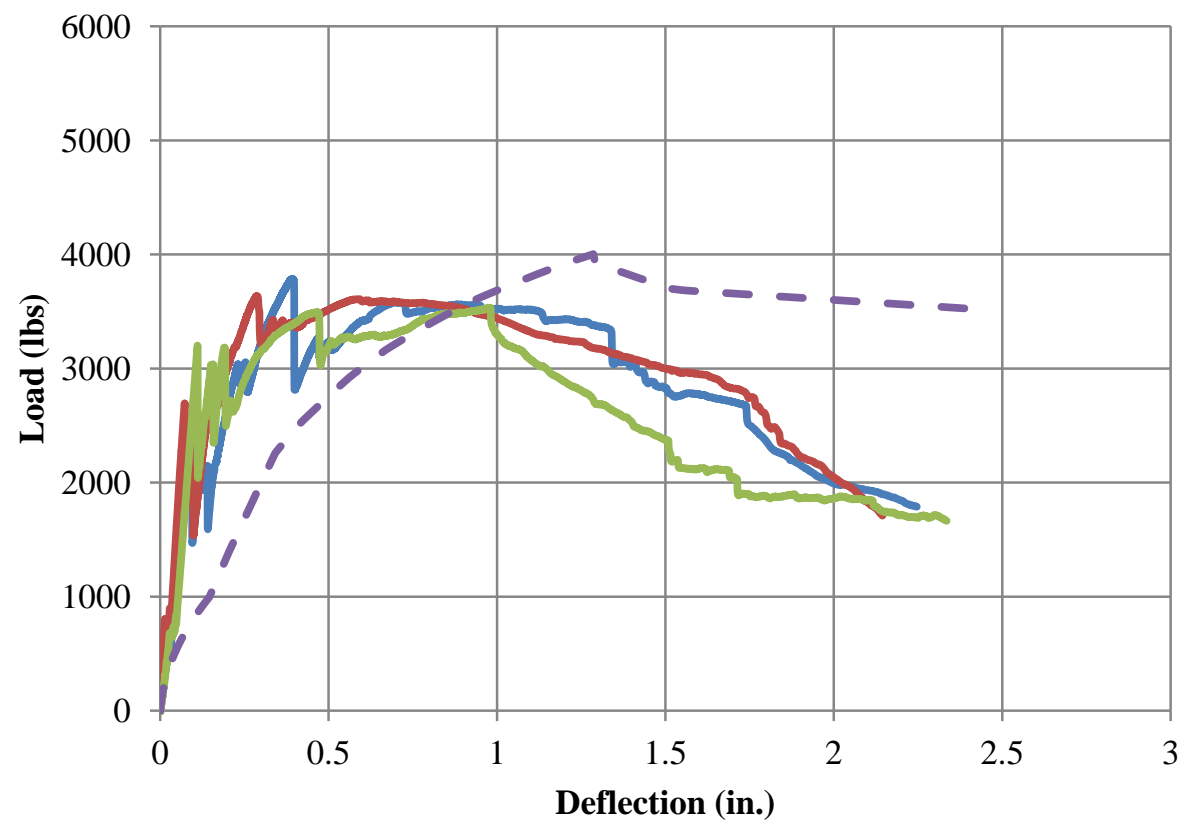

Figure 30 - Enhanced normal-weight concrete beam, no fibers 


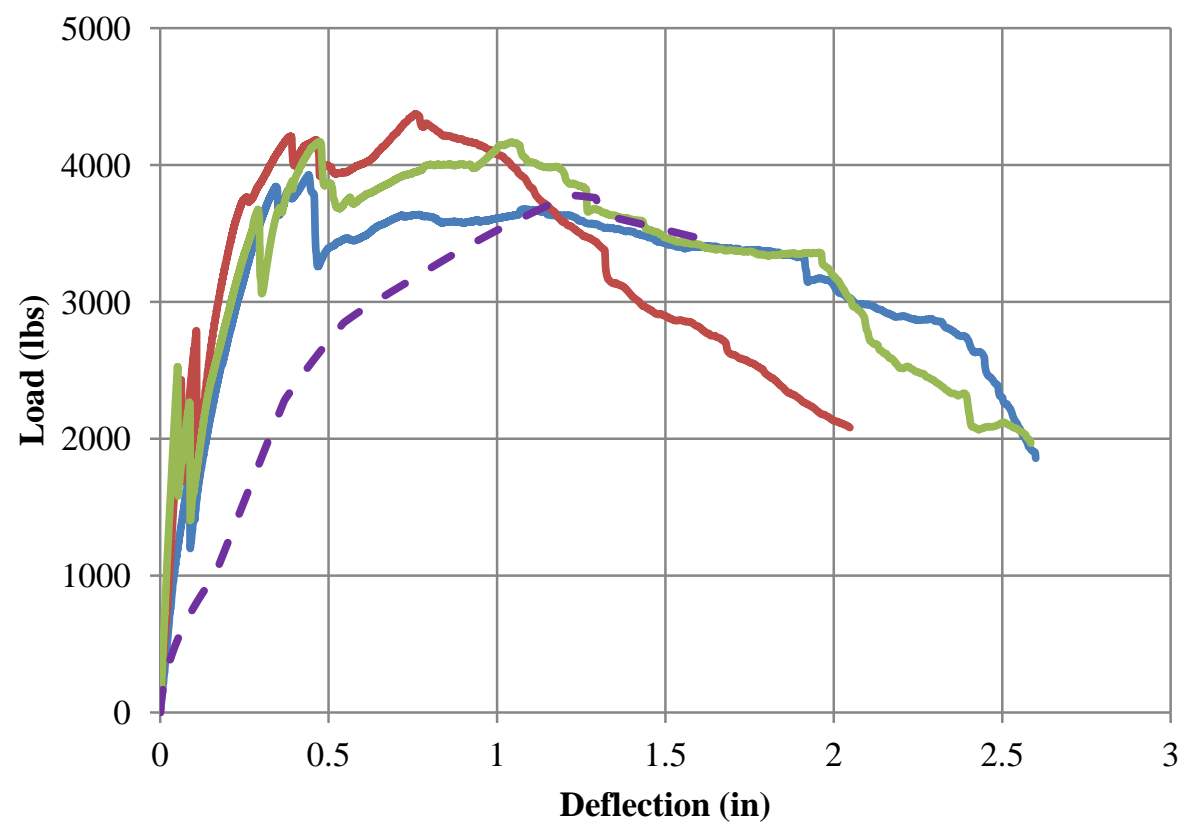

Figure 31 - Enhanced normal-weight concrete beam, Propex fibers

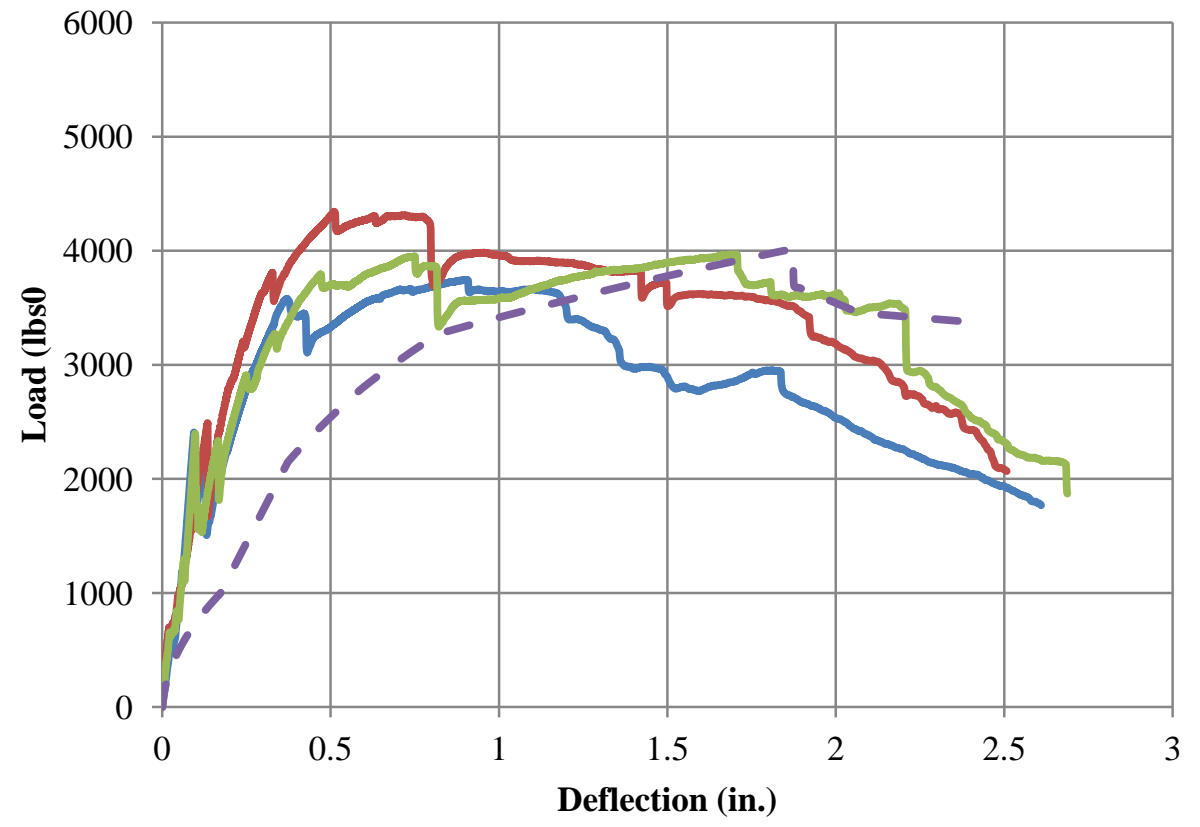

Figure 32 - Enhanced normal-weight concrete beam, Forta fibers 
Almost all beams experienced a shear failure near one of the applied loads (see Figure 33, left). A similar failure occurred in the beams without embedded fasteners, but the angle of failure was much higher, indicating a larger flexural component (see Figure 33, right). Upon deconstructive inspection of the failure surfaces, it became apparent that each one of the cracks in the enhanced beams originated from an embedded fastener (see Figure 34). Predictions of the strength indicated that the fastener would fail in pullout. It appears that during loading the fastener had a torque applied to it, so that it acted as a pry-bar in the tensile region of the concrete, serving to induce the formation of cracks rather than pulling out.

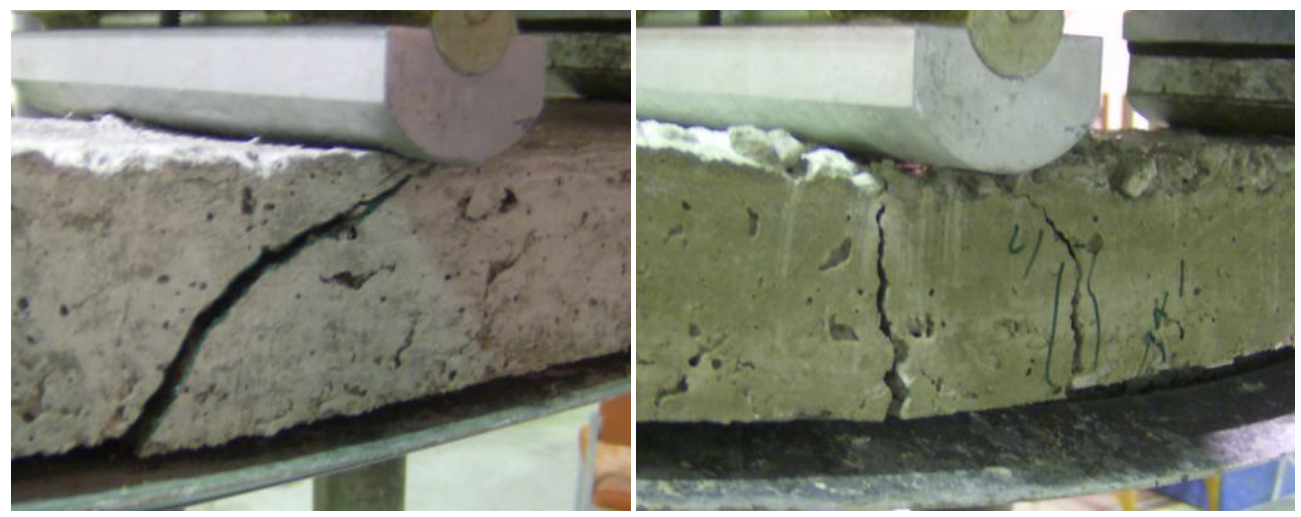

Figure 33 - Typical failure in beams with (left) and without (right) embedded fasteners 


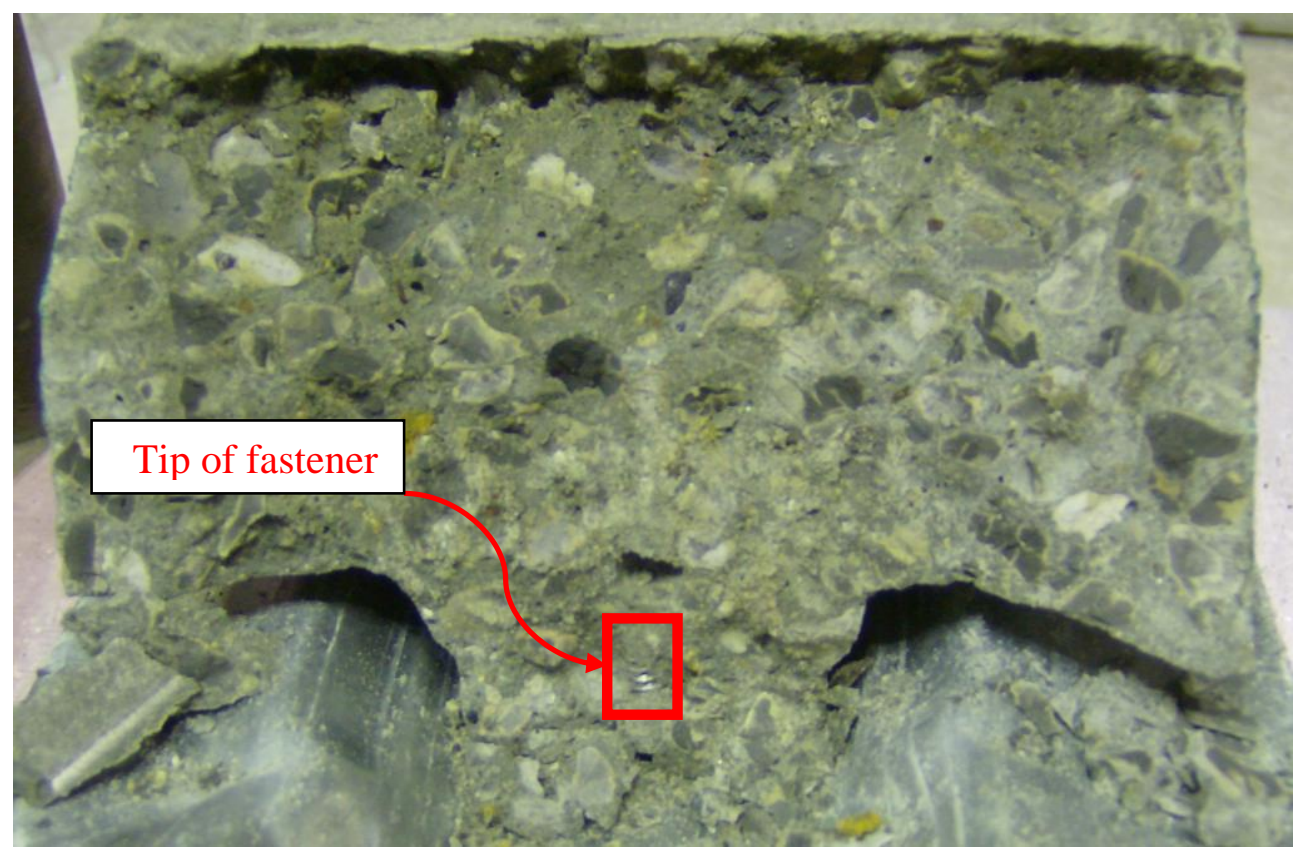

Figure 34 - Typical failure surface with screw at base

Despite the unexpected failure patterns, an obvious increase in load carrying capacity with the addition of embedded fasteners can be noted when observing Figure 26 and Figure 27. In addition, it is readily apparent that modest gains were made by the addition of fiber reinforcement. Table 6 shows the maximum moment strength of the beams, as calculated from the maxima of the above curves as well as the predicted strength of the beams. The performance of beams using normal-weight concrete with Forta reinforcing fibers was calculated using a compressive strength of 2300 psi. The measured compressive strength for this mix type was abnormally low (around 1760 psi, see Table 5), despite the fact that there was no noticeable lack of strength in the beams. The compressive strength of 2300 psi was chosen as a value close to that of the other two normal-weight mixes, and allowed the performance of the beam to be calculated well. In addition, the average and standard deviation for the lightweight beams using 
Forta reinforcing fibers were calculated using the two lowest strengths, as the highest strength was determined to be an outlier.

Table 6 - Comparison of measured and predicted strengths of beams

\begin{tabular}{|c|c|c|c|c|c|}
\hline \multirow[b]{2}{*}{ Aggregate Type } & \multirow{2}{*}{$\begin{array}{l}\text { Fiber } \\
\text { Type }\end{array}$} & \multicolumn{2}{|c|}{ Measured Strength (k-in) } & \multirow{2}{*}{$\begin{array}{c}\text { Predicted } \\
\text { Strength (k-in) }\end{array}$} & \multirow{2}{*}{$\begin{array}{c}\% \\
\text { Difference }\end{array}$} \\
\hline & & Average & St. Dev. & & \\
\hline Plain Lighweight & None & 10.3 & 0.4 & 9.4 & $-8.8 \%$ \\
\hline Lighweight & None & 22.1 & 2.2 & 22.0 & $-0.4 \%$ \\
\hline Lighweight & Propex & 24.8 & 0.9 & 17.1 & $-30.9 \%$ \\
\hline Lighweight & Forta & 26.2 & 0.4 & 24.0 & $-8.3 \%$ \\
\hline Normal-weight & None & 21.0 & 0.7 & 24.2 & $15.1 \%$ \\
\hline Normal-weight & Propex & 23.9 & 1.3 & 22.8 & $-4.8 \%$ \\
\hline Normal-weight & Forta & 23.1 & 1.7 & 24.3 & $5.3 \%$ \\
\hline
\end{tabular}

The predicted strengths in this table were determined using the model discussed previously. The number of discretized strips was 200 for every prediction. The steel used for every prediction was identical (ASTM 653), but the stress-strain curve for the concrete was based on the compressive strengths of the test cylinders. Load-displacement data directly from the direct shear tests was also incorporated into the predictions.

There is one major discrepancy in Table 6. The predicted strength of the lightweight beam with Propex fibers is $32 \%$ lower than the measured strength. The data from the direct shear tests was used to calculate the predicted strengths, so this discrepancy is due to the abnormally low strength measured in the direct shear tests for this mix design. The high measured beam strength indicates that the low direct shear test strength was most likely due to insufficient compaction, as expected. Using more realistic load-deflection data for the embedded fasteners would increase the strength notably. All other differences between experimental and predicted results fall within acceptable experimental variation. 
The model was also used to predict the deflection of the span as a function of applied load. The predicted performance curves are shown in Figure 27 through Figure 32 as a dashed line. In most of the figures, the predicted curve offered a good approximation of the actual behavior of the beams. However, the predictions fell short in several areas. First, in many cases the predicted maximum occurred at a deflection much higher than that of the experimental maximum. Second, the ultimate predicted deflection was often much lower than that measured experimentally. Third, the predicted strength immediately prior to failure was usually higher than that which was measured. These discrepancies can be primarily attributed to three phenomena which will now be discussed.

The first source of error was the development of the load-deflection relationships for the embedded fastener. As noted previously, the primary failure noted for fasteners in the flexural tests was similar to breakout. However, the primary failure mode displayed during direct shear testing was pullout. Pullout was actually made nearly impossible during flexural testing, since the concrete was pushed into the steel deck by the applied load. Therefore, it is conceivable that the in-situ load-deflection relationship was slightly different than that which was developed separately. Principally, the in-situ relationship would have displayed greater ductility, limited mostly by the failure of the steel deck as the angle of the fastener changed (see Figure 35). In contrast, the failure during direct shear testing was usually a sudden pullout of one of the fasteners. This assists in explaining the discrepancy with respect to ultimate deflection. 


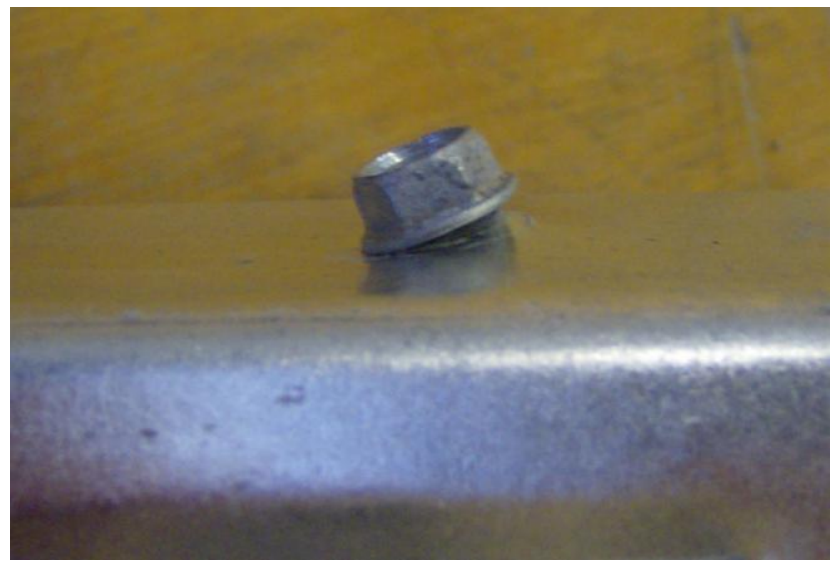

Figure 35 - Head of embedded fastener, post-failure

The second source of error was the unanticipated change in cross-section of the steel deck during loading. After the peak load was reached, it was observed that the steel deck started to buckle. This was not anticipated, and was not accounted for in calculations. The top flanges of the deck buckled downwards, pulling away from the concrete and reducing the overall moment of inertia of the steel deck considerably. When actually installed, this type of action will be impossible since the deck will be continuous. For this reason, the experimental post-peak performance of the deck will in fact be much lower than the actual performance. The crosssection of the deck at the midspan before (left) and after (right) loading is shown in Figure 36.

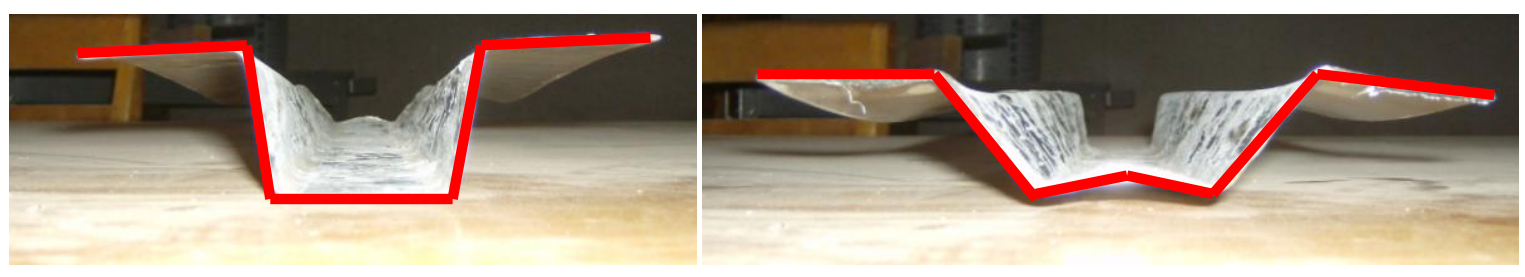

Figure 36 - Change of deck cross-section during loading

It is estimated that during the post-peak loading of the deck, the moment of inertia of the steel alone dropped from $0.231 \mathrm{in}^{4}$ to $0.166 \mathrm{in}^{4}$, a total drop of about $28 \%$. This helps to explain the difference concerning load at failure. Had the cross-section remained constant (as assumed when 
predicted the performance of the flexural specimens), the load at failure would have been considerably higher.

The third source of error concerns the fact that only a mechanical bond (the embedded fastener) was considered to resist transverse shear between the concrete and the steel deck. In other words, both the chemical and frictional bonds were considered to be negligible. However, this was not an accurate assumption. Figure 37 shows both experimental and predicted data for the enhanced, normal-weight concrete beams using Propex fibers. Data is only shown for very small deflection levels. The solid lines are experimental data. The top dashed line is the predicted performance of a beam with perfect composite action. The lower dashed line indicates the predicted performance of the partially composite beam, as calculated using data from direct shear tests.

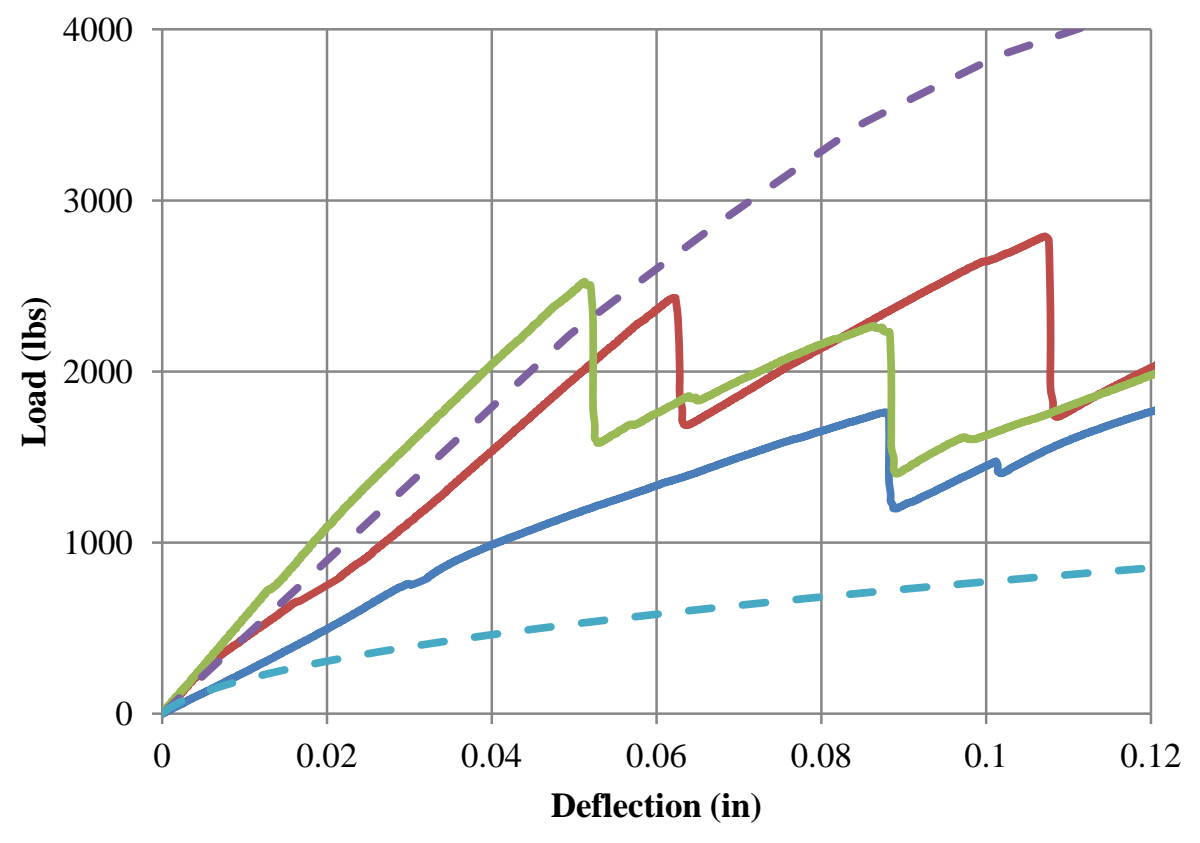

Figure 37 - Enhanced normal-weight concrete beam, Propex fibers (small deflection) 
Initially, the experimental curves are quite close to that of the fully composite section. Indeed, through the entire region shown on the graph, the slope of the experimental curves generally matches that of the fully composite section. The vertical drops in the experimental curves clearly indicate slip-catch behavior. This type of behavior is indicative of the presence of chemical and frictional bonds. These bonds have good elastic properties, but fail suddenly. It can be noted that the experimental curves begin to trend toward the partially composite section. This helps to reconcile the location of the predicted ultimate load and the experimental ultimate load. This indicates that the true performance could be more accurately resolved if the analytical model considered a region of full-composite action and a region of partially composite action, connected by a region displaying a transition between the two. In addition, if the steel deck had been lubricated to avoid chemical and frictional bonds, it is anticipated that the results would have much more closely approximated the predicted behavior.

\subsubsection{Discretization Resolution Analysis}

As previously stated, 200 discretized strips were used to predict the strength of the section. However, this number of strips might not have offered sufficient resolution to produce a converged answer. For this reason, the sensitivity of the solution to changes in the number of discretized strips was investigated. Solutions for all types of experimental beams were performed for varying numbers of discretized strips between 20 and 200. The difference between those values and the final value $(a t) 200$ ) were then determined. These differences were then averaged for each value of N. The results are shown in Figure 38. 


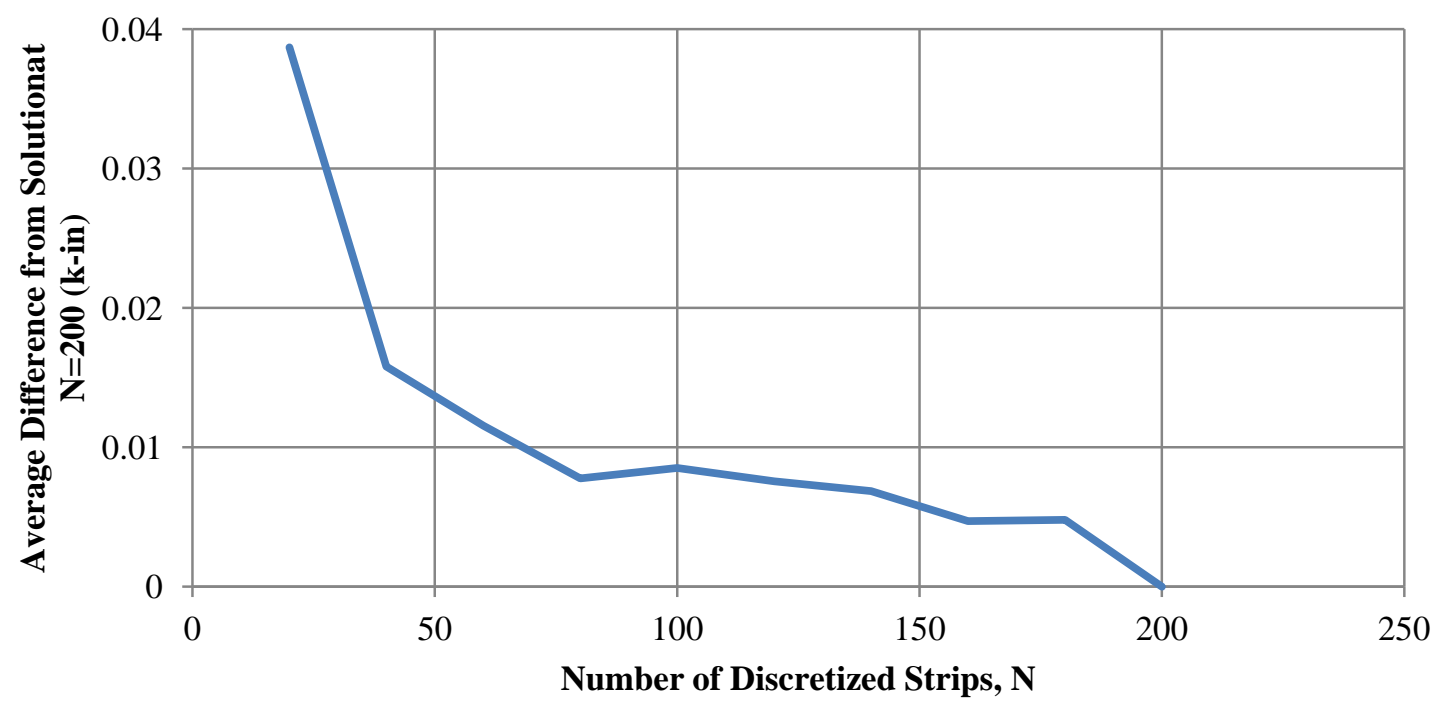

Figure 38 - Sensitivity of solution to number of discretized strips

This graph indicated that the result was adequately converged and stable at $\mathrm{N}=200$, and that little change in the final value could be expected with an increase in $\mathrm{N}$. A smaller number of strips, say $\mathrm{N}=100$, could also have been used with little loss in accuracy. Based on this observation, it is recommended that future simulations of a similar nature use $N=30 d$, where $d$ is the total depth of the section, in inches. In order to fully resolve complex deck profiles, the value of $N$ should be increased. 


\section{Revised Numerical Model}

The model presented previously (developed from an analysis of the flexural capacity of the deck) indicated adequate predictive capabilities for the ultimate strength of the deck. However, the load-deflection relationship was not predicted well. A revised model is presented that modified the previous model in three ways. First, the deck was assumed to exhibit the effective composite stiffness up to half of the ultimate calculated load (this was based on observations of the experimental data). This was approximated as the full composite stiffness, multiplied by the ratio of available shear strength to shear strength required for full composite action. Second, after half of the ultimate load the stiffness of the deck was calculated as the average of two other stiffnesses: the initial stiffness of the previous model, and the initial stiffness of the composite section. Third, the section reached a strength plateau, until the point at which the previous model calculated a peak. This was also based on observations of the experimental data. The post-peak performance calculated using the last model remains unmodified. The experimental data along with the revised predictions are shown in Figure 39 through Figure 43. The results for the lightweight aggregate beams with Propex fibers are omitted due to the inaccuracy of the direct shear test data. 


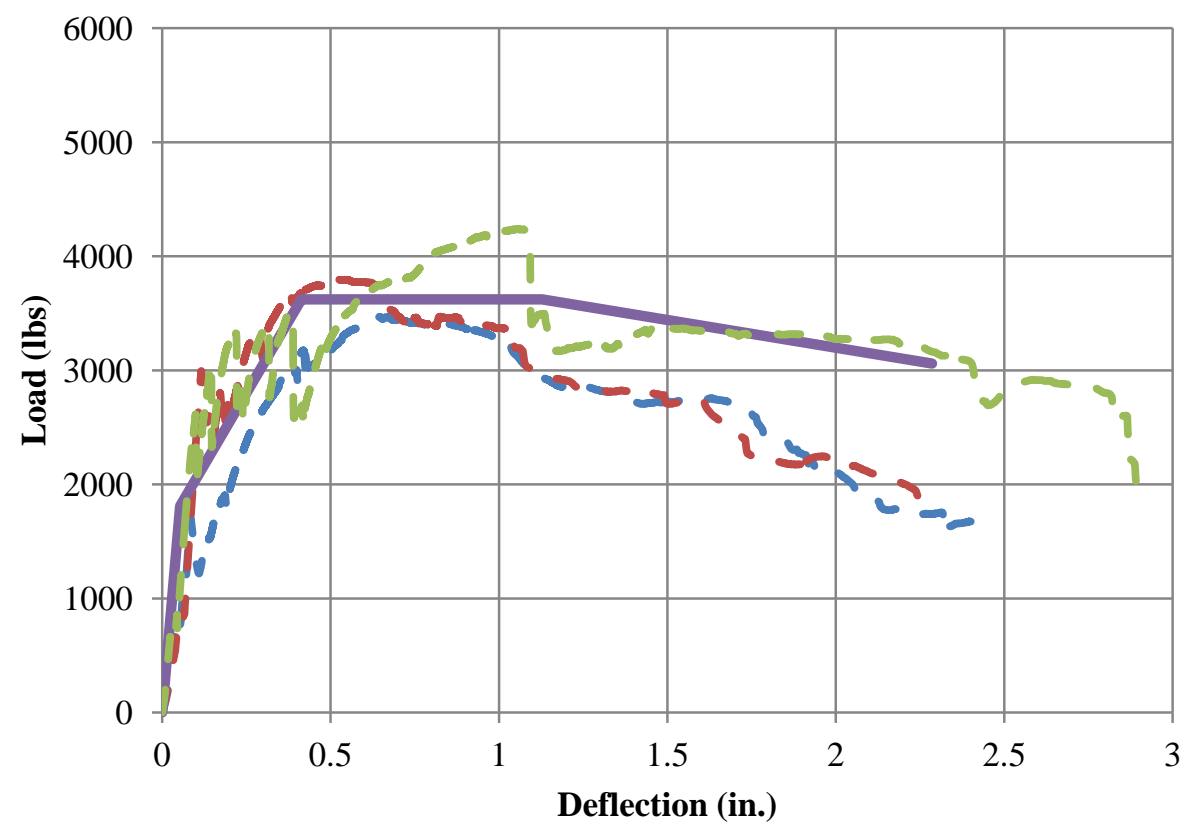

Figure 39 - Revised model, lightweight beam with no fibers

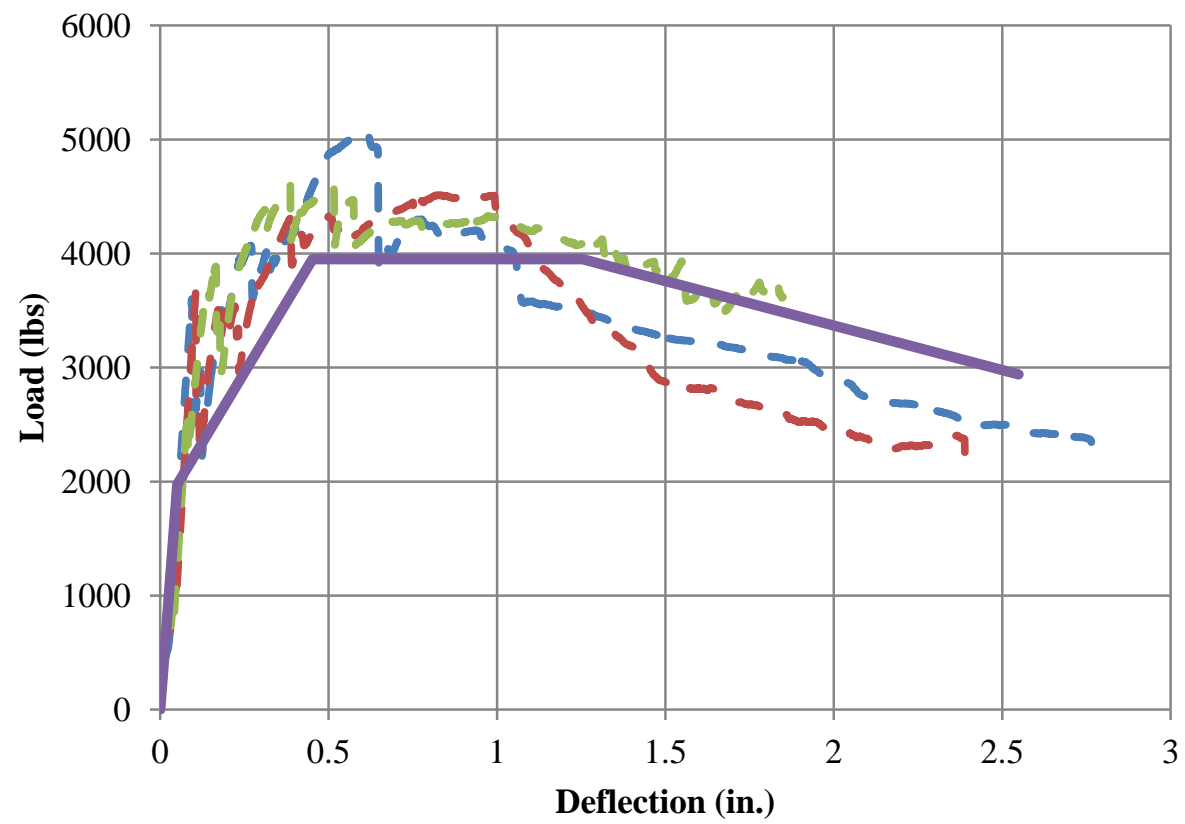

Figure 40 - Revised model, lighweight beam with Forta fibers 


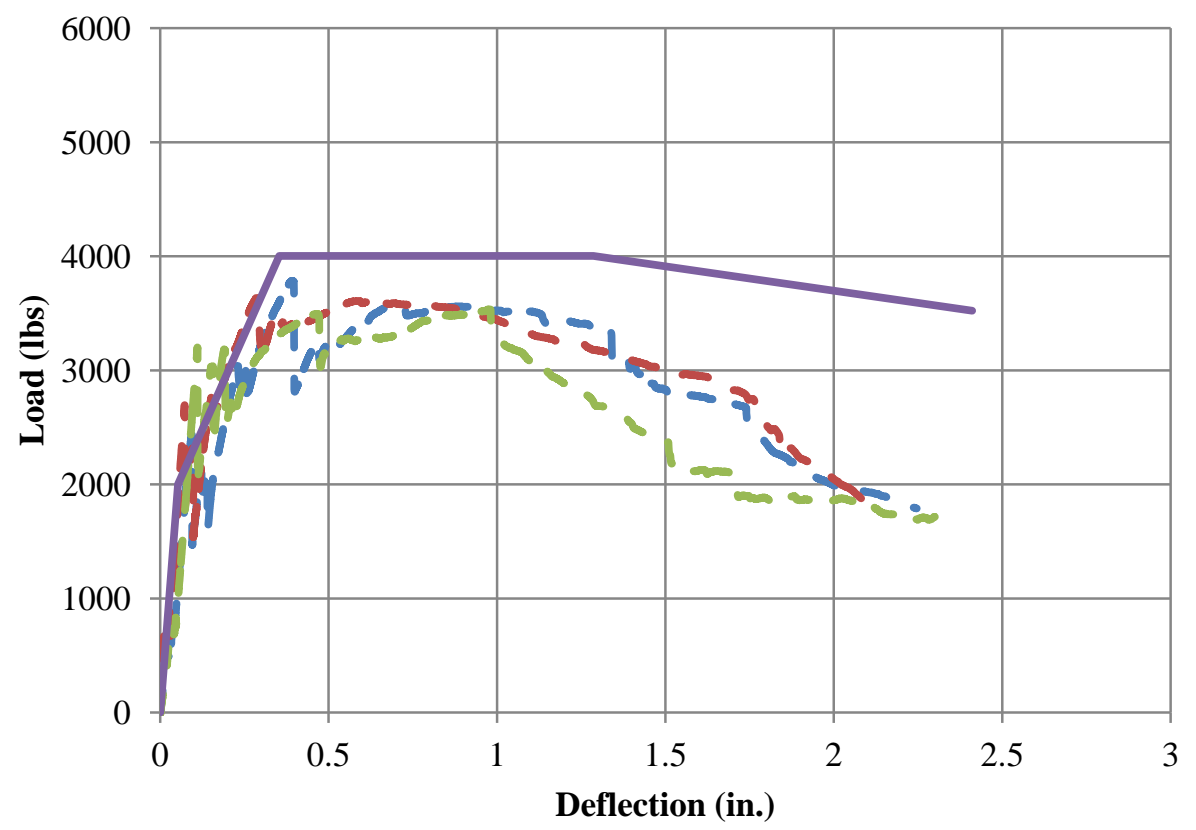

Figure 41 - Revised model, normal-weight beam with no fibers

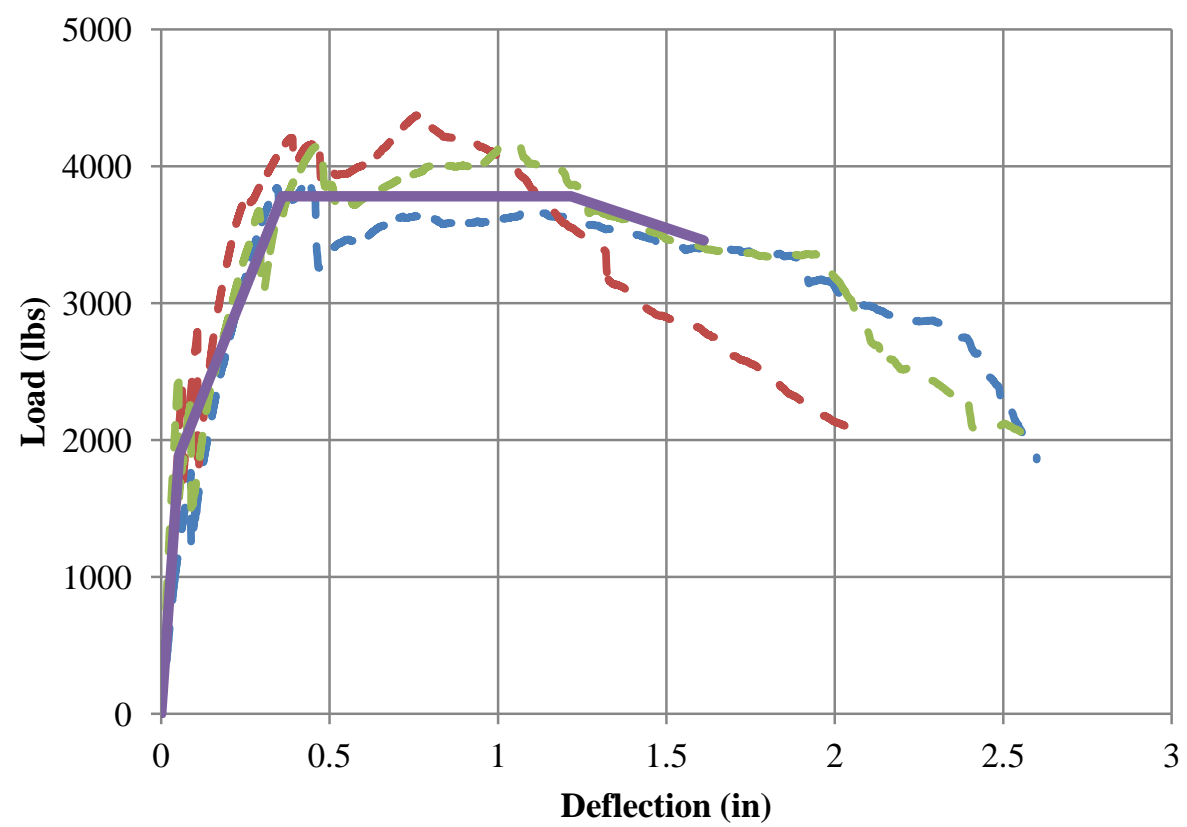

Figure 42 - Revised model, normal-weight beam with Propex fibers 


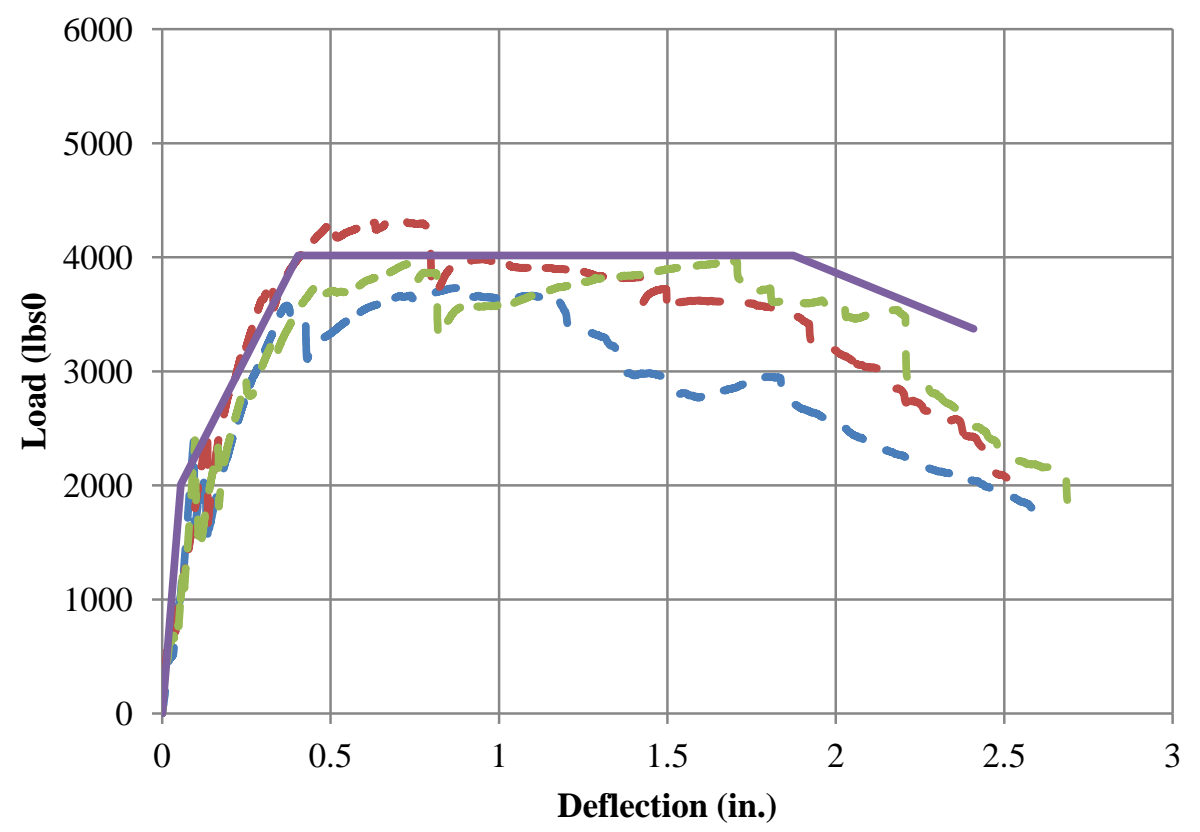

Figure 43 - Revised model, normal-weight beam with Forta fibers

This revised model does not offer high fidelity, as it is only 5 points connected by lines. Further fidelity could be obtained by fitting several curves to the data points. However, for much structural engineering design and practice such high fidelity is not required, and higher fidelity might impact the efficiency of calculations. The model predicts regions important for structural analysis (elastic, yielding, ultimate strength, and strain softening). 


\section{Conclusion and Recommendations}

This project aimed to increase the strength of composite decks by increasing the shear transfer between the two materials. The results presented, both analytical and experimental, indicate that this can be accomplished by the use of embedded sheet metal screws, driven through the steel deck prior to pouring the concrete. In addition, further gains can be realized with the addition of reinforcing fibers in the concrete. The experimental results match up well with the analytical model. This model allows sufficient predictive capacities regarding the loaddeflection behavior of the deck. More experimental validation of the model is recommended. The experimental validation offered here only used a single fastener size, single fastener spacing, and single deck type. All of these variables must be explored and tested to determine the limitations of the analytical model.

Furthermore, it should be noted that the findings from this project have the potential for application in both limited instances, and more general use. The process of driving sheet metal screws into steel deck is time intensive. Therefore, the method used in this project (i.e. that of driving the screws by hand) is suitable only for limited use. For example, the method might be used in locations where increased deck strength is beneficial in a specific and relatively small area. However, if this method were to be used for entire floors or roofs, it would be necessary to affix the screws (or a similar projection) using an automated manufacturing process.

Two such processes are recommended: friction welding and deep drawing. First, it is anticipated that threaded or smooth rod of an appropriate diameter could be friction welded to the deck after rolling. Although this is a thermal process, it is unlikely that the heat-affected zone would extend very far. However, this would not allow the deck to be stacked in a compact manner, which would increase transportation and storage costs. The second process that should 
be considered is some sort of deep-drawing process to create protrusions on the deck. Because of the nature of drawing, the deck could still be stacked as long as the protrusions were created at regular intervals. However, this process has several limitations. The length of protrusion is quite limited, and the thickness of the metal near the drawing and the thickness of the drawn metal would both be reduced. This could weaken the deck instead of offering additional strength. A combination of drawing and friction welding could also be pursued, to reach an optimal trade-off between structural integrity and efficiency of storage and transportation. 


\section{References}

[1] Neville, A. M. Properties of Concrete. 4th ed. New York: Wiley, 1996. Print.

[2] Wang, Chu-Kia et al. Reinforced Concrete Design. Hoboken, NJ: John Wiley \& Sons, 2007. Print.

[3] Yu, Wei-wen. Cold-formed Steel Design. New York: Wiley, 1985. Print.

[4] William D. Callister, Materials Science and Engineering: An Introduction. Hoboken, NJ: John Wiley \& Sons, 2007. Print.

[5] DeGarmo, E. Paul. Materials and Processes in Manufacturing. 10th ed. New York: Wiley, 2008. Print.

[6] M.C. Nataraja, N. Dhange, and A.P. Gupta, "Stress-strain curves for steel-fiber reinforced concrete under compression" Cement and Concrete Composites, vol. 21, pp. 383-390, 1999.

[7] Beaudoin, James J. Handbook of Fiber-Reinforced Concrete. New Jersey: Noyes Publications, 1990. Print.

[8] ACI Committee 544, "State-of-the-Art Report on Fiber Reinforced Concrete", effective 1996, reapproved 2002.

[9] ACI Committee 318, Building Code Requirements for Structural Concrete and Commentary. Farmington Hills, MI: American Concrete Institute, 2008. Print.

[10] Gay, Daniel et al. Composite Materials: Design and Applications. Boca Raton, FL: CRC Press, 2003. Print.

[11] G. J. Hancock, “Cold-formed steel structures” Journal of Constructional Steel Research, vol. 59, pp. 473-487, 2003.

[12] Zhong Tao and Lin Hai-Han, "Behaviour of concrete-filled double skin rectangular steel tubular beam-columns" Journal of Constructional Steel Research, vol. 62, pp. 631-646, 2006.

[13] J. M.Irwan, A.H. Hanizah, and I. Azmi, "Test of shear transfer enhancement in symmetric cold-formed steel-concrete composite beams" Journal of Constructional Steel Research, vol. 65, pp. 2087-2098, 2009.

[14] J. M.Irwan, A.H. Hanizah, and I. Azmi, "Large-scale test of symmetric cold-formed steel (CFS)-concrete composite beams with BTTST enhancement" Journal of Constructional Steel Research, vol. 67, pp. 720-726, 2011.

[15] Bruce L. Deam, M. Fragiacomo and A. H. Buchanan, "Connections for composite concrete slab and LVL flooring systems" Materials and Structures, vol. 41, pp. 495507, 2008. 
[16] M. Nithyadharan and V. Kalyanaraman, "Experimental study of screw connections in CFS-calcium silicate board wall panels" Thin-Walled Structures, vol. 49, pp. 724-731, 2011.

[17] "Cold Formed Steel Design for the Student", retrieved from http://www.ccfssonline.org/Student/Studentspecification.html

[18] "Product Technical Information" Steel Stud Manufacturers Association, www.SSMA.org, 2010

[19] Ahmad, S.H. and Shah, S.P. "Complete Triaxial Stress-Strain Curves for Concrete", ASCE Journal of the Structural Division, vol. 108, pp. 728-742, 1982.

[20] Ju, J.W. and Detwiler, R.J. "Application of the Continuum Damage Model to Concrete Report No. PU/CEOR/SM-89-2, Department of Civil Engineering and Operations Research, Princeton University, March 1989.

[21] Yamamoto, T. and Vecchio, F. "Analysis of Reinforced Concrete Shells for Transverse Shear and Torsion”, ACI Structural Journal, vol. 98, pp. 191-199, 2001.

[22] Park, R. and Paulay, T. Reinforced Concrete Structures, John Wiley and Sons, New York. 1975

[23] Legeron, F. and Paultre, P. "Prediction of Modulus of Rupture of Concrete", ACI Materials Journal, vol. 97, pp. 193-200, 2000.

[24] Filippou, F.C. and Kwak, H.G. "Finite Element Analysis of Reinforced Concrete Structures Under Monotonic Loading". UCB/SEMM-90/14. Structural Engineering, Mechanics and Materials, Department of Civil Engineering, University of California, Berkeley, August 1990

[25] Filippou, F.C., Popov, E.P. and Bertero, V.V. "Modeling of Reinforced Concrete Joints under Cyclic Excitations", ASCE, Journal of Structural Engineering, Vol. 109, No. 11, Nov. 1983.

[26] Tehrani, Fariborz M. Personal Communication. November 30, 2011.

[27] Tehrani, Fariborz M. "Performance of Steel Fiber-reinforced Concrete in Beam-column Connections." Thesis. University of California, Los Angeles, 2008. Print.

[28] Kostmatka, Steven H.; Kerkhoff, Beatrix; and Panarese, William C.; Design and Control of Concrete Mixtures, EB001, $14^{\text {th }}$ edition, Portland Cement Association, Skokie, Illinois, USA, 2002

[29] “Applications: Slab on Metal Deck", retrieved from http://www.fortaferro.com/applications/slab-on-metal-deck/

[30] Tehrani, Fariborz M. "Composite Action." Message to the author. 22 May 2012. Email. 


\section{Appendix A - Anchor Strength MATLAB Code}

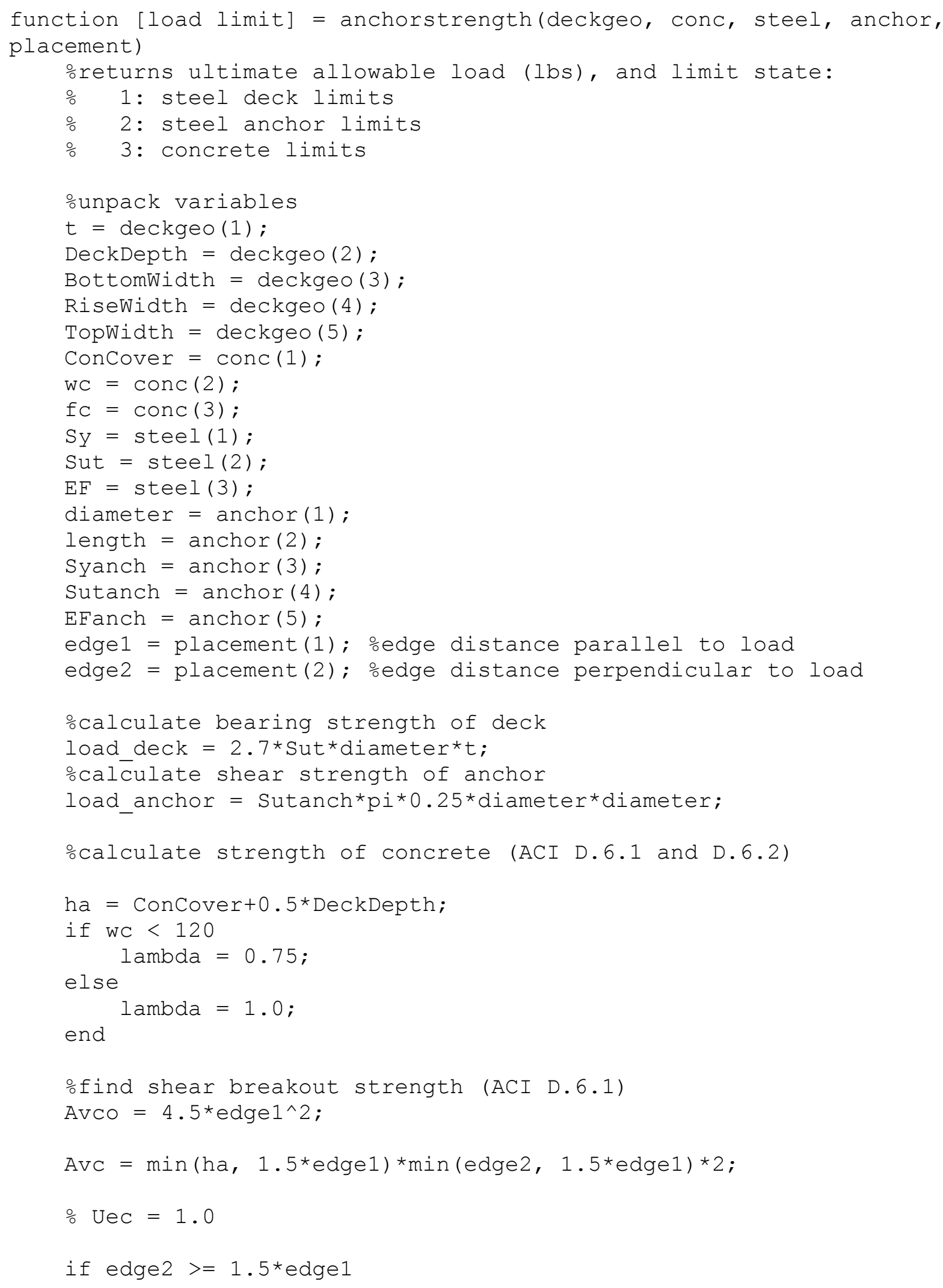




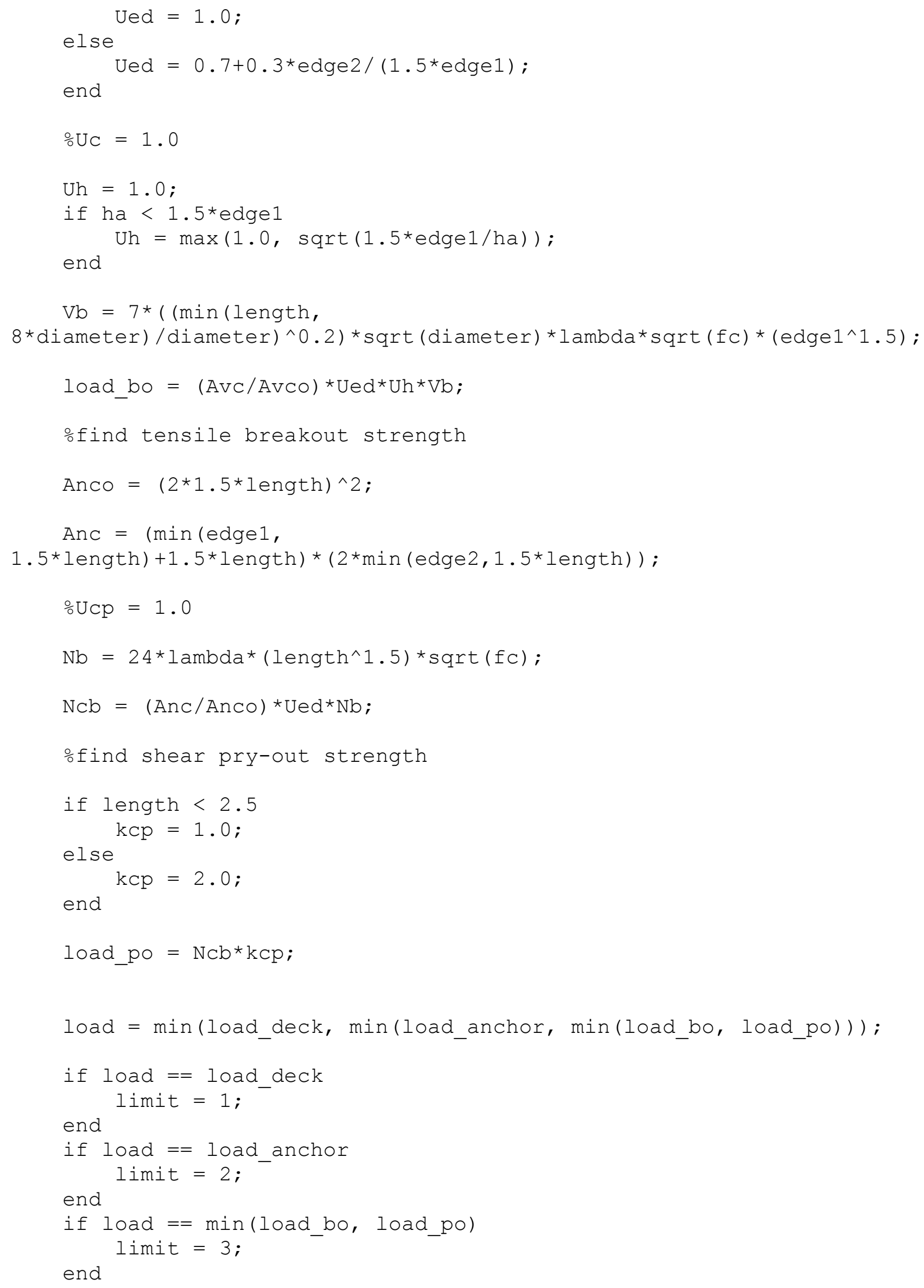




\section{Appendix B - Concrete Stress MATLAB Code}

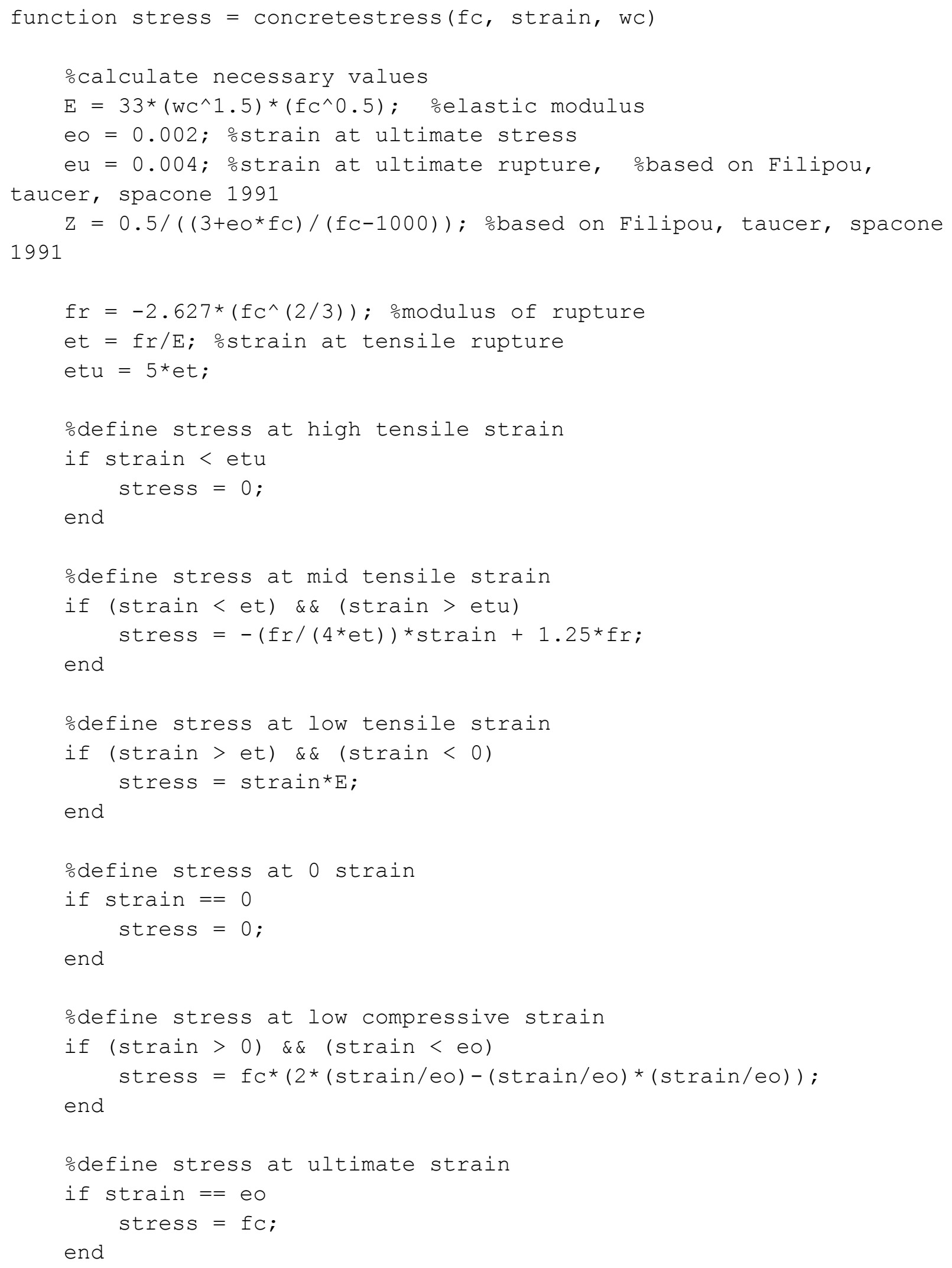




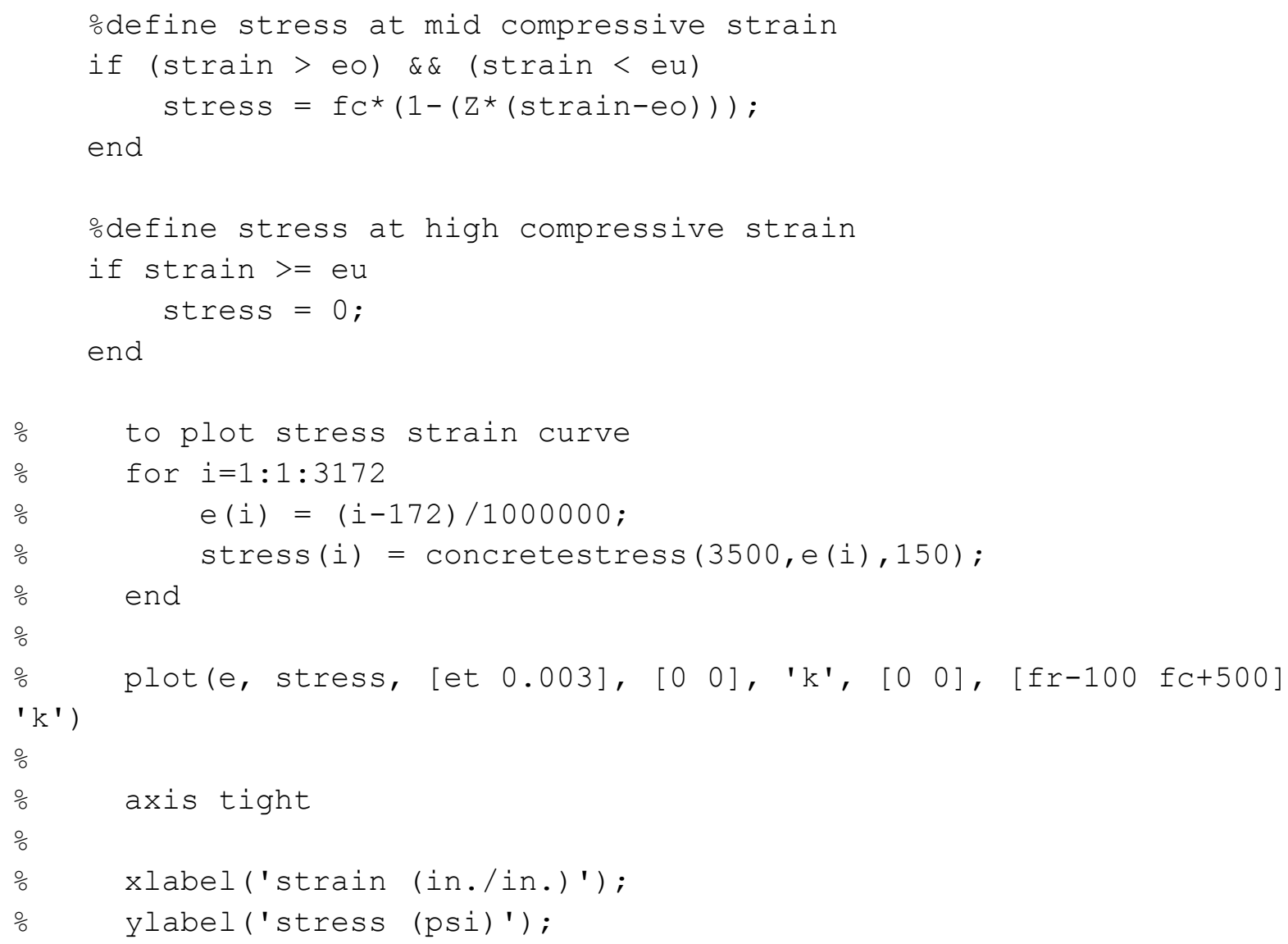




\section{Appendix C - Steel Stress MATLAB Code}

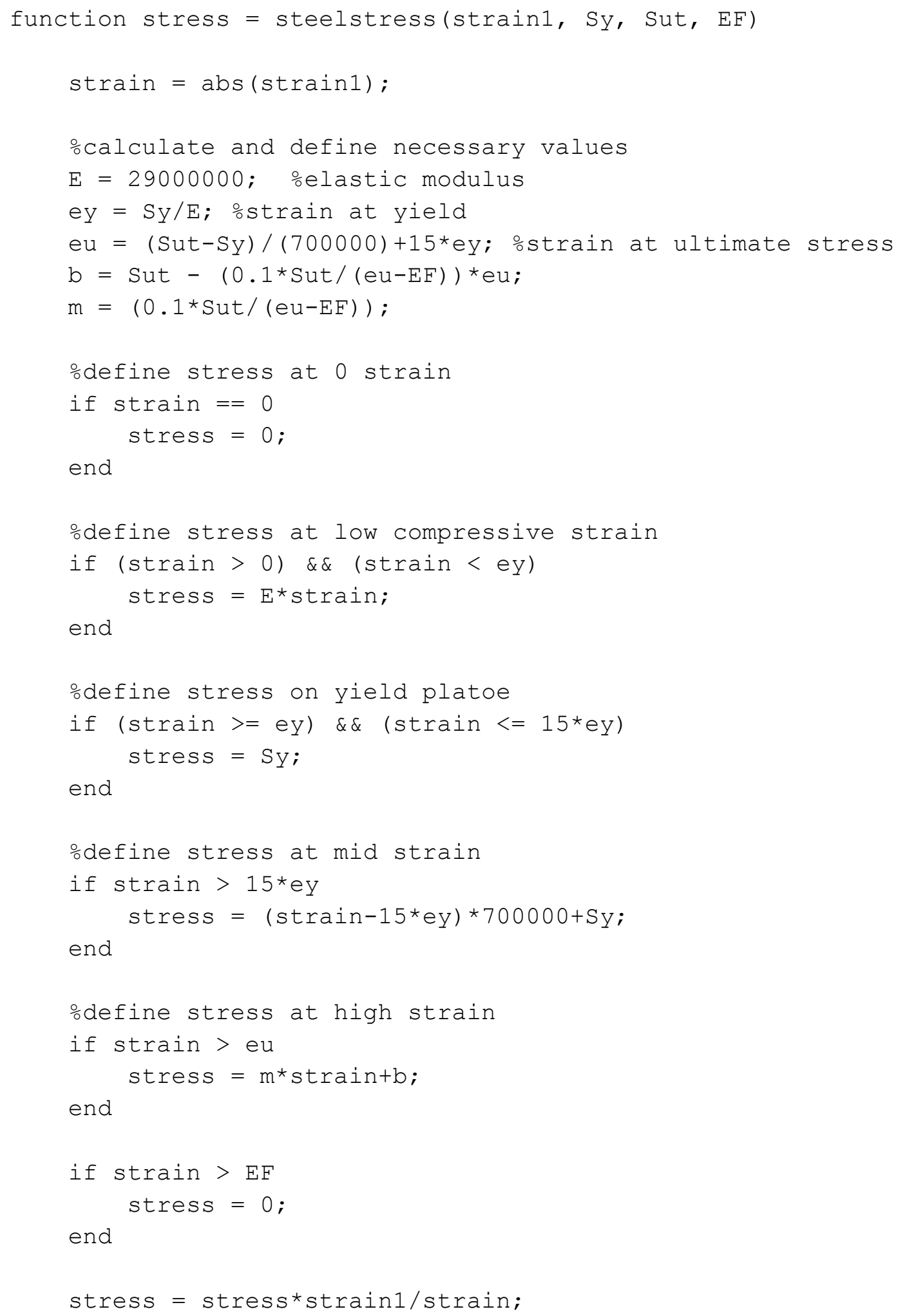




\section{Appendix D - Deck Strength MATLAB Code}

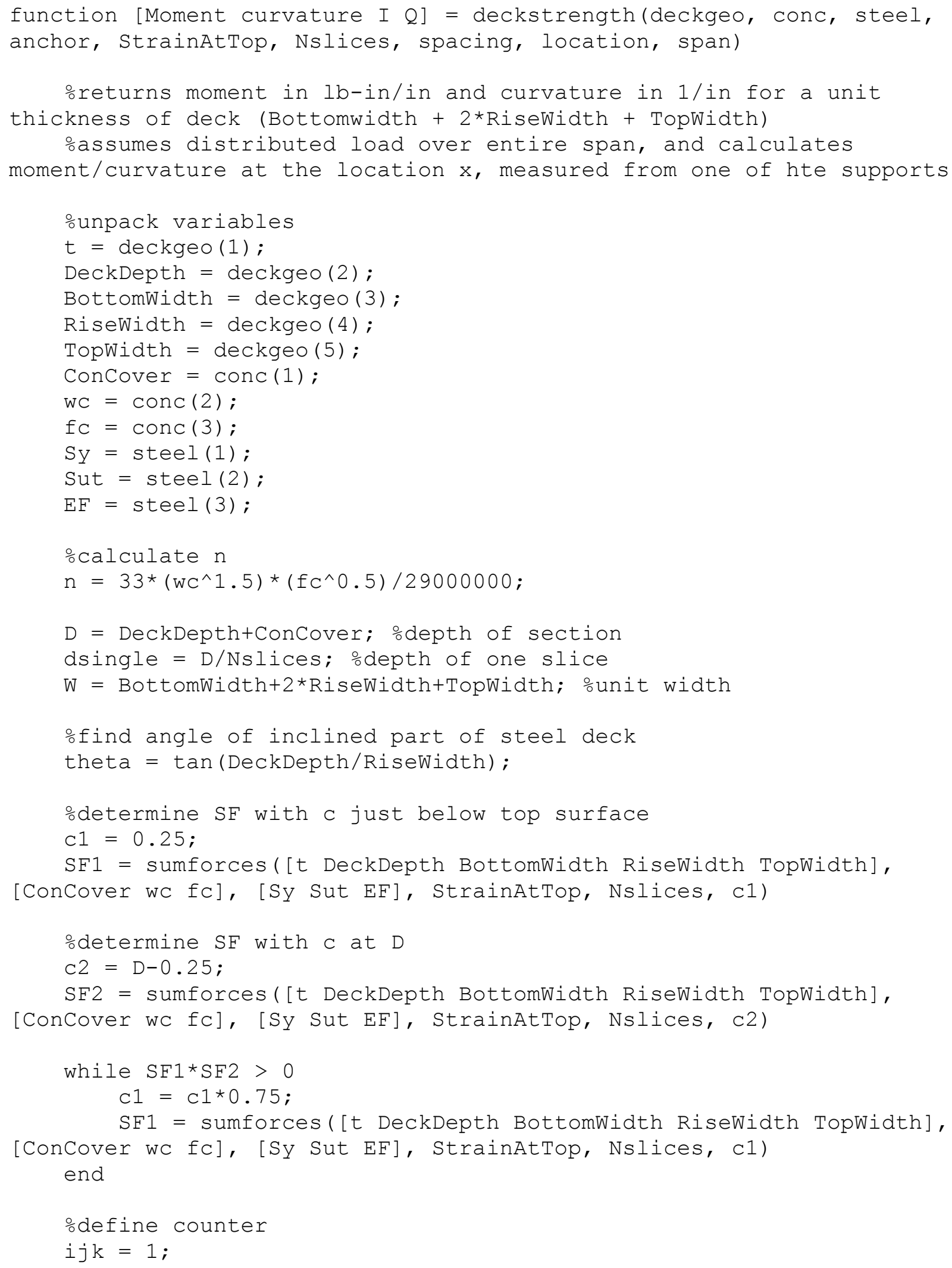




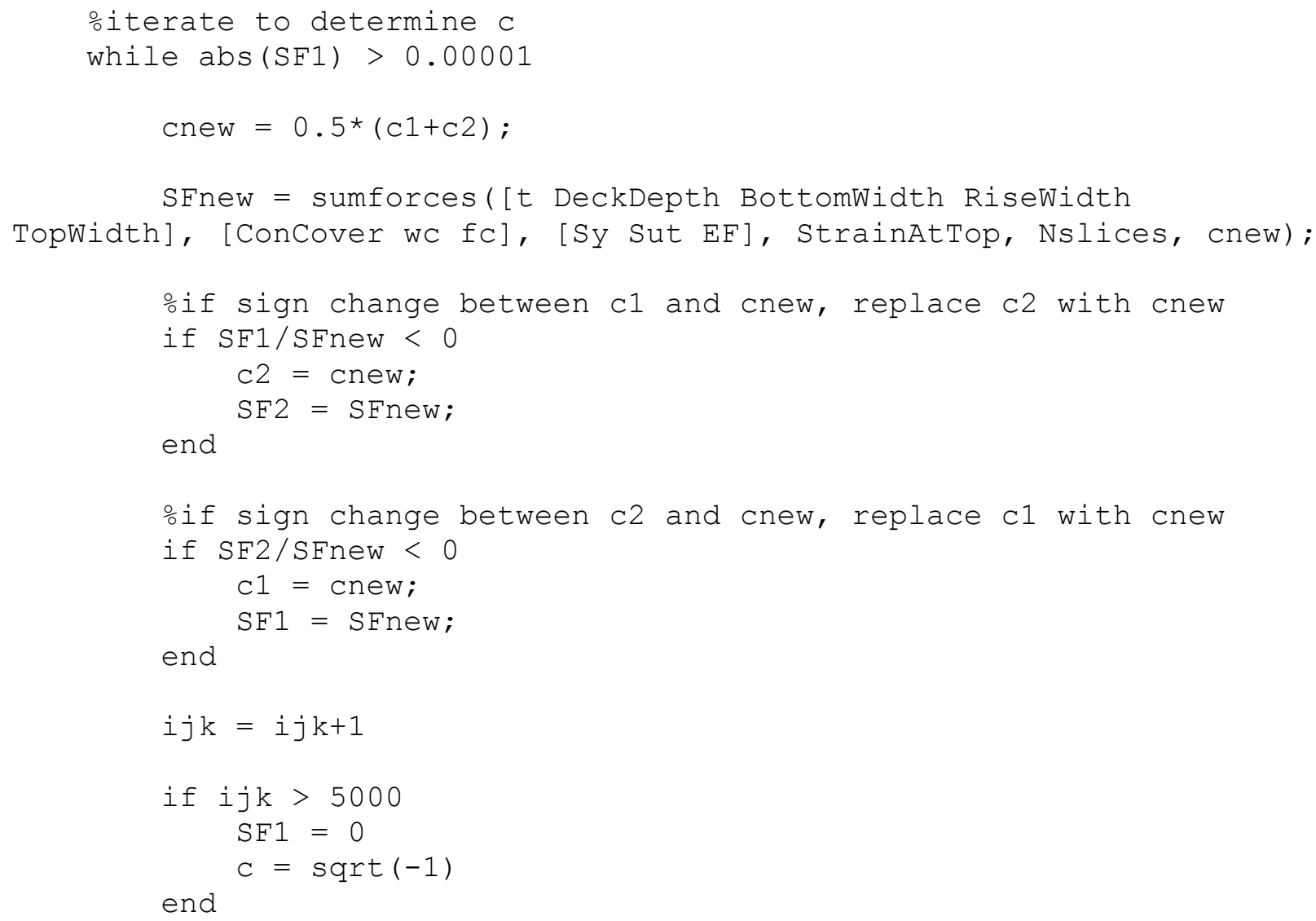




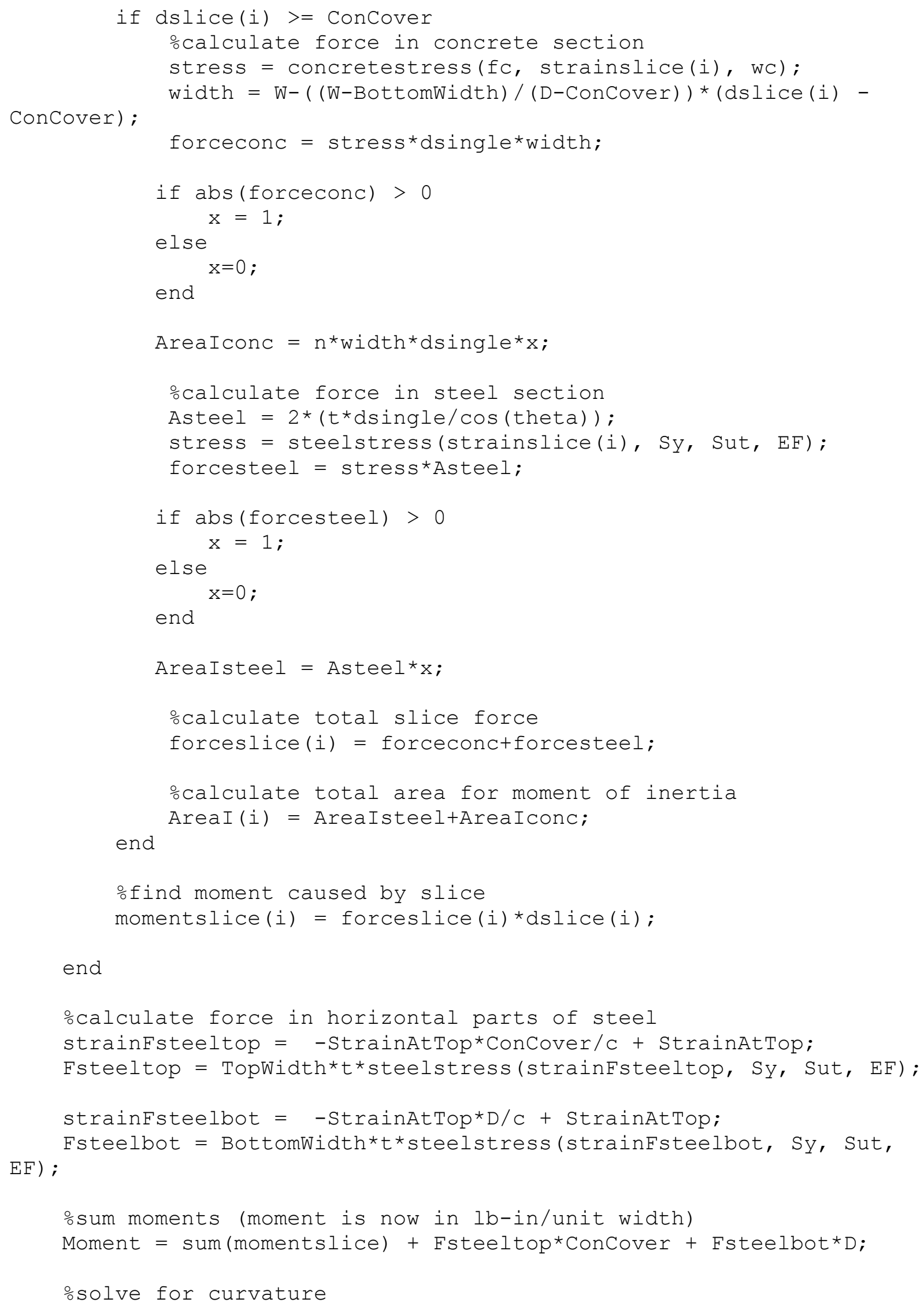




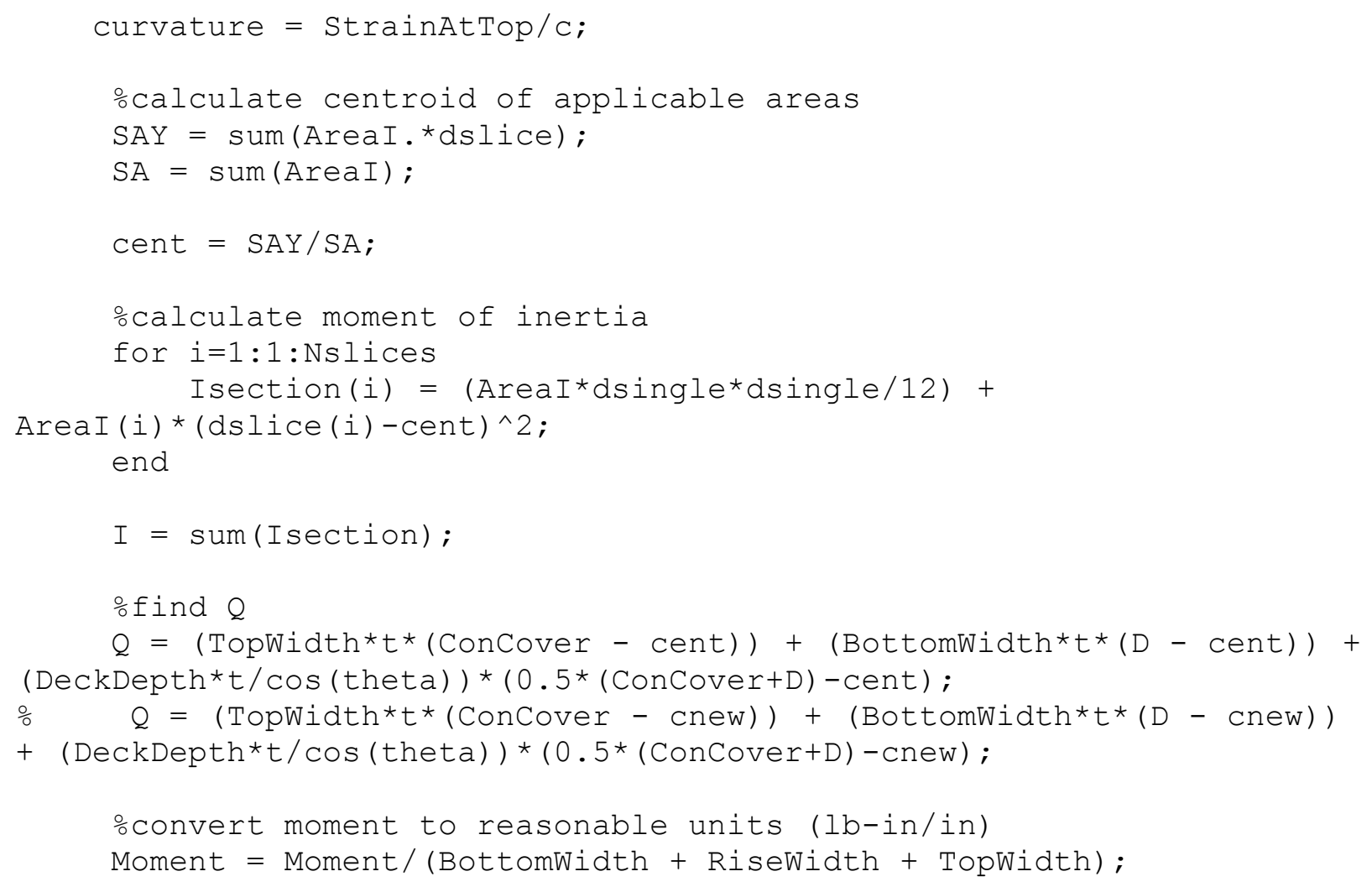




\section{Appendix E - Sum Forces MATLAB Code}

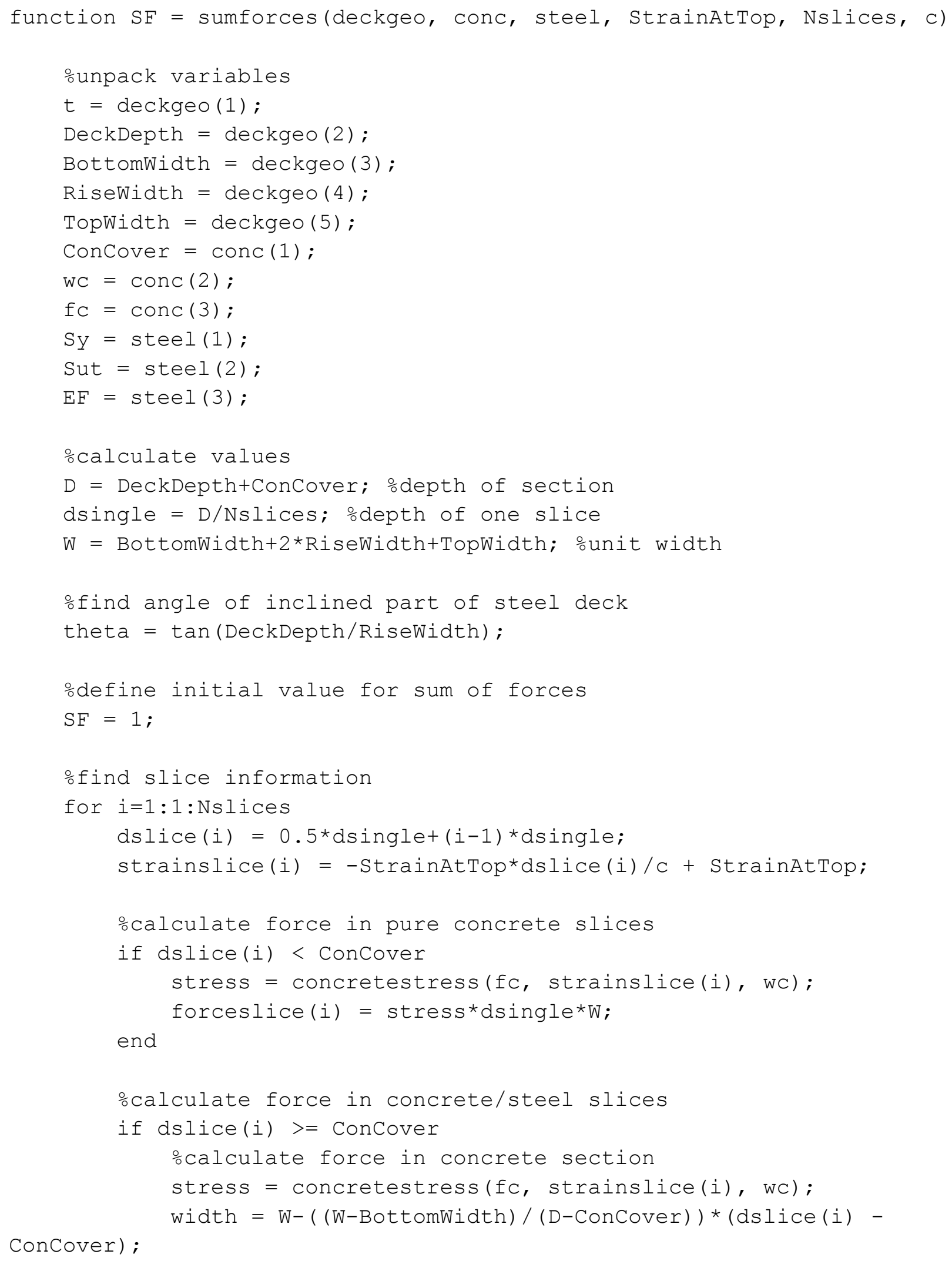




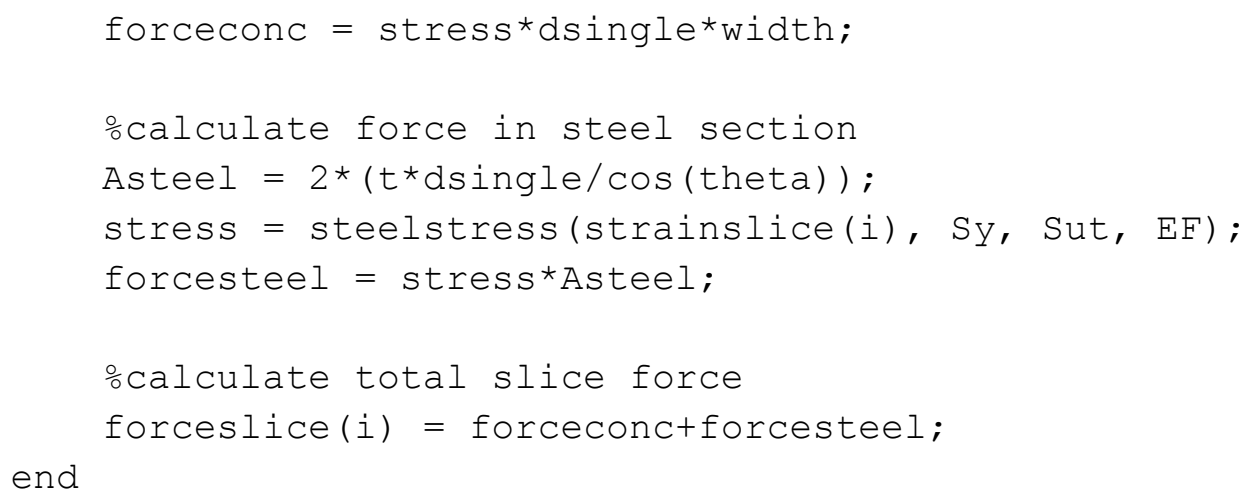




\section{Appendix F - Section Performance MATLAB Code}

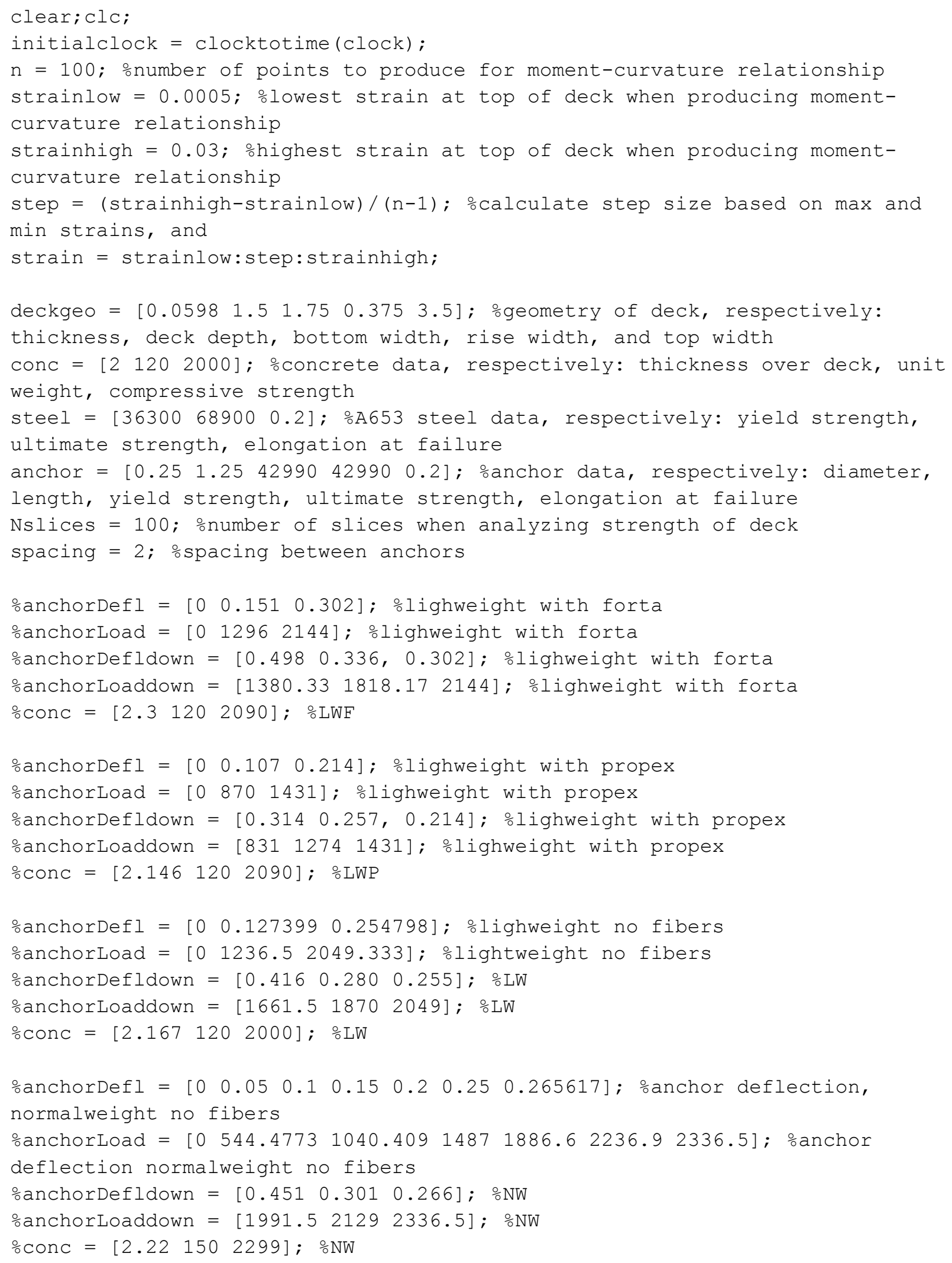




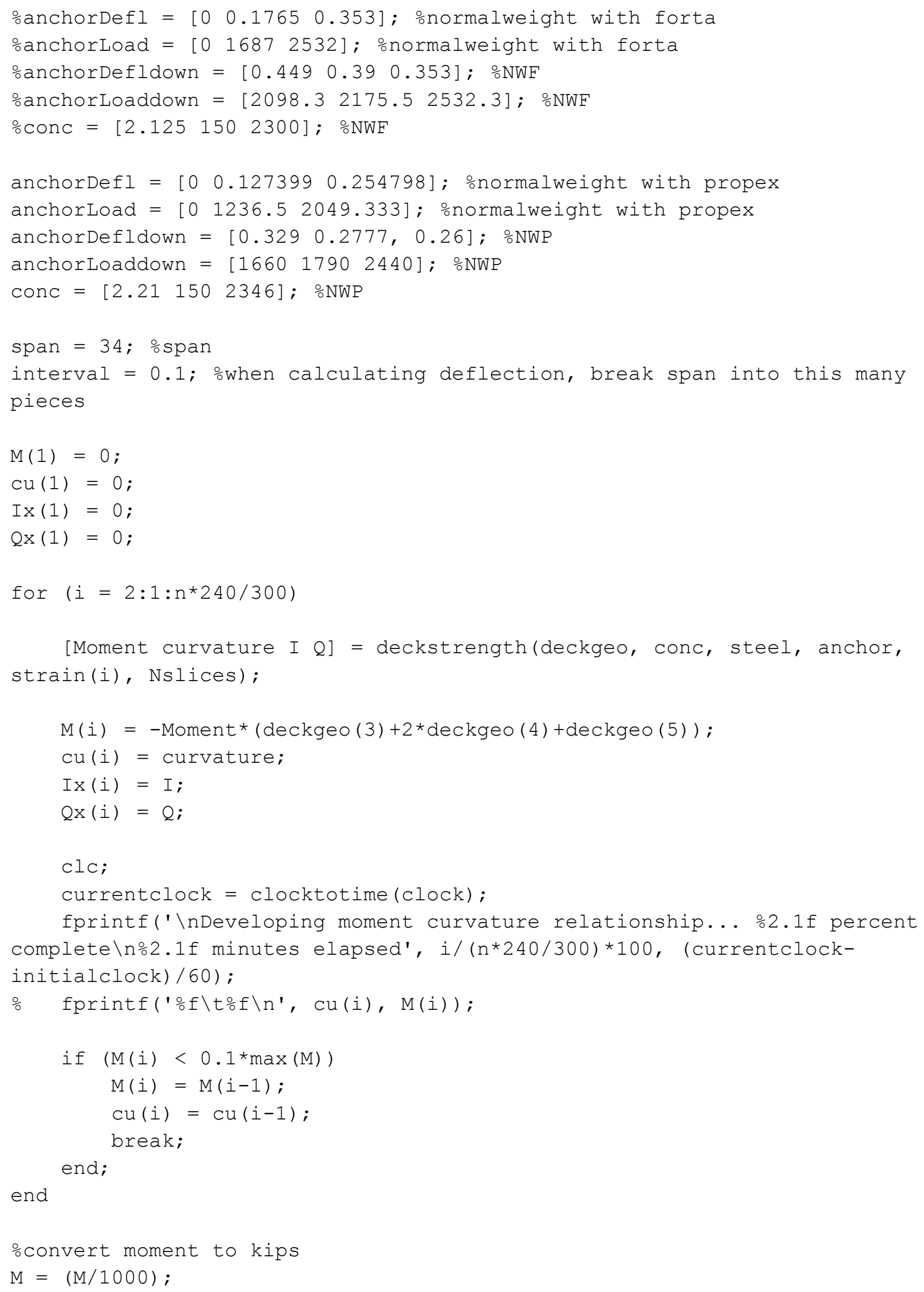




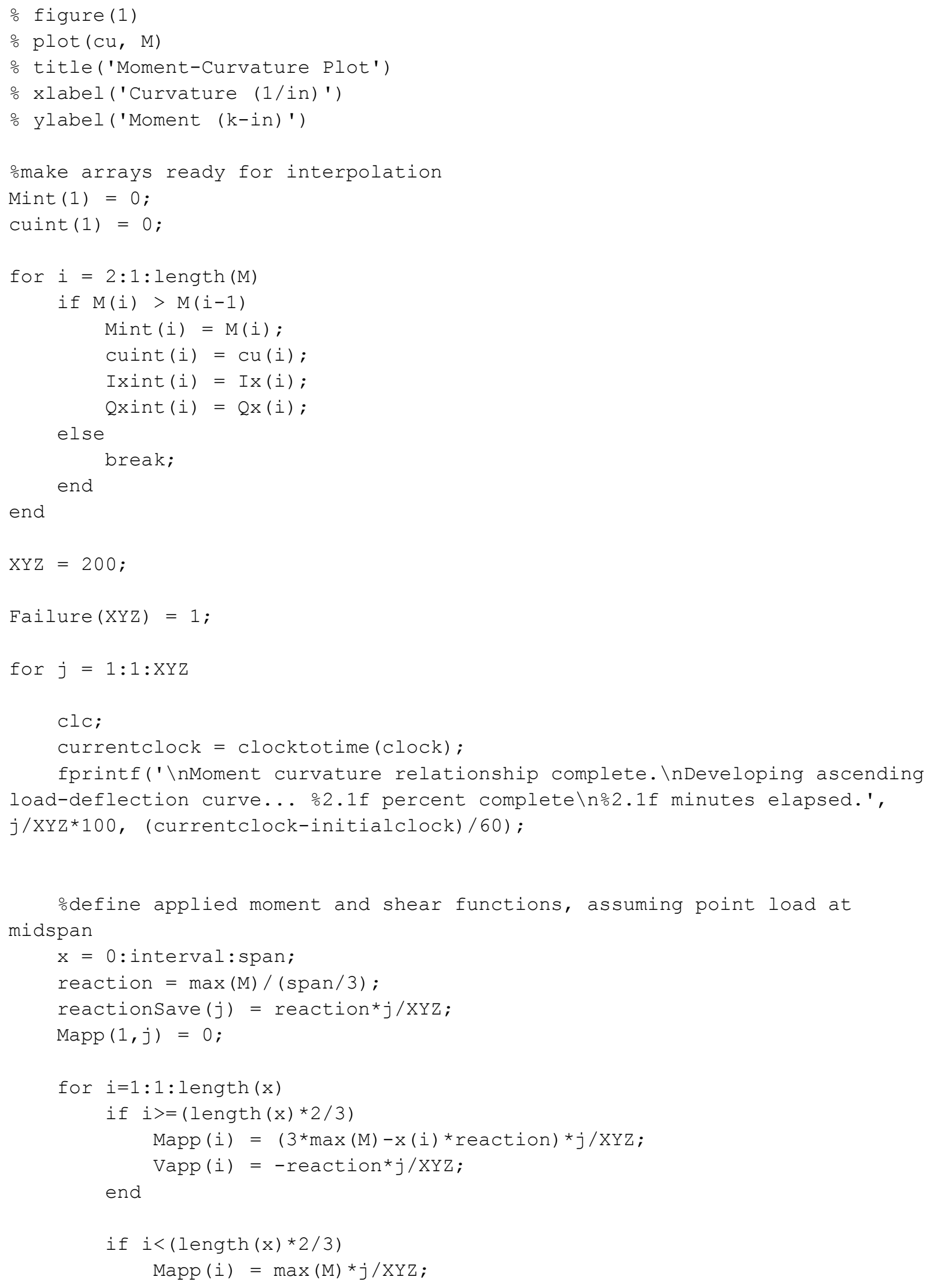




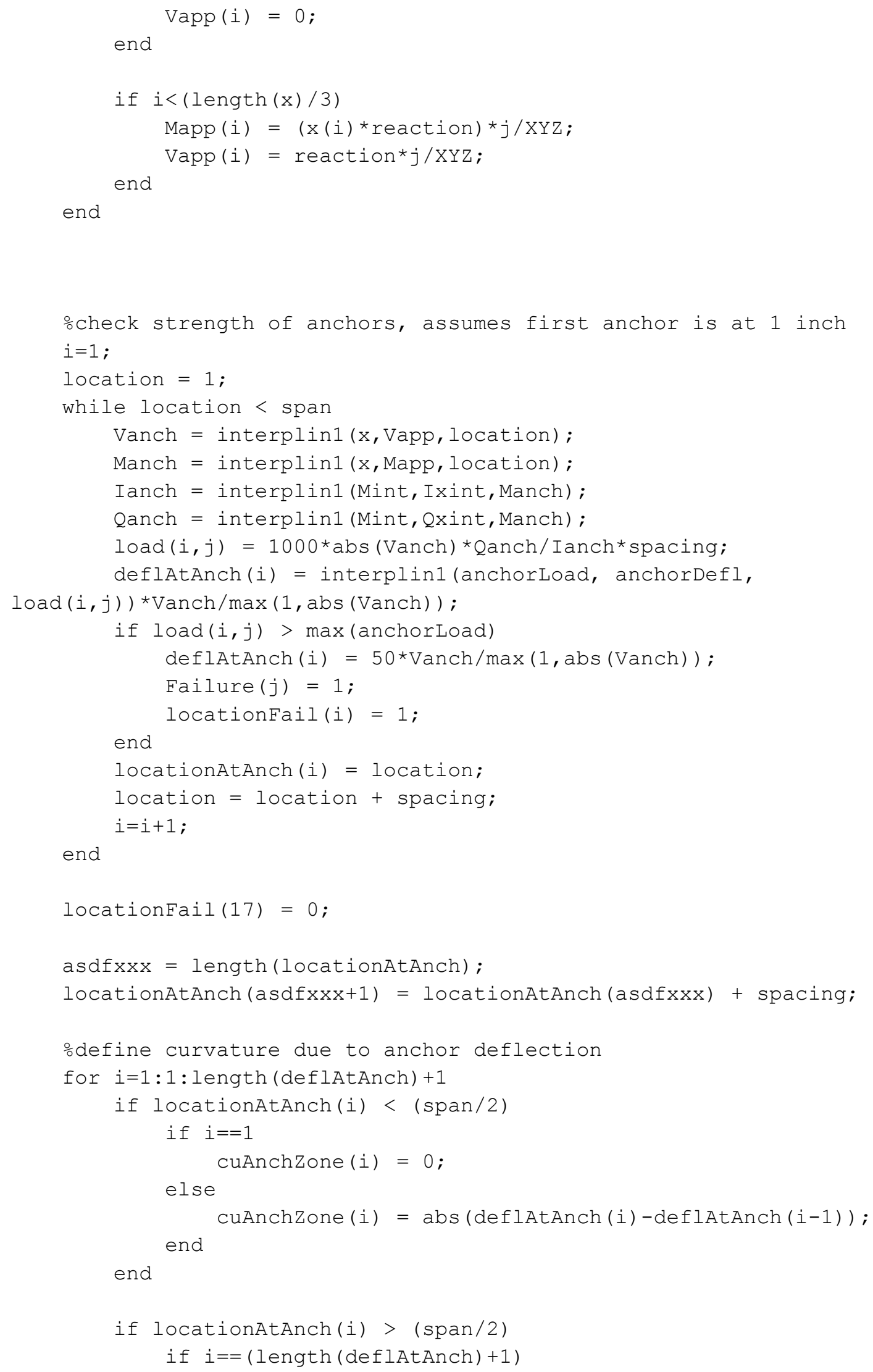




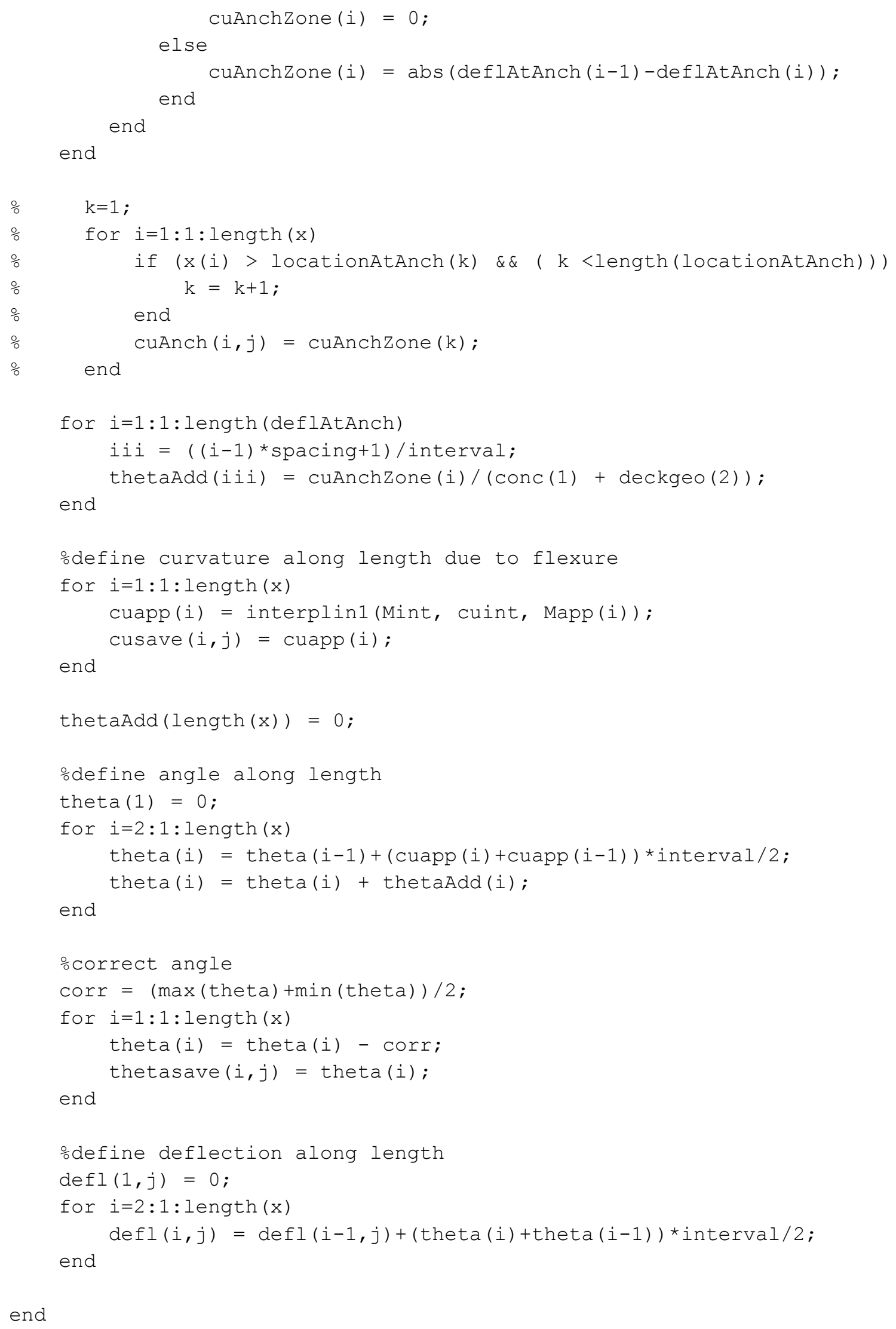




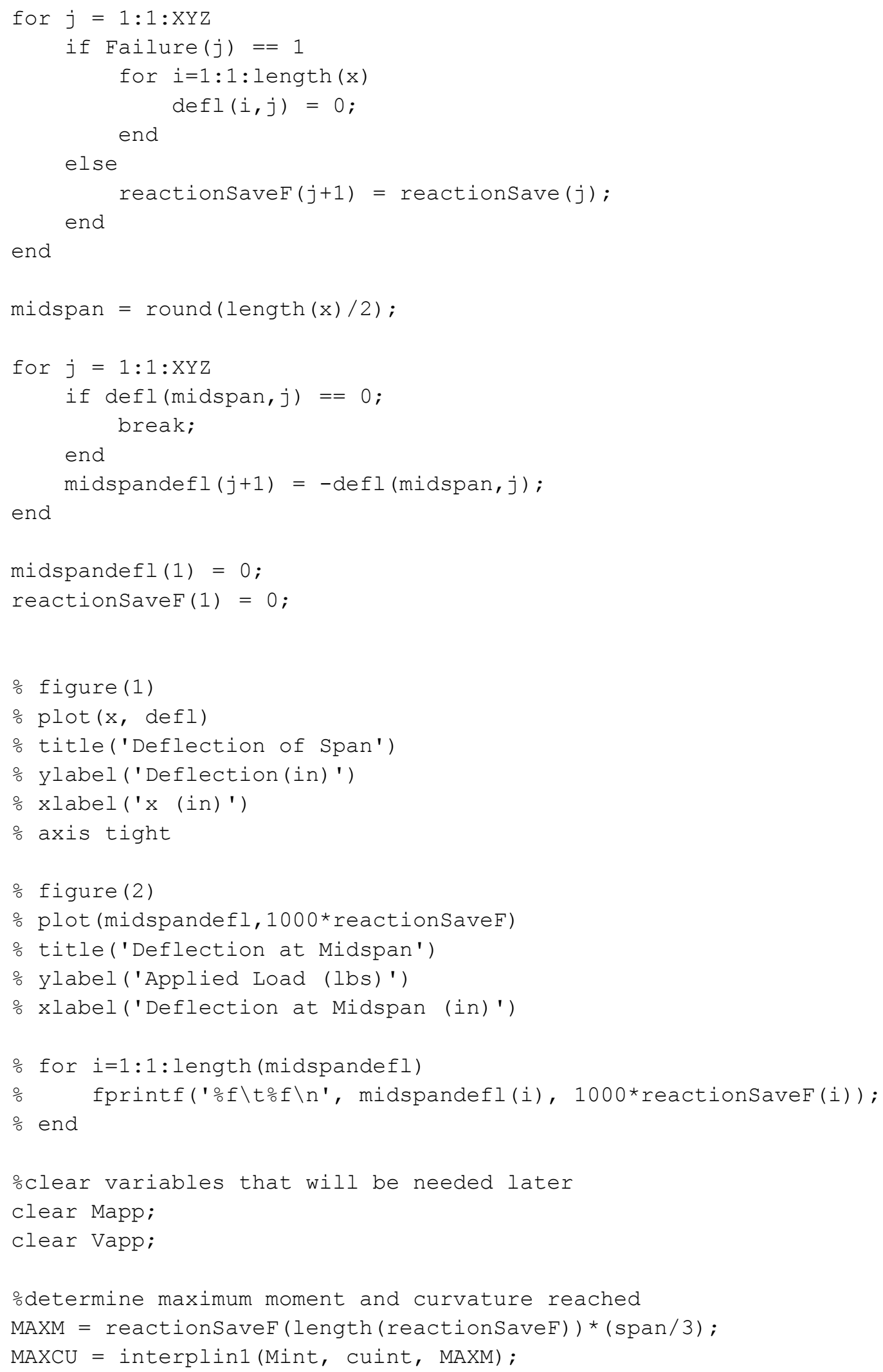




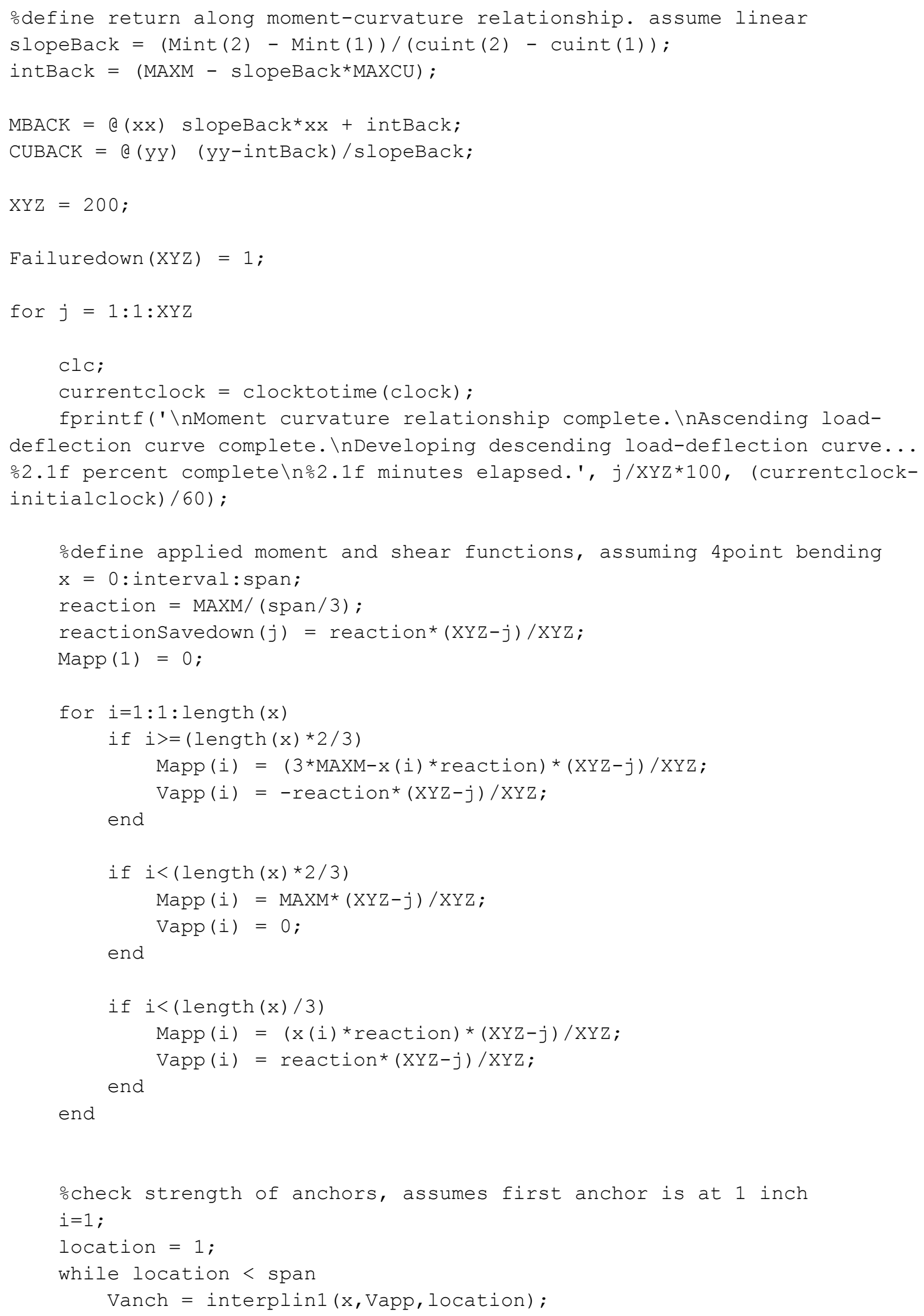




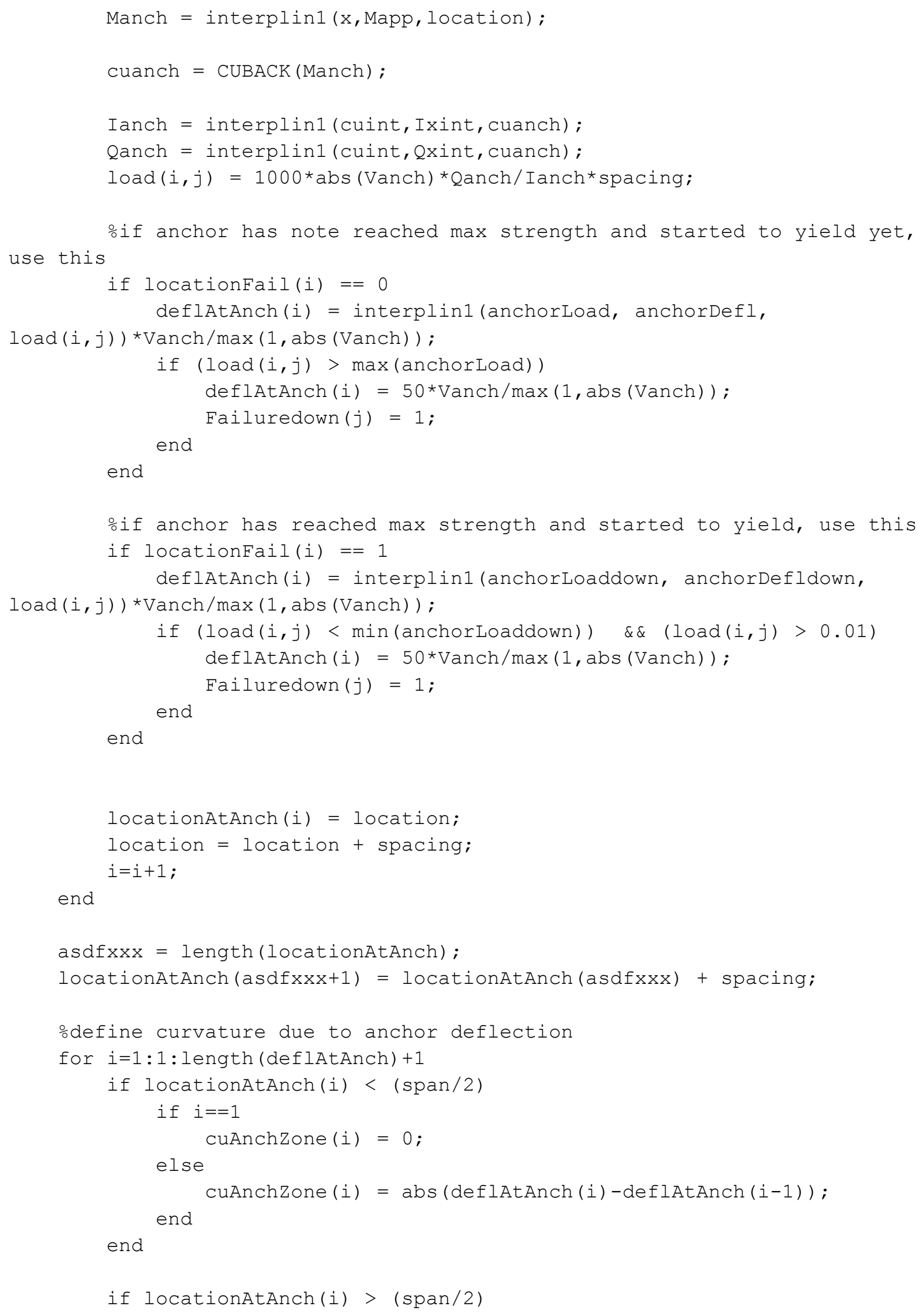




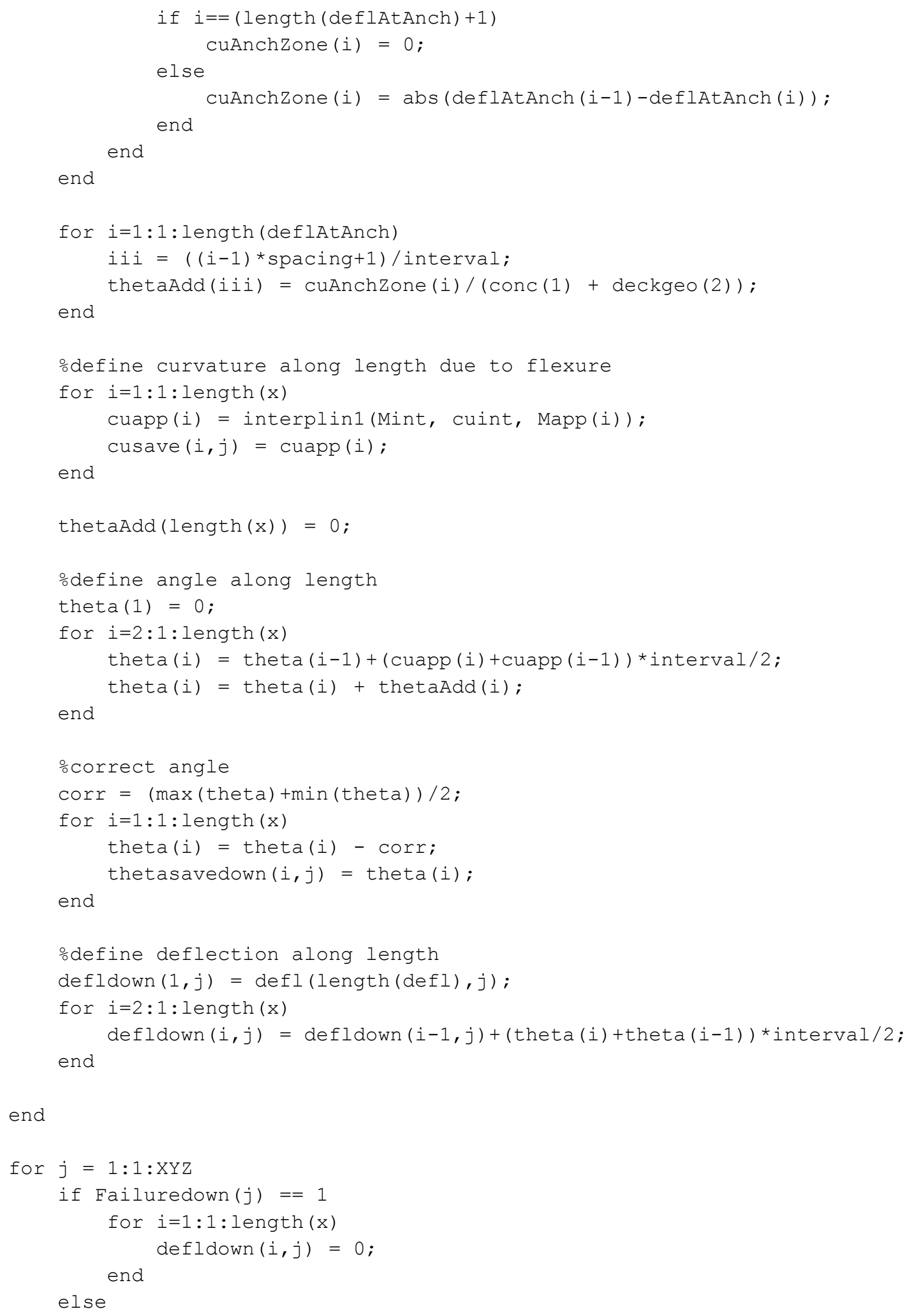




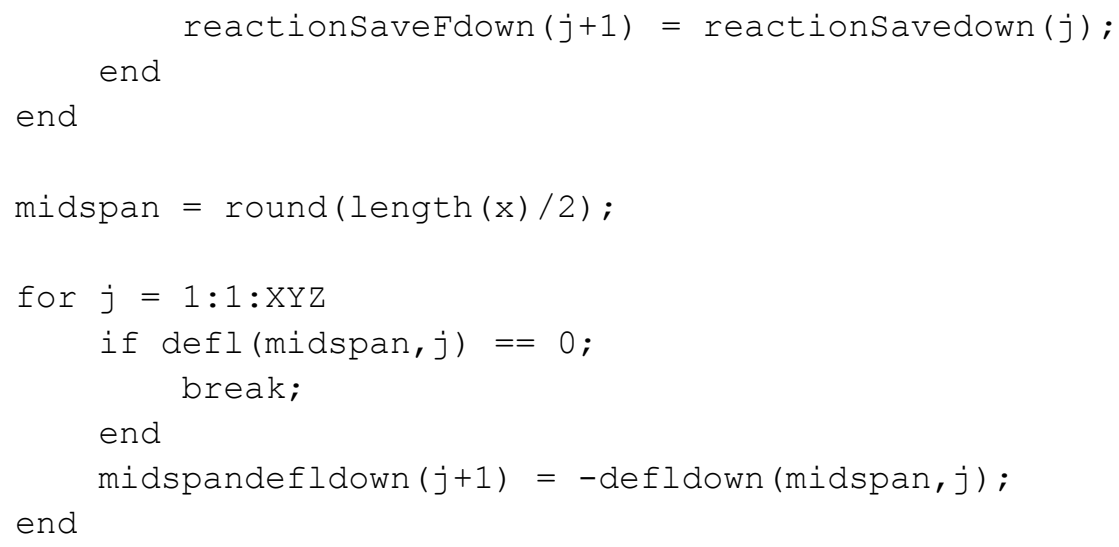


figure (2)

plot ( $\left.\left[\begin{array}{llll}0 & 0 & 1 & 1\end{array}\right],\left[\begin{array}{llll}0 & 1 & 1 & 0\end{array}\right]\right)$;

axis tight;

text $([0.05,0.05],[0.7,0.3],\{$ 'Put the beer down', 'I am done running'\}, 'fontsize', 40) 


\section{Appendix G - Gradation of Lightweight Aggregate}

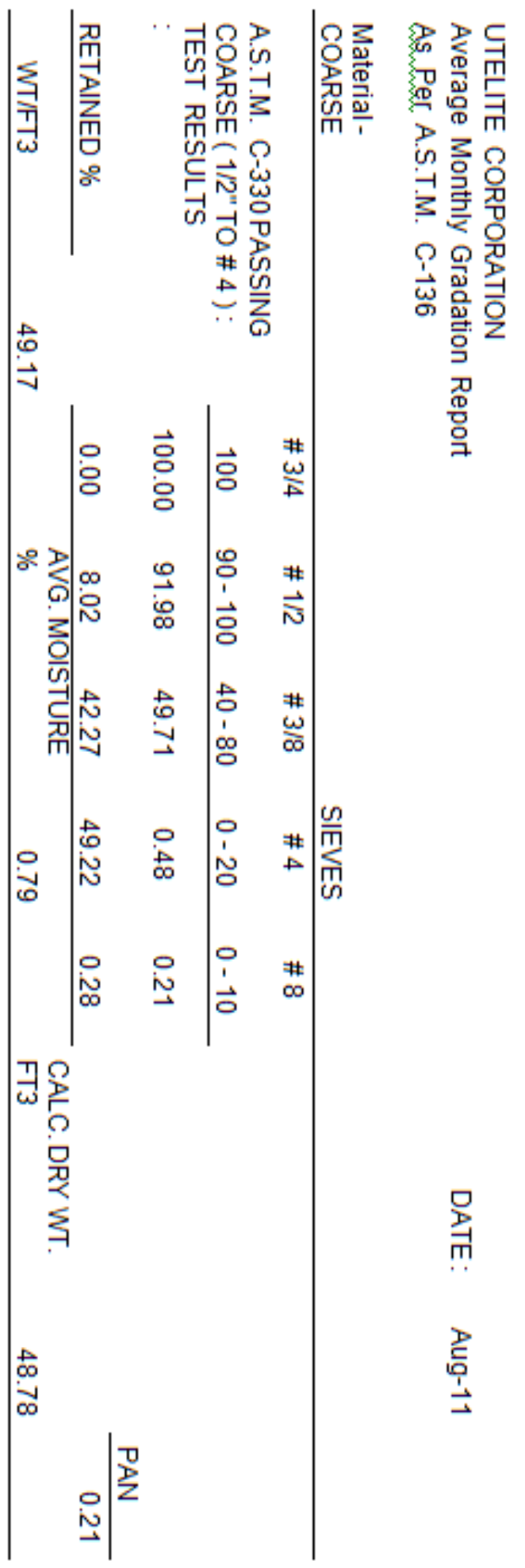




\section{Appendix H - Manufacturer Documentation for Forta Ferro Fibers}

[Intentionally Left Blank] 
FORTA 1 
FORTA 2 
FORTA 3 
FORTA 4 
FORTA 5 
Appendix I - Manufacturer Documentation for Propex Fibermesh 650 Fibers

[Intentionally Left Blank] 
PROPEX 1 
PROPEX 2 
PROPEX 3 
PROPEX 4 
PROPEX 5 
PROPEX 6 
PROPEX 7 